Ann. Abeille, I965, 8 (I), 5-77.

\title{
LA PRODUCTION DE CHALEUR CHEZ APIS MELLIFICA L. (1)
}

\author{
M. ROTH \\ Office de la Recherche scientifique et technique Outre-Mer, Bondy (Seine)
}

SOMMAIRE

INTRODUCTION.

Chapitre Premier.

I. Principes expérimentaux.

2. Appareillage.

3. Pratique de l'expérimentation - Établissement des résultats.

4. Correction concernant l'apport de calories dû à la température propre du corps des abeilles.

5. Précision des mesures.

Chapitre II. - Étude qualitative des courbes thermiques obtenues.

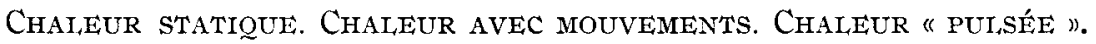

I. Différents aspects de la production thermique.

2. Mécanisme de la thermogenèse.

Résumé du chapitre II.

Chapitre III. - Variations de ra Thermogent̀se.

I. Abeilles en diverses conditions physiologiques.

a) Abeilles en hivernage.

b) Abeilles testées en période de sécheresse.

c) Modifications dues à l'élevage en cagettes.

d) Production thermique suivant l'âge.

(1) Cette étude a fait l'objet d'une thèse de Docteur-Ingénieur soutenue le 5 décembre i 964 à la Faculté des Sciences de Paris. 
2. Infunence sur la thermogenèse et effet d'économie thermique du groupe.

a) Effet de groupe.

b) Formation de la "grappe».

c) Effet d'economie thermique du groupe.

3. Adaptation de la thermogenèse à la température ambiante.

4. Abeilles en conditions anormales.

a et b) Abeilles anesthésiées.

c) Abeilles en contention

Résumé du chapitre III.

\section{Chapitre - IV.}

I. Résultats obtenus par respirométrie.

2. Production de chaleur en anaérobiose.

Résumé du chapitre IV.

CONCLUSTON GÉNÉRAI.E.

RÉsumé.

BIBLIOGR.APHIE.

\section{INT'RODULTION}

Les abeilles domestiques ont fait l'objet d'études détaillées depuis l'époque des philosophes et naturalistes de l'Antiquité jusqu'à nos jours, où les recherches ne cessent de nous apporter multitudes de nouveautés plus surprenantes les unes que les autres.

Dans cet immense domaine, un point fort important nous semble avoir été un peu négligé : celui de l'origine de la chaleur produite dans la ruche.

De nombreuses expériences ont été réalisées pour mesurer la température interne des ruches et ses variations nycthémérales et ses variations saisonnières. VoN FRISch, entre autres, a constaté, sans trop approfondir, que la température de la ruche avoisinait pendant la belle saison 35 à $36^{\circ} \mathrm{C}$ près des rayons à couvain. Il a vu que, par temps froid, les ouvrières se rassemblaient sur ces rayons à couvain "pour leur faire comme un lit de plume".

Il est bien évident qu'un tel processus de protection thermique serait fort peu efficace s'il n'existait pas une possibilité de production de chaleur chez l'abeille domestique et c'est l'étude de ce phénomène qui n'avait pas été jusqu'ici entreprise de façon directe et systématique.

Beaucoup de chercheurs se sont intéressés à ces problèmes de température. En ce qui concerne la température des rayons à couvain, citons les travaux de Gates (I9I4), Philips et Demuth (I9I4), Hess (I926), Himmer (I93I, I933), Lindauer (I95I, I952, I954), WoHlGEMUTh (I957), etc.

En ce qui concerne les travaux plus particulièrement relatifs à la température 
de la grappe d'hiver, citons ceux d'Armbruster (I922), Himmer (I925), Hess (I926), HERAN (I952).

PARHON (I9O9), FREE et BOTH (I958) se sont respectivement intéressés au bilan respiratoire et à la régulation thermique, nous avons fait à ces derniers de nombreux emprunts dans le cours de cette étude.

Citons enfin les travaux de BRUNNich (I922) et la remarquable étude de Iisch (r960) sur la température interne du corps des abeilles et à laquelle nous aurons l'occasion de nous référer plusieurs fois au cours de cet exposé.

En I 953 , R. Chauvin nous avait demandé de reprendre les études faites par HeRAN sur le thermopréférendum des abeilles. Nous avions donc utilisé le " temperaturorgel " construit par notre camarade LAVIE d'après des plans de HERTER, plans très améliorés par Chauvis. L'orgue de température originel se composait d'une rampe de cuivre chauffée à l'une de ses extrémités, refroidie à l'autre, de façon à réaliser un gradient thermique continu. Les abeilles sont posées sur ce trottoir et se fixent théoriquement au point de température recherchée. CHAuvis perfectionne l'appareil en lui adjoignant une voûte de rhodoïd rouge qui élimine la nécessité de travailler dans l'obscurité, les abeilles restant tout aussi tranquilles dans ces conditions. Il lui adjoint également une voûte chauffante, montrant alors que la direction des radiations est infiniment plus importante encore à considérer que la température du substrat. Les essais que nous avons faits avec cet appareil, nous ont permis de retrouver, à très peu de chose près, les résultats de HERAx. Nous avons pu recueillir des séries de choix de températures comprises entre 20 et $40^{\circ} \mathrm{C}$. Si l'on reporte ces chiffres sur un graphique indiquant en abscisse le nombre d'abeilles qui se sont fixées en un point de température donnée et en ordonnée ces températures, on obtient une courbe de Gauss très aplatie.

Les caractéristiques de cette courbe sont donc telles que les résultats ne pouvaient être donnés que dans des linites très larges, ce qui était loin de nous satisfaire.

Supposant que les abeilles sont capables de produire de la chaleur, retrouvant ainsi l'hypothèse de CIESIEISKY et BRUXXICH (I922), nous avons enfermé une grappe d'abeilles dans une enceinte et plongé au milieu un thermomètre. Dans ces conditions, nous avons pu constater que, systématiquement, la température au coeur de la masse d'abeilles se stabilise assez rapidement au voisinage de $32^{\circ} \mathrm{C}$, quelle que soit la température initiale de l'enceinte. Nous en avons conclu que cette température devait correspondre au thermopréférendum ou tout au moins à sa limite inférieure. Il y a évidemment certaines précautions à prendre pour obtenir ces résultats, il ne faut pas par exemple enfermer un trop petit nombre d'abeilles dans une enceinte trop vaste et trop froide. Si l'on prend soin de veiller ainsi à ne pas demander aux insectes en expérience une production de chaleur qui excède leurs possiblités, on obtient très facilement le thermopréférendum ou tout au moins la température qui paraît lui correspondre.

Ce chiffre corrobore les travaux de HERAx. Il est inférieur aux $35,3^{\circ}$ habituellement cités par les auteurs, mais ces chiffres correspondent, comme nous l'avons dit, à la température exigée par le couvain et non par les ouvrières.

Cette méthode de mesure est donc basée sur le fait que les abeilles peuvent produire des quantités de chaleur très appréciables. C'est pourquoi nous avons complété nos expériences par des essais de calorimétrie qui ont mis cette production en évidence. 


\title{
CHAPI'TRE PREMIIER
}

\section{PRINCIPES EXPÉRIMENTAUX - APPAREII, AGE - ÉTABLISSEMENT DES RÉSUITATS}

\author{
§. Principes expérimentaun
}

Il existe divers procédés pour apprécier une production animale de chaleur ; nous pouvons les classer en deux groupes : les méthodes directes, les méthodes indirectes.

\section{A. Méthodes directes.}

Elles consistent à placer dans des calorimètres les insectes à tester et à mesurer directement les quantités de chaleur produites. Ce sont ces méthodes que nous avons essentiellement utilisées. Il existe de très nombreux modèles de calorimètres : à eau, à glace, électricjues... simples ou différentiels, etc., on peut les classer en deux types : $a$ ) les calorimetres adiabaliques qui isolent aussi bien que possible le milieu interne du milieu externe et emmagasinent la chaleur produite que l'on mesure, et b) les calorimètres isothermiques dont le milieu interne est maintenu à une température déterminée ; on mesure alors l'importance du phénomène physique qui est responsable de ce maintien de température (fonte de la glace, effet PELTIER, etc.).

Nous traiterons dans le paragraphe" "appareillage " des techniques calorimétriques utilisées lors de nos travaux.

\section{B. Methodes indirete's.}

On peut, comme l'a fait Fisch ( 1960$)$, mesurer lit température interne des abeilles et observer ses variations suivant les circonstances expérimentales. Compte tenu de la déperdition de chaleur que subit le corps des abeilles, il est possible d'évaluer les quantités de chaleur produites, mais ce procédé est très imprécis car il faut apprécier la différence entre la température interne et la température ambiante, l'état de repos ou l'agitation, l'importance des pertes par évaporation, etc.

La méthode indirecte la plus aisément utilisable consiste à nesurer la consommation en oxygène et à établir le quotient respiratoire de l'insecte. C'est ce que PARHON a entrepris de faire en 1909. Ces travaux ont été repris par FreE et Botu en 1958 ; citons également Sotavalta (1954), Aluev (I959), Jongrlete et Wiersma (1935). Beutler (I936).

Les résultats obtenus ont été souvent contradictoires et nous pensons à ce propos que ces diverses expérimentations ont sans doute été faites, sinon avec des appareils insuffisamment précis, mais tout au moins qui ne permettaient pas de faire face à toutes les conditions expérimentales nécessaires à la compréhension du problème.

Nous avons repris ces études en collaboration avec Heusner au laboratoire de Physiologie de II. le Pr Kayser de la Faculté de Médecine de Strasbourg.

Il ne nous appartient pas de décrire ici les appareils mis au point par IIEUSNER, nous en donnerons cependant le principe fondamental décrit par KEHREN (1953-54) et RuILAND et IIEUSNER (r959).

Les insectes à tester sont placés dans un récipient étanche contenant de la chaux sodée ou barytée et communiquant, d'une part avec un générateur d'oxygène (voltamètre à sulfate de cuivre), d'autre part avec un manomètre contacteur. Ce dernier est lui-même relié à un vase compensateur, ce qui permet d'éliminer les variations de pression dues ì la température (voir fig. r).

L'ensemble est par ailleurs placé dans me enceinte maintenue à température constante.

Lorsque l'insecte consomme de l'oxygène et rejette du $\mathrm{CO}_{2}$, ce dernier est immédiatement absorbé par la chaux et une dépression se produit dims le manomètre.

Le circuit est alors fermé. 
Périodiquement (toutes les 2 ou 3 minutes par exemple), on laisse passer un courant électrique dans ce circuit; il se produit alors un dégagement d'oxygène qui diffuse vers le vase où est placée l'abeille. I.orsque cet apport d'oxygène a compensé très exactement la consommation de l'insecte, le manomètre revient à sa position d'équilibre et le circuit est rompu.

Il suffit donc de mesurer le temps de passige du courant électrique pendant la reconstitution de l'atmosphère originelle et de calculer la production d'oxygène correspondante dans le voltamc̀tre pour connaitre la quantité de gaz absorbée par l'insecte pendant la période de temps choisie (dégagement gazeux d'un voltamètre : $\left.v=\frac{\mathrm{I}}{\mathrm{F}} \times \frac{22,4}{2 n} \times \mathrm{I} t\right)$.

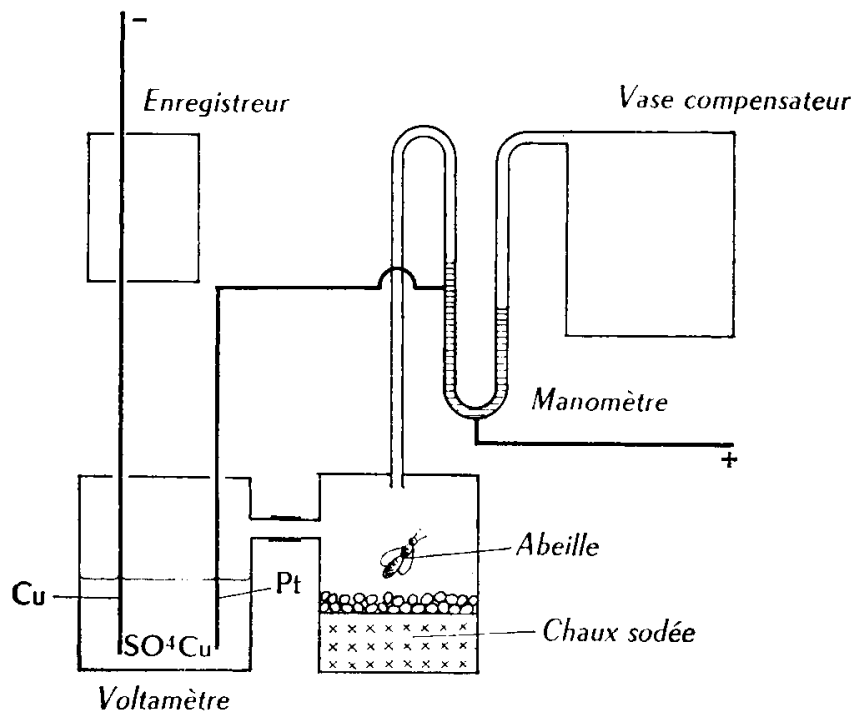

FIG. I. - Principe du respiromitre de Heissier.

Vous domnons ci-clessous l'une des courbes obtenue lors de nos expériences.

Chaque bâtonnet de cet histogramme représente la consommation d'oxygène en 3 minutes. A la longueur en millimètres, on fait correspondre un temps $t$, de passage du courant, d'après des paramètres établis expérimentalement, par étalomnage, et qui varient avec les appareils.

On peut alors calculer la consommation d'oxygène grâce it la formule ci-dessus citée.

Ces calculs sont évidemment assez complexes, on peut cependant les réaliser avec une précision très satisfaisante.

lour transposer les résultats obtenus en calories, il suffit de considérer (qu'un litre d'oxygène équivaut environ à 5.06 kilocalories.

Nous devons faire observer :

$1^{\circ}$ que ce chiffre de 5,06 kilocalories est un chiffre expérimental moyen et ne valant d'ailleurs que pour les glucides ( 1 ).

$2^{\circ}$ que la quantité de calories trouvée par ce calcul est valable au sens physiologique du terme, mais ne correspond pas obligatoirement, dans le moment de l'expérience, à un réel dégagement de chaleur.

Ainsi, dans son travail sur la température du corps des abeilles, H. LscH, reprenant des mesures de JoNGilod et WiERsul, expose les calculs suivants:

tu moment de l'envol, la consommation d'oxygine est de I,450 ml par minute et par gramme d'abeille, ce qui correspond a :

$$
5,06 \times 1,45=7,3+\text { calories }
$$

soit environ $0,7,34$ calories par abeille et par minute.

Esch déduit alors du chiffre obtenu 0,015 calories nécessaires aux "échanges organiques ", puis 3 à 4 p. roo du reste sont comptés comme ét ant absorbés par l'énergie du vol.

Il reste alors 0,69 calories effectivement transformées en chaleur.

(1) Lipides : 4,7 - protides : 4,5. 


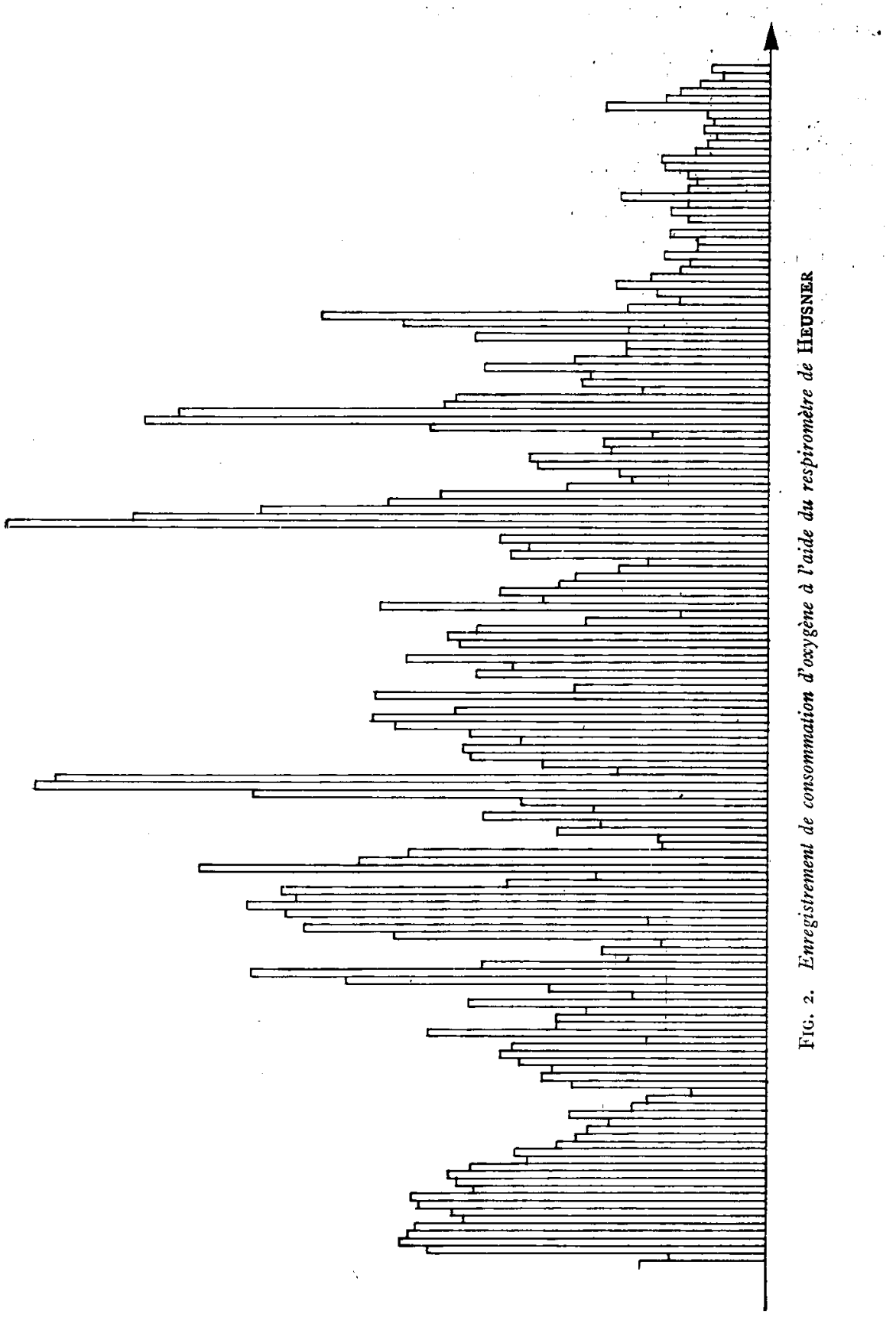


Ce chiffre, comme nous le verrons plus loin, est très fort par rapport à ccux que nous avons trouvés par nos diverses méthodes, mais constatons qu'il est lié au cas particulier qu'est l'envol, cas que nous n'avons pas étudié, en ce sens que nos essais intéressent essentiellement la régulation thermique de la ruche.

Remarquons à ce propos que ce calcul fait intervenir le poids moyen d'une abeille, considéré ici comme étant 0 , Io g. Ce chiffre nous paraît un peu faible. Beaucoup d'abeilles que nous avons pesées lors de nos essais accusaient le plus souvent un poids de 0,115 i $0,135 \mathrm{~g}$. Il est vrai que nous avons pesé des abcilles en bon état physiologique, fraîchement tirées de la ruche. Signalons toutefois qu'après quelques jours passés en cagettes de 100 à 200 individus, à l'étuve, abondamment pourvues en sucre et en eau, le poids moyen des abeilles peut tomber en 4 à 5 jours, ì 0,00, 0, 100 g, mais ceci est un problème sur lequel nous reviendrons au chapitre III.

ESCir poursuit le calcul de la production de chaleur en évaluant la déperdition occasionnée par la circulation de l'hémolymphe du thorax vers l'abdomen (le thorax étant considéré comme le siège de la thermogenése).

Volume moyen d'hémolymphe circulant che $z$ une abeille : o,or $\mathrm{mm}^{3}$ (BEtTLER, I936).

Vitesse de circulation : a minutes pour un circuit total.

Il passe donc, par minute, $0,005 \mathrm{~mm}^{3}$ d'hémolymphe, ce qui correspondrait à un échange de 0,005 calories par ninute et par degré thermique de différence de température entre thorax et abdomen.

Il nous semble finalement que, quoique infiniment plus délicate, la méthode directe, éliminant les diverses évaluations ci-dessus décrites, est en définitive plus valable pour obtenir l'exact dégagement de chaleur chez l'abeille domestique.

\section{§2. Appareillage}

\section{Le calorimètre électrique de CAI,VET el PRAT.}

Le calorimètre Calvet-PRAT est un calorimètre isothermique de conception très particulière. A l'inverse des calorimètres classiyues chez lesquels on recherche un isolement thermique aussi parfait que possible, on permet ici le déplacement de la chaleur produite de l'enceinte interne vers une enceinte externe, et c'est ce flux de chaleur que l'on mesure par des procédés thermoélectriques.

Le procédé habituel pour effectuer de telles mesures consiste à disposer de deux calorimètres jumelés ; dans l'un est placé le corps à tester et dans l'autre un système d'équilibrage, par exemple une résistance chautfante. Sur charue enceintc est fixé un thermocouple et ces éléments sont en opposition et reliés à un galvanomètre (voir fig. 3).

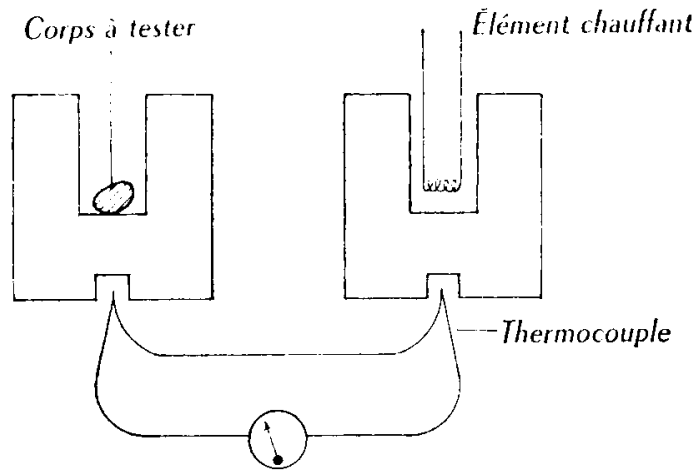

FIG. 3. - Principe de la calorimétrie électrique

Si l'on place un corps chaud dans le premier calorimètre, l'aiguille du galvanomètre dévie. On la ramène au 0 en chauffant le deuxième calorimètre à l'aide de la résistance et les quantités de chaleur alors mises en jeu sont rigoureusement égales si l'on a soin de maintenir le galvanomètre au point mort. On peut alors calculer, d'après la quantité de courant envoyée dans la résistance, la quantité de chaleur produite.

Dans le calorimètre CALvET-PRAT, le rôle de ces deux éléments est tenu par l'enceinte interne et l'enceinte externe, cette dernière étant maintenue à une température constante. Le phénomène 


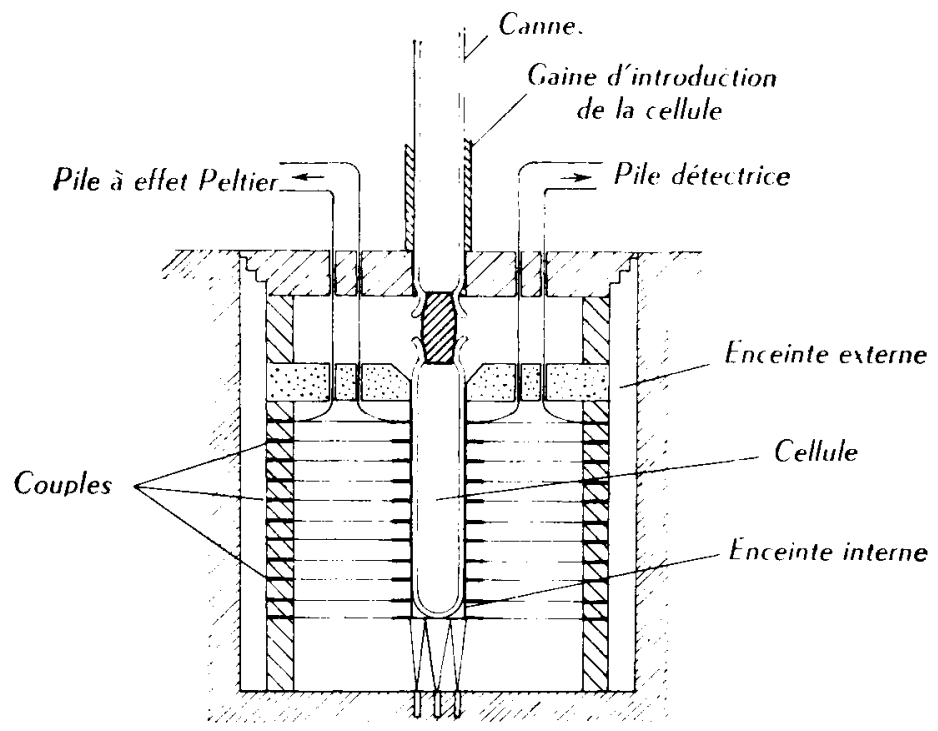

FIG. 4. - Élément calorimétrique Tian

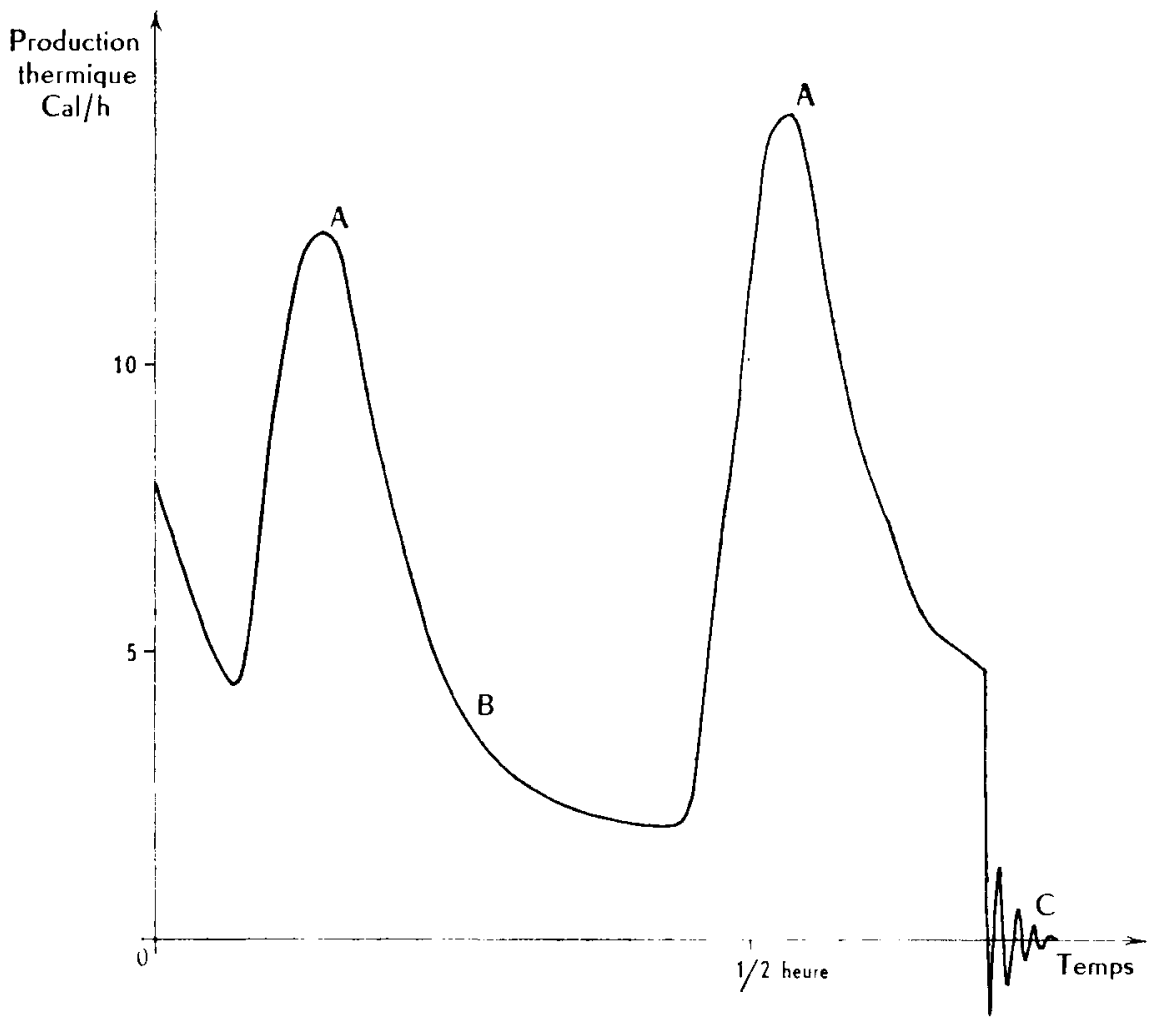

FIG. 5. - Un enregistrement obtenu avec un calorimètre CALVET 
électrique compensateur est ici inverse ; en effet, si le phénomène mesuré est exothermique, l'enceinte externe doit être refroidie (CALveT utilise ici l'effet Peltier), si le phénomène est endothermique. l'enceinte externe est réchauffée par l'effet Joule. CALvET et PRAT n'ont d'ailleurs pas cherché à obtenir une compensation rigoureuse du phénomène mesuré, mais une compensation approchée, constante et bien mesurable; la partie non compensée (généralement io p. Ioo) est enregistrée et mesurée; l'erreur tinale n'at teint pas le $\mathrm{I} / \mathrm{r}$ ooo de l'énergie totale mise en jeu.

Nous donnons ci-après le schéma très simplifié (fig. 4) d'un élément microcalorimétrique du type 'Tian, c'est sur ce principe que sont construits les calorimètres CALVET, avec de très nombreux perfectionnements (signalons par exemple que la liaison entre les deux enceintes et qui sert de passage au flux thermique se fait par l'intermédiaire de 800 à I 000 couples thermoélectriques, reliés soit à une pile détectrice, soit à la pile d'équilibrage (effet Peltier).

L'ensemble du calorimètre est placé dans un bloc ì température réglable, et le tout dans une pièce climatisée. Précisons que ces calorimètres comprennent toujours au moins deux ensembles calorimétriques en opposition ; ce montage différentiel permet de compenser les variations éventuelles du zéro expérimental, on ne produit en effet jamais d'effets thermiques dans l'enceinte témoin.

Ces calorimètres sont d'une précision vrainent remarquable et d'une très grande sensibilité de mesures. I.es déviations galvanométricjues sont d'ailleurs amplifiées par l'utilisation d'un faisceau lumineux qui se réfléchit sur le miroir du galvanomètre et est recueilli par des cellules photoélectriques mobiles et qui suivent le spot dans ses déplacements. In déplacement de I/ Io de $\mathrm{mm}$ est enregistré.

Signalons enfin que l'enceinte interne étant presque totalement recouverte par les thermocouples, il s'opère une véritable intégration du flux thermique et il n'est pas nécessaire d'homogénéiser les températures à l'intérieur de l'appareil comme avec les calorimètres classicques.

خous avons pu utiliser un tel calorimètre grâce à l'amabilité de MM. les Prs LEGAY et NIGoN de la Faculté des Sciences de Lyon.

\section{B. Les calorimetres Berthclot.}

Il nous est apparu que les chaleurs mises en jeu dans la thermométrie des abeilles étaient telles qu'il n'était pas nécessaire (tout au moins pour les groupes supérieurs à 5 ou 6 insectes) de disposer de calorimètres extrêmement sensibles. Il reste bien entendu que l'étanchéité thermique devait en être aussi parfaite que possible pour que les erreurs soient bien inférieures aux variations individuelles de production de chaleur des insectes mis en expérience.

Il n'existait pas dans le commerce de calorimètres simples dont la taille convienne à nos travaux, aussi les avons-nous réalisés au laboratoire.

Nos appareils sont du type Berthelot. Ils se composent d'un petit bac en matière plastique contenu dans un deuxième bac plus grand ; entre les deux est placé du coton cardé. Plusieurs thermomètres à tige fine, type grain d'orge, traversent ces deux enceintes, l'un aboutissant dans la masse liquide placée au fond du bac interne, les autres soit dans l'atmosphère du compartiment réservé aux abeilles, soit dans l'atmosphère des autres chambres. Le bac interne est en effet cloisonné par des parois métalliques qui ont pour but de conduire, aussi vite que possible et aussi uniformément que possible, la chaleur produite vers l'eau du bac interne.

Nous avons été amenés, en raison de la variabilité du nombre des abeilles à tester, à construire des calorimètres de deux tailles différentes; nous en indiquons les cotes ci-dessous :

\begin{tabular}{|c|c|c|}
\hline Désignation & $\begin{array}{l}\text { Calorimetre pour } \\
10 \text { à } 50 \text { abeilles }\end{array}$ & $\begin{array}{l}\text { Calorimètre pour } \\
1 \text { à } 10 \text { abeilles }\end{array}$ \\
\hline 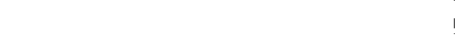 & $\mathrm{mm}$ & $\mathrm{mm}$ \\
\hline Profondeur du bac interne ......... & 50 & 40 \\
\hline Diamètre du bac inteme . . . . . . . . . & 40 & 30 \\
\hline Profondeur du bac externe . . . . . . . & 80 & 80 \\
\hline Diamètre du bac externe ........... & 65 & 65 \\
\hline Profondeur du compartiment à insectes. & 25 & 20 \\
\hline Distance maximum entre la paroi métal- & & \\
\hline lique et la paroi du bac interne.... & 26 & 20 \\
\hline Quantité d'eau placée dans le bac in- & & \\
\hline terne $\ldots \ldots \ldots \ldots \ldots \ldots \ldots \ldots$ & $10 \mathrm{cc}$ & 5 à $6 \mathrm{cc}$ \\
\hline
\end{tabular}


Il est indispensable d'adapter la taille du calorimètre au nombre des abeilles à tester car plusieurs précautions doivent être prises :

il faut mettre le moins d'eau possible à l'intérieur pour que les variations de sa température

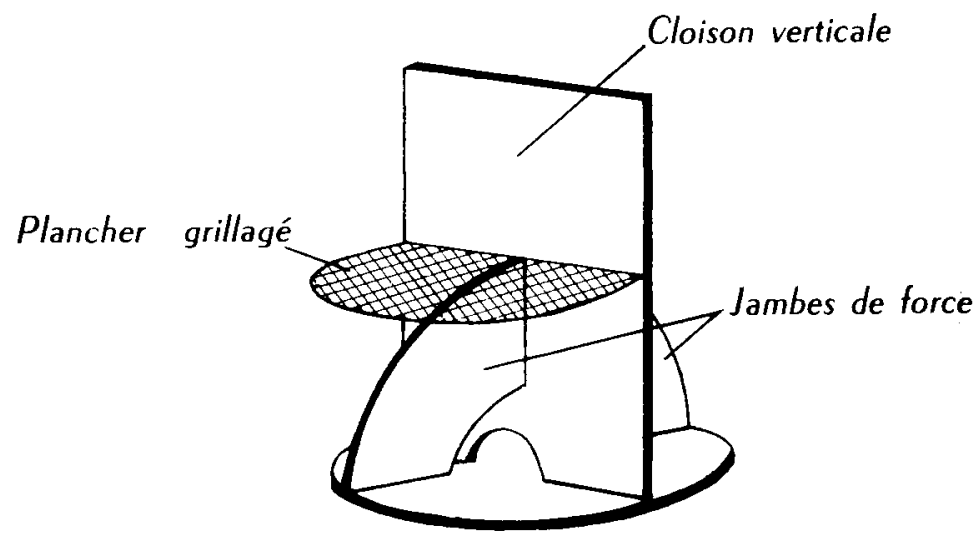

FIG. 6. - Disposilif métullique conducleur de chaleur

soient plus appréciables, mais il est bon que sa hauteur soit aussi grande que possible afin d'augmenter les contacts entre la masse liquide et le dispositif métallique thermoconducteur,

- il faut éviter l'asphyxie et autoriser une certaine liberté de mourements mais il est cependant nécessaire que le calorimètre ne soit pas trop grand; on a en effet intérêt à limiter la valeur en eau

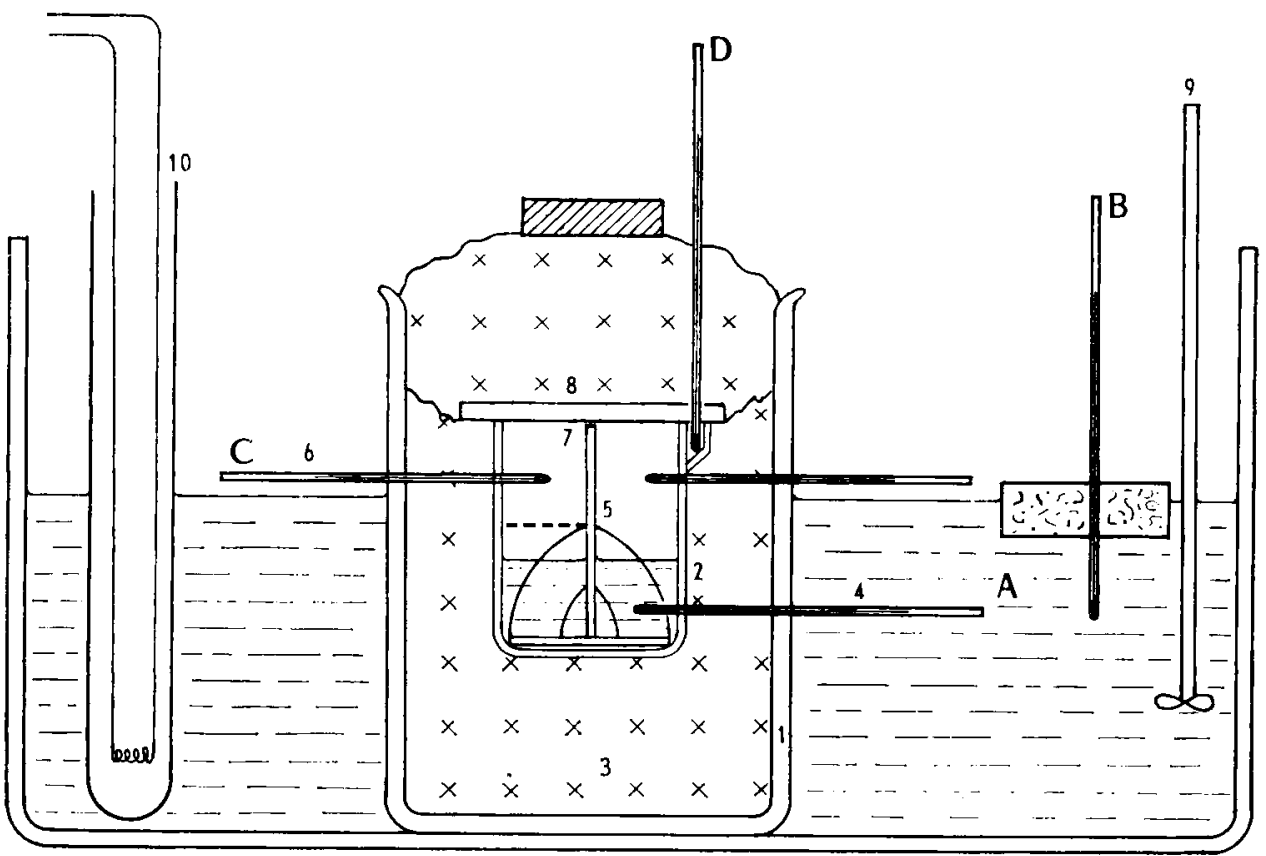

FIG. 7. - Calorimetre de type Berthelot

: I - Bac externe, 2 - Bac intene, 3-Isolant thermique,

4 - Thermomètre indiquant la température de l'eau interne, 5 - Dispositif métallique conducteur (voir fig. 6), 6-Thermomètre indiquant la température dans la chambre des insectes, 7 - couvercle isolant, 8 - Isolant thermique, $9-$ Agitateur, 1o - Résistances chauffantes. 
propre à l'appareil car les températures finales n'y sont pas homogènes, et ceci occasionne des calculs de correction assez complexes. Infin, si l'on veut pouvoir apprécier la température au sein d'une grappe d'abeilles, pendant l'expérimentation, il faut que la taille de la chambre soit telle que les insectes ne puissent pas trop se disperser.

Iin ce qui concerne les dispositifs métalliques thermoconducteurs, ils nous ont donné entière satisfaction.

Ils se composent d'une plaque rectangulaire formant une cloison verticale. Cette cloison est soudée à une rondelle métallique (qui épouse le fond du bac interne) et porte une grille semi-circulaire horizontale formant le plancher de la chambre aérienne réservée aux abeilles. Elle porte également des jambes de force qui rejoignent la plaque basale et qui ont pour but de conduire les calories dans une direction perpendiculaire à celle de la cloison verticale.

Ainsi, la chaleur produite par les abeilles est rapidement conduite vers l'eau du calorimètre et équitablement répartie dans la masse liquide.

Si l'on place un corps chaud dans le compartiment réservé aux insectes, on voit la température de l'eau interne s'élever instantanément et d'une facon uniforme en différents points de la masse liquide, ainsi que nous avons pu le constater grâce à différents thermomètres.

Cette disposition permet d'éviter d'agiter l'eau dans le calorimètre ; les mouvements de brassage ayant pour effet de perturber les abeilles $\left(^{(i)}\right.$.

Nous avons toutefois effectué plusieurs essais en agitant l'eau du calorimètre et nous n'avons pas observé de différences significatives entre les résultats de ces expériences et nos mesures habituelle.

Conme nous l'avons vu, les températures sont lues à l'aide de simples thermomètres. En principe, il suffit d'une légère correction de lecture pour obtenir la température réelle, correction qui relève de la profondeur d'enfoncement du thermonètre dans le corps étudié et qui est donnée par la formule :

$$
x==\mathrm{T}+n \cdot 0,000 \mathrm{I} 56(\mathrm{~T}-t)
$$

Il nous est apparu très rapidenent, que cette correction était négligeable surtout par rapport aux erreurs apportées par la présence même des thermomètres, le verre se révélant relativement bon conducteur de la chaleur pour des excès de température assez grands.

C'est pourquoi, après avoir analysé dans le détail, lors de nos premiers essais, l'évolution des températures à l'intérieur de nos calorimètres, nous avons par la suite, supprimé la plus grande partie des thermomètres, ne laissant subsister que ceux indiquant la température dans la masse liquide et au sein de la grappe d'abeilles.

De plus, nous avons placé le calorimètre dans une masse d'eau dont la température est maintenue constamment au même degré que celle de la masse liquide interne. Ceci implique bien entendu un système d'échauffement doux et continu de cette première masse. Un excellent moyen consiste à reprendre le principe des dispositifs thermoélectriques utilisés par TAYLOR et CrESCITELLI (I937) pour leur microcalorimètre et dont nous donnons ci-dessous un schéma très simplifié (fig. 8).

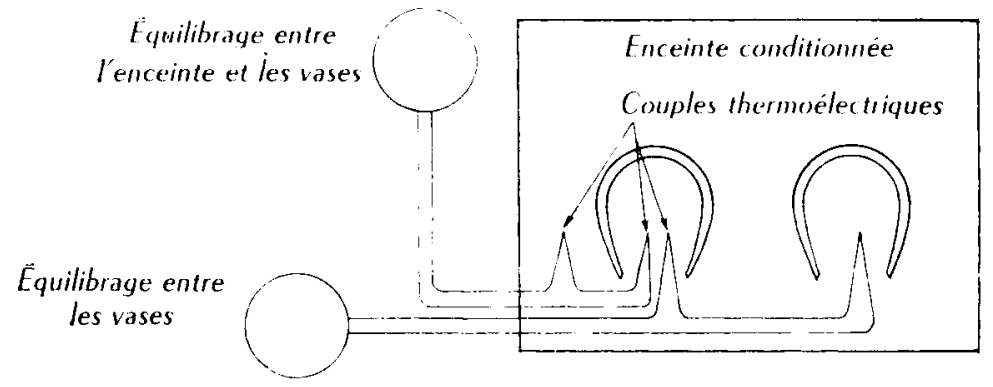

FIG. 8. - Principe du microcalorimetre différentiel de TAYLOR et CRescitelli

Ces calorinètres se composent de deux vases aussi semblables que possible. Chacun d'eux contient une sonde thermoélectrique et une résistance chauffante suivant le principe habituel de la mesure des flux thermiques par couples thermoélectriques ainsi que nous l'avons exposé plus avant. Un dispositif électrique équilibre en permanence la température des deux vases et un semblable dispositif est prévu pour équilibrer les températures des vases et de l'enceinte. En ce qui nous concerne,

(1) Ajoutons que l'agitation de l'eau produit par elle-même de la chaleur, mais cela ne peut perturber que des mesures de grandeurs extrêmement petites. 
il s'agit simplement d'équilibrer la température de l'eau d'environnement et de celle contenue dans le bac interne. Nous nous sommes donc contenté de placer dans cette eau d'environnement, des résistances électriques dont le contact est fermé ou rompu au gré de l'expérimentateur, celui-ci lisant directement sur les thermomètres $\mathrm{A}$ et $\mathrm{B}$ (voir fig. 7 ) les températures à équilibrer.

Nous avons pu constater d'ailleurs qu'il n'y avait pas d'échanges thermiques appréciables, par l'intermédiaire des thermomètres, lorsque la différence des températures entre les masses interne et externe n'excède pas ${ }^{\circ}{ }^{\circ} \mathrm{C}$.

Nous avons tenté de pallier ces difficultés d'une autre façon par l'utilisation de sondes thermorésistantes de très petite taille. Ces pièces métalliques sont intégralement plongées dans le milieu testé et ne communiquent avec l'extérieur que par des fils gainés de caoutchouc, imperméables à toute influence externe. Cependant, l'emploi de ces sondes ne nous a pas donné satisfaction car les fils métalliques conducteurs apportent des perturbations en libérant dans l'eau interne des calories en quantités incontrôlables. Il faut veiller également à ce que les ponts de Wheatstone ou les mégohmètres utilisés pour les mesures soient de qualité suffisante pour être fidèles.

Ces calorimètres Berthelot présentent l'avantage d'être d'un maniement aisé et peuvent être facilement réalisés au laboratoire, comme nous l'avons indiqué. On peut leur faire quelques critiques :

$\mathrm{I}^{\mathrm{o}}$ la température est variable au cours de l'expérimentation et les insectes testés ne se trouvent pas dans des conditions rigoureusement constantes,

$2_{2} \mathrm{O}$ les corrections calorimétriques sont délicates et apportent incontestablement un pourcentage d'erreurs très supérieur à ce qu'on peut obtenir avec un calorimètre électrique.

Quoi qu'il en soit, eu égard aux quantités de chaleur mises en jeu et la brièveté relative des expérimentations, ils nous ont permis des résultats d'une précision satisfaisante.

Nous avons essayé d'utiliser un autre type de calorimètre, adiabatique également, construit à partir d'un vase de Dewar.

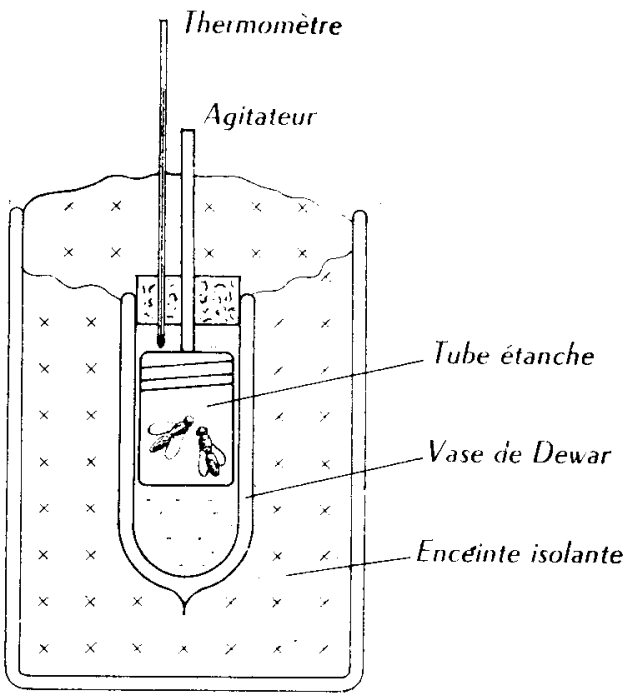

Fig. 9. - Calorimètre à vase de Dewar

Il se compose donc d'un vase à double paroi argentée entre lesquelles est réalisé un vide poussé.

Ce vase est placé dans un épais manchon de coton cardé ou de laine de verre et obturé par un bouchon, lui-même recouvert d'un tampon thermo-isolant.

L'ensemble de ce couvercle étanche est percé par une tige de bois et un thermomètre à tige fine type grain d'orge.

Les abeilles sont placées dans un tube métallique d'un diamètre un peu inférieur à celui du vase de Dewar $(30 \mathrm{~mm})$ qui est rempli d'eau.

Ainsi la production de chaleur, dont la diffusion se fait dans toutes les directions, peut être absorbée sans aucune latence à l'inverse de ce qu'on pourrait reprocher à nos calorimètres de type Berthelot. Comme la température est prise seulement à la partie supérieure de l'eau, il faut, cette fois, brasser cette dernière. On le fait simplement et sans trop perturber les abeilles en enfonçant le tube métallique dans l'eau à l'aide de la tige de bois puis en le laissant remonter sous la poussée du liquide plusieurs fois de suite.

Après quelques brassages, les températures s'équilibrent très bien.

Annales de l'Abeille. $-\mathbf{1} 965$. 
Nous avons effectué, avec ce calorimètre, des mesures comparatives avec les calorimètres Berthelot, sur des lots d'abeilles aussi semblables que possible ( 50 abeilles sont prélevées dans un groupe de 150 ou 200 insectes, 25 sont placées dans le Dewar, 25 dans le Berthelot).

Mais lors des essais que nous avons effectués, nous n'avons pas trouvé de chiffres comparables et les résultats obtenus avec le vase de Dewar son $t$ en moyenne 3 fois plus faibles.

En effet, en ce qui concerne ce calorimètre, nous avons été contraints de placer les insectes à tester dans un petit récipient étanche. Dans ces conditions, les abeilles ne disposent plus d'une quantité d'oxygène suffisante, celia n'entrave pas leur production thermique, comme nous le verrons au chapitre IV, mais la diminue cependant d'une façon très nette $\left(^{1}\right)$.

Indiquons enfin que nous n'avons pas voulu utiliser des calorimetres type Bunsen. Ces calorimètres dont le principe est basé sur la fonte de la glace sont peu précis quant à l'évaluation de la quantité d'eau de fusion recueillie, en outre ils ne permettent d'expérimenter qu'à $0^{\circ} \mathrm{C}$ et, dans ces conditions, les abeilles sont paralysées.

\section{§ 3. Pratique de lexpérimentation - Établissement des résultats}

En ce qui concerne l'expérimentation avec le CaLveT-PRat, les conditions de travail sont délicates mais parfaitement précises et nous ne nous étendrons pas sur ces techniques. Signalons cependant un inconvénient de cet appareil qui réside dans le fait qu'on ne peut commencer la mesure dès l'introduction des insectes dans le vase interne. En effet, l'appareil étant très sensible, la seule mise en place du vase interne suffit à produire un dégagement de chaleur qui fausse les mesures. Il faut donc attendre 20 à 30 minutes avant de brancher l'appareil sur le galvanomètre, et c'est précisément pendant ce laps de temps qu'il serait intéressant d'enregistrer la production thermique des abeilles.

Nous avons pu heureusement pallier cet inconvénient dans le cas de nos expériences. Les dégagements thermiques étaient tels que nous avons dû placer des résistances de plusieurs milliers d'ohms en série avec le galvanomètre : cela a ramené le temps de latence au départ à quelques 5 à 7 minutes. culières.

En ce qui concerne nos calorimètres Berthelot, leur exploitation nécessite des précautions parti.

Pour effectuer une mesure, on place, dans le calorimetre, une certaine masse d'eau de volume bien précisé grâce à l'emploi d'une pipette à tige fine.

On remplit le cristallisoir d'eau à une température aussi voisine que possible de celle du calorimètre, et l'on attend la stabilisation, c'est-à-dire que tous les thermomètres indiquent exactement la même température, ce qui se réalise, en général, en quelque trente minutes.

On prépare alors le lot d'insectes à tester, ce peut être un groupe d'abeilles mortes (tuées au cyanure ou autres produits) ou mise en contention de diverses façons, dans ce cas le problème est simple. Par contre, si l'on veut introduire un lot d'abeilles libres et bien vivantes, il est nécessaire de les anesthésier très légèrement au $\mathrm{CO}_{2}$ avant de les introduire dans le calorimètre. Nous avons pu réaliser des essais sans cette anesthésie et les résultats n'ont pas été différents (par contre, les productions de chaleur deviennent faibles ou aberrantes après trois ou quatre anesthésies successives).

Pour placer les insectes dans le calorimètre, on soulève légèrement la rondelle de carton, on glisse prestement le lot d'insectes et on place sur l'assemblage de carton et de coton formant couvercle, la plaquette de plomb qui en assure le maintien de son seul poids. Avec un peu d'habitude, on arrive à opérer sans introduire de quantité de chaleur parasite, quelle que soit la température de la pièce où l'on opère.

Il reste à lire les températures résultantes, soit d'une façon continue si l'on veut suivre l'évolution du processus thermogène, soit en fin d'expérience si l'on veut simplement apprécier la quantité de chaleur produite dans le temps de l'essai.

Pour fixer la durée des mesures, il nous a été nécessaire de faire de nombreuses expériences préalables en lisant les températures aériennes d'une façon continue, afin de pouvoir bien préciser pendant combien de temps les abeilles peuvent effectivement produire de la chaleur.

Il est bien évident que quelques abeilles (et surtout une seule abeille) ne peuvent maintenir une même température de l'air ambiant, qu'un groupe plus important de ces insectes.

Comme nos résultats sont en général exprimés en quantité de chaleur par abeille et par minute, il est donc nécessaire de savoir pendant combien de temps les abeilles peuvent faire face au froid que nous leur imposons.

Nous avons pu observer divers phénomènes thermiques sur lesquels nous reviendrons d'ailleurs, disons simplement qu'une abeille isolée ou un petit nombre d'abeilles résistent peu de temps au froid de l'atmosphère dans laquelle ils sont placés.

Il est donc indispensable de suivre, sur le thermometre aérien, les variations de la température.

(1) Remarquons en outre que la capacité calorifique d'un vase Dewar est mal définie car elle dépend de la durée de l'expérience. 
La température de l'air s'élève, se maintient plus ou moins uniformément (le plus souvent en effet, elle monte et descend par saccades brèves) puis finit par décroître rapidement.

On peut admettre que les abeilles cessent de produire de la chaleur au moment où la courbe des températures de l'air amorce sa descente. On pourrait donc prendre comme temps d'expérience la durée qui sépare le début de l'essai de cet instant où la température commence à décroitre.

Cependant, il est facile de constater que la pente de cette portion de courbe est moins forte qu'elle ne devrait l'être en considérant la latence du passage des calories de l'air à l'eau et au refroidissement du corps des insectes; donc, les abeilles produisent encore un peu de chaleur pendant cette période. On peut mesurer la pente de la courbe imputable à la latence et au simple refroidissement des corps grâce ì des mesures sur insectes morts.

On constate donc que les courbes obtenues ont une pente environ deux fois moins forte que cette pente théorique. Il est donc valable et très simple de prendre pour temps d'expérimentation :

$$
t=t_{1}+\frac{t_{2}}{2}
$$

$t_{1}$ étant le temps compris entre le début de l'essai et le début de chute définitive de la courbe, et $t_{2}$ le temps compris entre ce début de la chute et le moment où cette courbe des températures de l'air rejoint celle des température de l'eau. Cette jonction ne s'opère théoriquement qu'exponentiellement ; dans la réalité, eu égard à l'imperfection des appareils et... de l'expérimentateur, on observe un moment où l'on peut estimer que la pente de la courbe est devenue nulle (voir fig. ro).

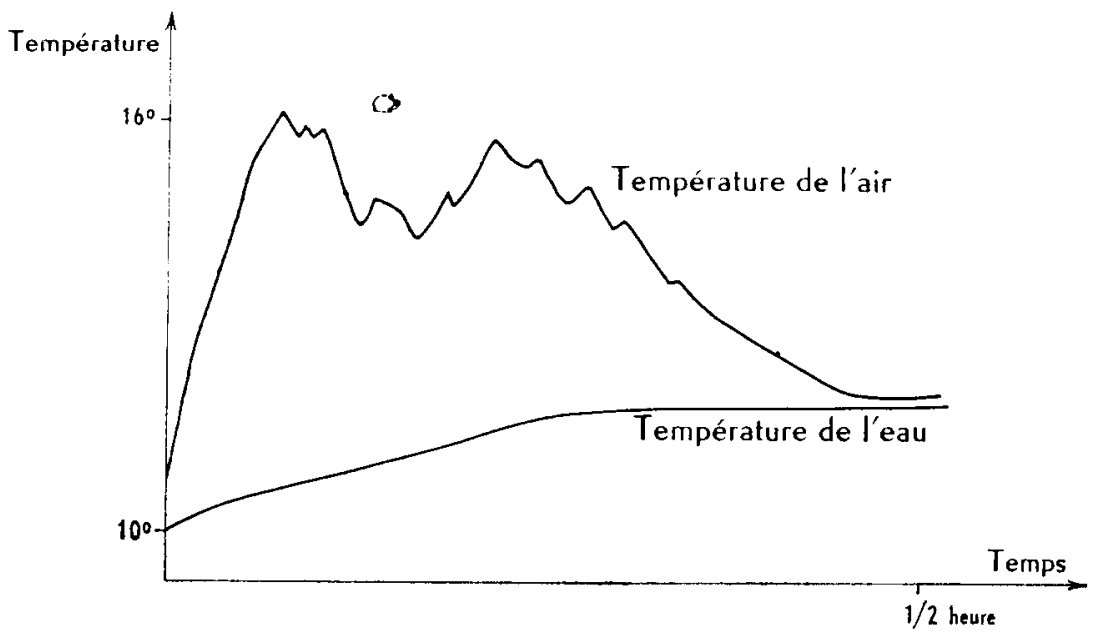

FIG. 10. - Courbes obtenues au calorimètre Berthelot avec 2 abeilles

Dans le cas où on expérimente avec assez grand nombre d'abeilles, comme c'est le cas dans la grande majorité de nos mesures, celles-ci sont susceptibles de maintenir une forte température de l'air pendant des heures (jusqu'à i4 et is heures).

Dans ces conditions, il est nécessaire de fixer une limite à la durée des expérimentations ; nous avons choisi celle-ci égale à une demi-heure.

En effet, la chaleur produite peut être le résultat de deux phases bien distinctes et dont nous reparlerons au chapitre II, et cette durée que nous avons adoptée permet la mise en évidence de ces deux processus. Une durée moindre évincerait le dernier, une durée supérieure ne présenterait aucun intérêt supplémentaire comme nous avons pu le constater au cours d'essais de plus longue durée (voir fig. II).

De plus, l'atmosphère oir sont logées les abeilles étant confinée, la raréfaction de l'oxygène fausserait a la longue les résultats. Comme nous l'avons remarqué avec Heusser, roo abeilles consomment à peu près autant d'oxygène qu'un rat blanc au repos (à température égale).

En ce qui concerne le critère adopté dans cette étude, nous avons symbolisé cette valeur sous le sigle :

Q/t/a (nombre de calories produit par abeille et par minute).

On appelle $T_{1}$ la température initiale en ${ }^{\circ} C, T_{2}$ la température de l'eau interne en fin 
d'expérience, T les températures des diverses parties du calorimètre toujours en fin d'expérience, $t$ le temps de l'essai en minutes, $n$ le nombre d'abeilles, $q$ la quantité d'eau interne en $\mathrm{cm}^{3}$ et $m$ les valeurs en eau des différentes parties du calorimètre dont on repère les températures en fin d'essai, on a :

$$
Q t_{i} a=\frac{\left(\mathrm{T}_{2}-\mathrm{T}_{1}\right) q+\mathrm{V}\left(\mathrm{l}-\mathrm{T}_{1}\right) m}{n \cdot t}
$$

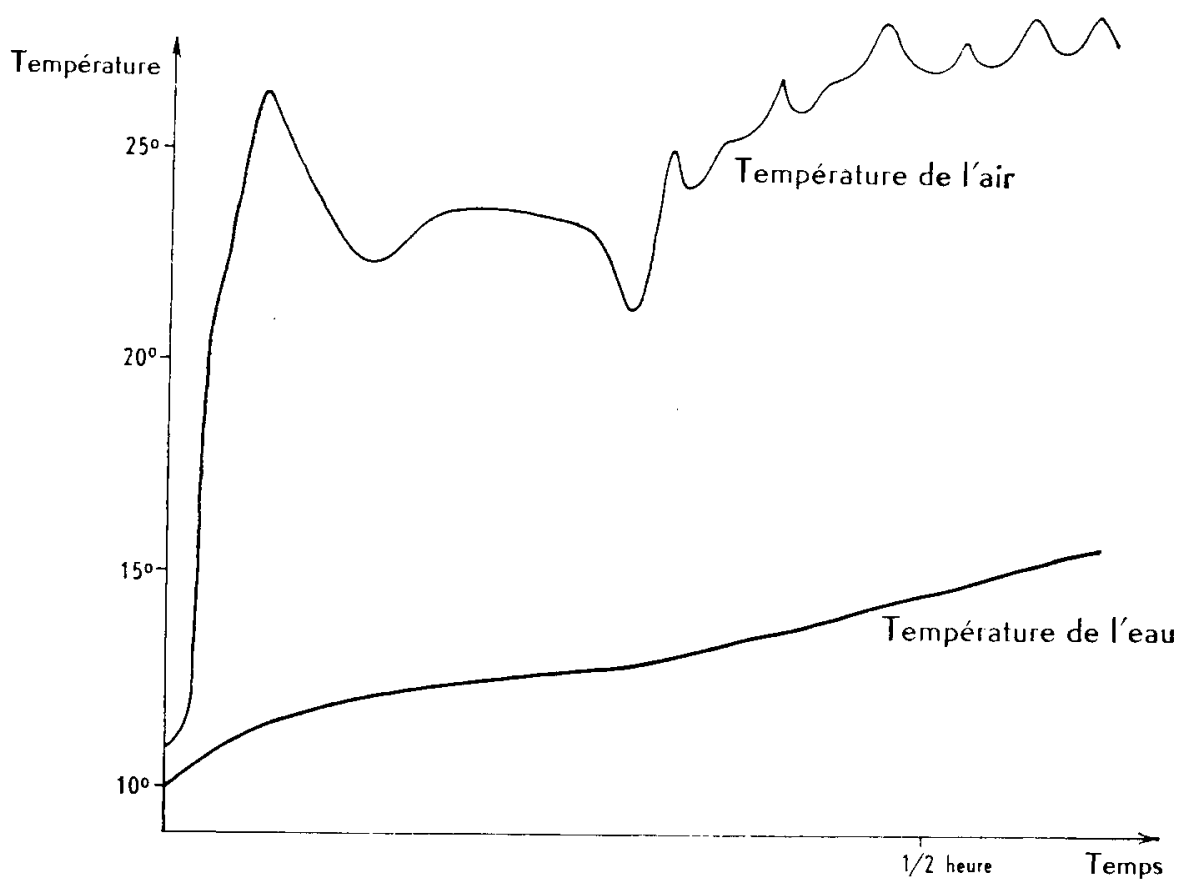

Fıg. I. - Conbes oblenues au calorimètre Berthelot añec un groupe de 25 abeilles

C'est très exactement la quantité moyenne de calories que peut produire une abeille, par minute, avant épuisement ou raréfaction de ses réserves énergétiques et dans les conditions de l'expérience.

Ce calcul est cependant très difficile à réaliser et admet vraisemblablement un pourcentage d'erreur assez important.

En effet, en fin d'expérience, les températures dans le calorimètre ne sont pas homogènes puisque le lot des insectes testés continue d'être chaud et de dégager des calories.

Ainsi par exemple, le bas du calorimètre et l'eau interne peuvent être à 13 ou $14^{\circ} \mathrm{C}$, et la chambre des abeilles à 25 ou $26^{\circ} \mathrm{C}$. De plus, comme nous sommes obligés de placer une cloison métallique verticale conductrice de chaleur, le compartiment réservé aux insectes n'occupe que la moitié de la lumière du bac interne, on a donc, dans le haut du calorimètre, deux zones thermiques, l'une chaude où sont les abeilles, l'autre plus tiède de l'autre côté de la cloison verticale.

On est alors en présence de deux gradients thermiques issus de la chambre des insectes, l'un vertical, l'autre horizontal.

On peut établir une valeur en eau théorique du calorimèt re qui tienne compte de ces phénomènes. Il existe cependant un moyen plus rigoureux de calculer cette valeur et qui consiste à étalonner l'appareil en remplaçant le groupe d'insectes par un corps chaud, de poids, de température et de capacité thermique connus.

Ce corps est placé dans la logette à insectes et cède immédiatement des calories à l'ensemble du dispositif. En fin d'expérience, on relève les élévations de température du calorimètre. Connaissant l'exacte quantité de calories cédées par le corps, on peut calculer la valeur en eau effective du calorimètre.

La logette étant petite, le corps utilisé pour cet étalonnage ne peut être très volumineux; comme il est nécessaire pour une bonne précision de mettre en jeu une assez notable quantité de calories, il faut utiliser un corps de forte capacité thermique. La méthode qui nous a donné entière satisfaction consiste à utiliser un petit récipient contenant $+\mathrm{cm}^{3}$ d'eau chaude; de plus, la température d'un 
liquide peut se mesurer d'une façon très précise, ce qui n'est pas toujours le cas avec un solide dans lequel un éventuel gradient thermique n'est pas aisément décelable.

Nous avons tenté de remplacer ce corps chaud par une résistance de valeur connue dans laquelle nous faisions passer un courant électrique d'intensité connue. Nous avons dû cependant abandonner ce dispositif car, de la même façon qu'avec les sondes thermorésistantes de mesure des températures, il nous a été impossible d'apprécier très exactement la perturbation thermique due aux fils conducteurs.

Précisons enfin que la quantité de chaleur mesurée pendant nos expériences relève de deux origines :

- la production de chaleur proprement dite, et

- l'apport originel dû au fait que le corps des insectes introduits dans le calorimètre est à une certaine température.

Pour évaluer cet apport parasite de nos mesures, nous avons réalisé plusieurs expériences à partir de lots d'abeilles fraîchement tuées au cyanure de potassium. La quantité de chaleur $Q_{m}$ obtenue avec ces insectes morts est à déduire de la quantité totale Q que l'on mesure au cours des expériences. Nous avons effectué un certain nombre de mesures à partir desquelles nous avons calculé un $Q_{m}$ moyen que nous avons soustrait systématiquement de toutes nos mesures (précisons que $Q_{m}$ est toujours assez petit par rapport à $Q$ - résultats chiffrés au paragraphe suivant). Il est nécessaire, avec ce principe, de toujours tester les abeilles mortes ou vivantes après les avoir fait séjourner dans une enceinte à température déterminée, température que nous avons choisie à $32^{\circ} \mathrm{C}$ (thermopreférendum déduit de nos travaux antérieurs).

Signalons que l'apport de chaleur parasite éventuellement dû aux manipulations entre également dans cette valeur $Q_{m}$ et se trouve du même coup déduit du résultat global.

Dans certaines conditions expérimentales, cette correction est impossible (mesures sur des abeilles ayant séjourné une heure par exemple dans une enceinte froide afin d'épuiser leurs réserves caloriques) ; il est alors nécessaire de calculer un nouveau $\mathrm{Q}_{m}$ mais, dans ces conditions, on peut le considérer comme négligeable si la température de l'enceinte froide de séjour est voisine de la température initiale dans le calorimètre ( $10^{\circ} \mathrm{C}$ dans la généralité de nos expériences).

\section{$\$ 4$. Correction concernant l'apport de calories}

dî à la température propre du corps des abeilles

Nous avons donc procédé à des essais pour déterminer ce que nous avons appelé le $Q_{m}$ moyen quantité de chaleur qu'il nous faut déduire de $Q$ total calculée, pour obtenir la véritable production: thermique dans le temps de l'expérience.

Nous avons d'abord procédé à des essais portant sur des lots d'abeilles dont la tête avait été écrasée. Sachant que le thorax de ces insectes est le siège principal de la production de chaleur et qu'un insecte décérébré peut continuer à vivre végétativement, nous avons rapidement abandonné ce procédé par lequel il nous arrivait d'ailleurs de trouver des productions de chaleur équivalentes à celles d'abeilles intactes (remarquons qu'avec des abeilles décapitées les Q/t/a trouvés sont très faibles, c'est donc que le simple écrasement de la tête ne privait pas les insectes de toutes leurs possibilités motrices).

Nous avons donc, avant essai, placé nos abeilles un certain temps (d'I/2 h à quelques heures suivant les besoins en abeilles mortes) dans des flacons de cyanure de potassium. La mort est ainsi réelle pour presque tous les tissus. Pour avoir des résultats comparatifs, nous avons toujours placé les flacons en étuve à $32^{\circ} \mathrm{C}$, température à laquelle sont soumises avant essai toutes les abeilles testées vivantes ou non.

Pour calculer le $Q_{m}$, on note les températures de début èt de fin d'expérience. Les calorimètres étant thermiquement bien étanches, on peut relever la température finale après un temps aussi long que l'on veut, on peut cependant la noter dès le moment où la température aérienne rejoint, à peu de chose près, la température de l'eau.

On a alors :

$$
Q_{m} \text { par abeille }=\frac{\left(\mathrm{T}_{2}-\mathrm{T}_{1}\right) \mathrm{M}}{n}
$$

$T_{1}$ étant la température de début, $T_{2}$ la température en fin d'expérimentation, $M$ la valeur en eau de calorimètre et de son contenu et $n^{\prime}$ le nombre des abeilles mortes.

Les résultats sont assez variables; nous les avons calculés pour des lots de 25 abeilles, nous avons obtenu des $Q_{m}$ variant de ro à I4 calories.

Il est apparemment gênant de vouloir en tirer un $Q_{m}$ moyen apte à se soustraire automatiquement de la quantité $Q$ résultante d'une expérience quelconque.

Mais, dans la très grande généralité des cas, les $Q_{m}$ trouvés, sont de 10,8 calories et ce chiffre expérimental n'est statistiquement pas arbitraire. 
Ajoutons que ces quantités de chaleur sont assez faibles eu égard aux quantités réellement produites dans le temps d'une expérience.

Par exemple, examinons un essai choisi au hasard:

- Essai $n^{\circ} 72$ sur 20 abeilles libres et vivantes: $Q=210$ calories en 30 minutes,

$$
\begin{aligned}
& \text { soit un Q/t/a fictif de }: \frac{210}{20 \times 30}=0,35^{\circ} \text {. } \\
& \text { Correction : } Q_{m}^{20}=\frac{Q_{m}^{25} \times 20}{25}=8,64 \\
& Q \text { réel }=210-8,64=201,36 \\
& Q / t / a \text { réel }=\frac{20 \times 30}{201,3^{6}}=0,335
\end{aligned}
$$

Nous voyons que la correction au niveau du Q/t/a est relativement faible (ici 4,3 I p. I00) et que surtout l'erreur relative sur le $\mathrm{Q}_{m}$ utilisé est de ce fait rendu assez négligeable par rapport aux variations individuelles.

Remarque : Les tissus d'un insecte mort asphyxié dans la cellule d'un calorimètre électrique continuent de dégager de la chaleur, " probablement conclut PRAT (I960) par le fait de réactions enzymatiques ${ }^{\prime}$. Cela se produit à un degré moindre dans le cas de nos expériences, car les abeilles sont tuées au CNK qui bloque après un temps assez bref, une grande partie des activités cellulaires.

\section{$\S$ 5. Précision des mesures}

En ce qui concerne les appareils électriques que nous avons utilisés, nous nous contenterons d'indiquer que le respiromètre HEUSNER a une précision de l'ordre de $3 \mathrm{p}$. roo; quant au calorimètre Calvet, on admet couramment que sa précision attteint le I/I 000 de l'énergie totale mise en jeu.

Les calorimètres du type Berthelot sont évidemment moins précis et nous avons établi quelle pouvait être l'erreur maximum possible avec ces appareils.

Les causes d'erreurs sont de plusieurs sortes :

- erreur de mesure sur le volume d'eau introduit dans le calorimètre,

- erreurs de lecture concernant les températures de début et de fin d'expérimentation,

- erreur sur la valeur en eau, M, du calorimètre et de son contenu.

En ce qui concerne les premières sources d'erreurs, on peut faire un calcul classique, mais il nous a fallu procéder de façon différente en ce qui concerne $M$.

Nous avons procédé à un étalonnage des calorimètres en y introduisant, comme nous l'avons exposé précédemment, des corps de poids, température et capacité thermique connus. A partir de chaque expérience, il a été calculé une valeur $\mathrm{M}$ de l'ensemble calorimétrique et ces valeurs ont été reportées sur un graphique indiquant, en ordonnée, ces valeurs en eau et, en abscisse, les températures finales de chaque essai.

Ces points se sont trouvés répartis dans des ellipsoïdes à grand axe horizontal, ce qui prouve que la valeur en eau de nos calorimètres ne variait pas quelle que soit la valeur de la température de travail.

Une série de points a été établie pour chacun des deux calorimètres utilisés lors de nos expériences et dont les cotes ont été définies précédemment.

Nous avons pu alors calculer statistiquement les moyennes et les écarts-types de ces deux populations de résultats.

Ce sont :

- pour le calorimètre I (grande taille)

$\begin{array}{ll}\text { moyenne } \ldots \ldots \ldots \ldots \ldots \ldots & 3^{6,2} \\ \text { écart-type } . \cdots \cdots \cdots \cdots & { }^{6,744} \\ \text { coefficient de variation } \ldots & 4,8\end{array}$

- pour le calorimètre 2 (petite taille)

$\begin{array}{ll}\text { moyenne. } \ldots \ldots \ldots \ldots \ldots & \text { I3,9 } \\ \text { écart-type } \ldots \ldots \ldots \ldots \ldots & \text { I,3I4 } \\ \text { coefficient de variation... } & 9,4\end{array}$


Grâce à ce procédé, toutes les erreurs commises en cours d'étalonnage se trouvent incluses dans ces coefficients, ainsi d'ailleurs que l'erreur que l'on peut commettre lorsqu'on introduit le volume d'eau choisi dans le calorimètre.

La formule utilisée pour le calcul de la production de chaleur est : $Q=\left(t_{2}-t_{1}\right) \mathrm{M}$; il faut donc connaître également le coefficient de variation de $\left(t_{2}-t_{1}\right)$. L'écart-type en a été déterminé expérimentalement au moyen d'une série de mesures faites dans un milieu à température constante (glace fondante) à l'aide des thermomètres habituellement utilisés pour nos mesures. On a trouvé pour cette série de mesures :

$$
s_{\mathrm{t}}^{2}=0,0085552
$$

soit $s_{\left(l_{1}-l_{2}\right)}^{2}=2 \times 0,0085552$ et $\left.s_{\left(t_{2}\right.}-t_{1}\right)=0,1,308 \mathrm{I}$.

On peut adopter, dans le cas de nos expériences, comme valeur movenne de $\left(t_{2}-t_{2}\right):{ }_{2}{ }^{\circ} \mathrm{C}$, ce qui donne un coefficient de variation de $:$ I.I p. Ioo.

On sait que le coefficient de variation d'un produit $\mathrm{P}=\mathrm{X}$.Y est donné par la formule :

$\mathrm{C} v$ de $\mathrm{P}=(\mathrm{C} v \mathrm{X})^{2}+\left(\mathrm{C} v \mathrm{~S}^{\circ}\right)^{2}$, aux termes du $t^{e}$ degré près. On obtient alors :

pour le calorimètre $\mathrm{I}, \mathrm{C} z \mathrm{P}=0,0494$ soit une précision de $5 \mathrm{p} .100$. pour le calorimètre $2, \mathrm{C} i \mathrm{P}=0,095$ I soit une précision de ro p. 100.

Le calorimètre de plus grande taille s'est donc révélé être d'une précision très suffisante ; celui de petite taille a fourni des mesures plus approximatives, ceci nous a précisément conduits à utiliser le calorimètre électrique CALVET pour expérimenter avec des abeilles isolées ou en très petit nombre. 

CHAPITRE， II

\author{
ÉTUDE QUALITATIVE DES COURBES THERMIQUES OBTENUES \\ CHALEUR STATIQUE - CHALEUR PULSÉE \\ MÉCANISME DE LA THERMOGENÈSE
}

Avant d'entreprendre l'examen des résultats chiffrés relatifs aux diverses modalités de nos expériences, examinons d'abord ce que l'on peut déduire de l'étude des courbes de température ou de production thermique enregistrées.

\title{
$\S \mathrm{I}$. Différents aspects de la production thermique
}

Examinons l'évolution des températures à l'intérieur d'un de nos calorimètres Berthelot, lors d'une mesure de production thermique.

a) Dès la mise en place d'un lot d'abeilles dans le calorimètre, nous observons une élévation brutale de la température de l'air dans la logette des insectes, due à 1'apport de chaleur effectué par l'introduction des insectes chauds.

La courbe des températures de l'eau amorce également une montée, plus lente évidemment, mais avec un retard très faible grâce au dispositif distributeur de calories placé dans le calorimètre (fig. 6), voir fig. I2, partie $\mathrm{A}$.

b) Dans un deuxième temps, nous observons que la température de l'air, après avoir parfois légèrenıent décru, se maintient ou même augmente généralement par saccades brèves (fig. I2, partie B).

Cette période dure généralement une douzaine de minutes dans le cas de nos expériences (température au départ : $10^{\circ} \mathrm{C}, 25$ abeilles groupées).

c) Dans une troisième phase, qui suit une chute parfois assez importante de la température de l'air, cette dernière augmente brutalement, fortement, pour redescendre, remonter, redescendre encore, etc. (fig. I2, partie C).

$\mathrm{Si}$ nous effectuons ces expériences non plus dans des calorimètres mais dans une enceinte vitrée refroidie, nous pouvons observer le comportement des abeilles en expérience.

Nous constatons alors que, dans les débuts de l'expérience (correspondant à la partie B de la courbe I2), les abeilles restent parfaitement immobiles, réagissant au déficit thermique de l'enceinte par un processus de production de chaleur apparemment purement métabolique (nous reparlerons de ce problème à la fin de ce chapitre, au $\S 2)$.

Dans certains cas (comme dans l'exemple choisi représenté par la figure I2), 
ce processus se révélant insuffisant, les abeilles se mettent à s'agiter. Cette période correspond à la partie $\mathrm{C}$ de la courbe 12 , dans laquelle nous observons des sautes brusques de la température de l'air.

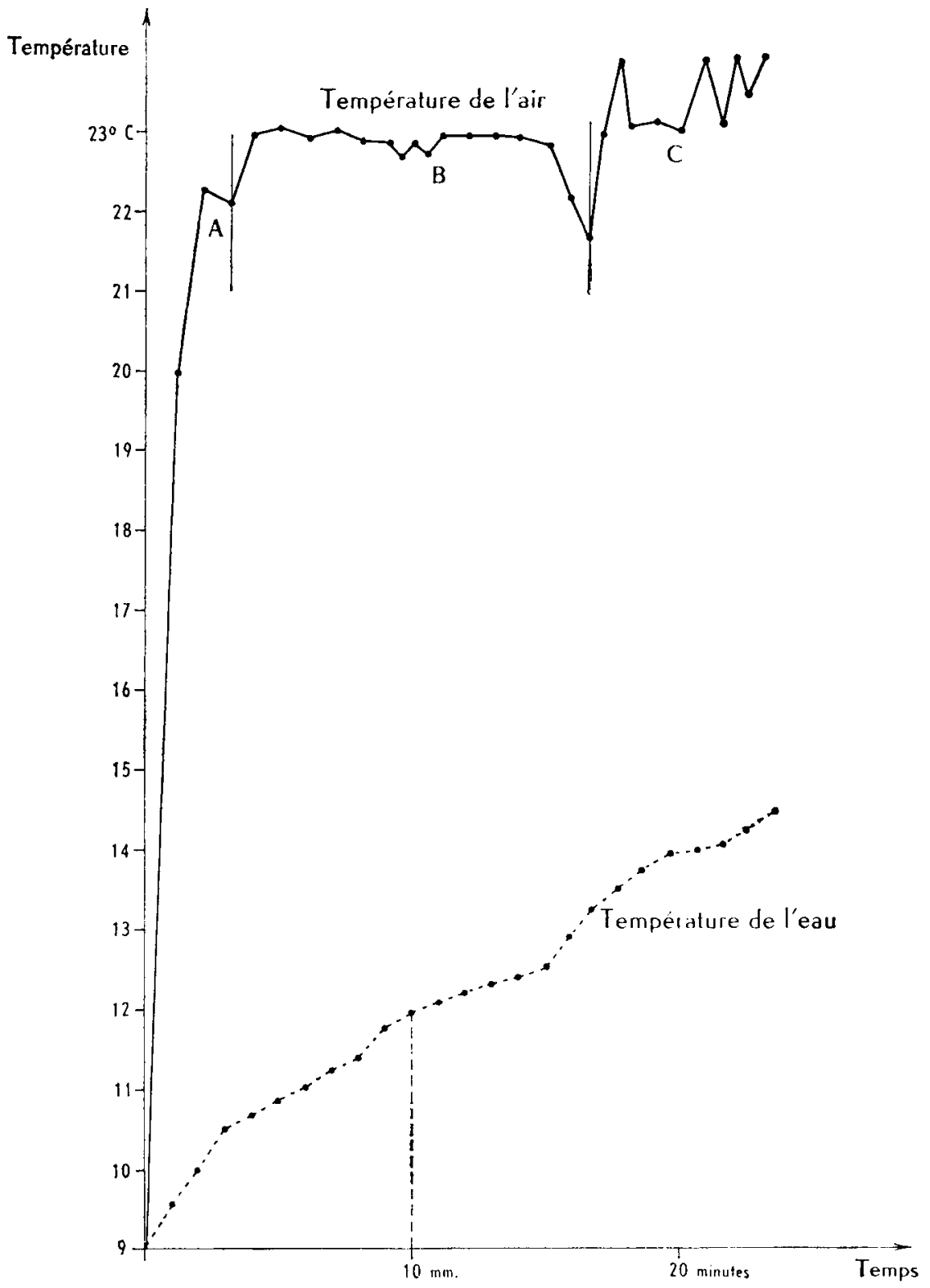

FIG. J 2. - Courbes de tempérulures obtenues atec un calorimètre Berthelot

Si nous examinons, lors de cette période, la courbe de température de l'eau, nous pouvons constater que celle-ci n'augmente guère plus rapidement qu'au moment de la période précédente. Donc, si dans ce deuxième temps, les poussées thermiques 
sont plus brusques et plus fortes, la production de chaleur moyenne n'est en définitive guère plus élevée que pendant la phase où les abeilles restent calmes.

L'agitation que nous observons pendant la dernière phase de l'expérience n'a

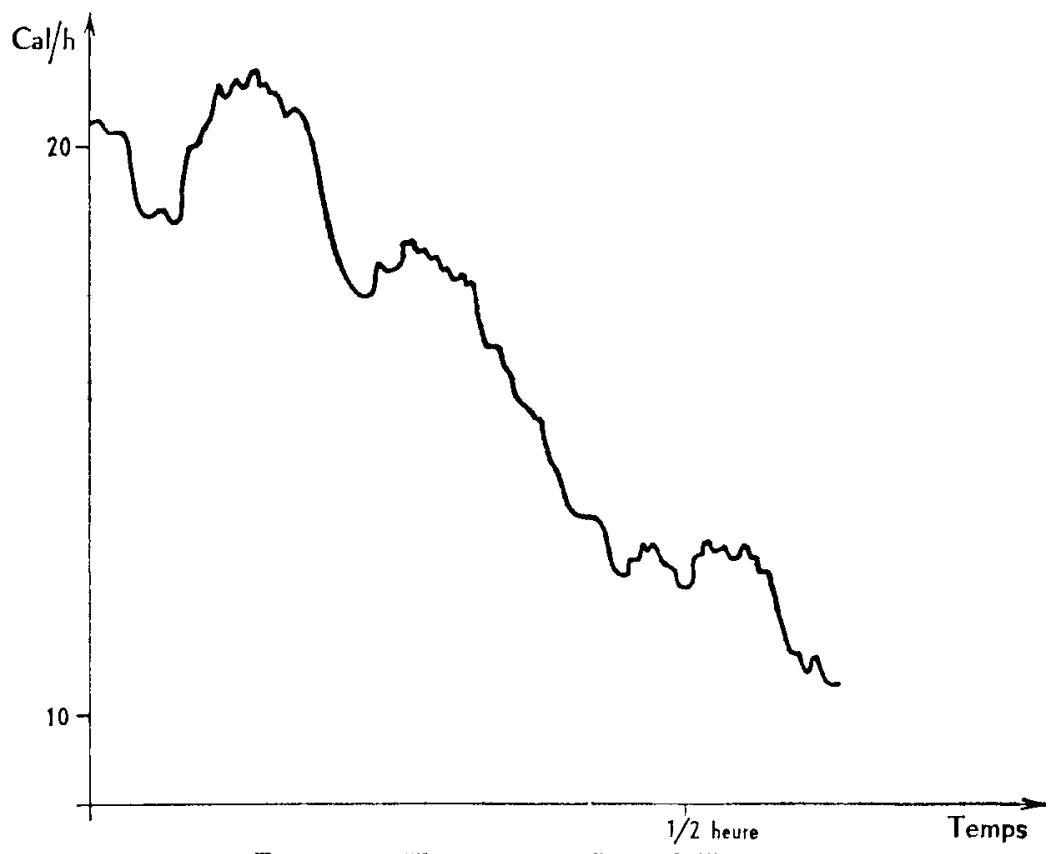

FIG. I3. - Thermogramme d'une abeille agilee

donc pas pour effet de suppléer, par un travail musculaire, à une insuffisance du pouvoir de thermogenèse des abeilles, mais traduit simplement un trouble provoqué par le froid ambiant.

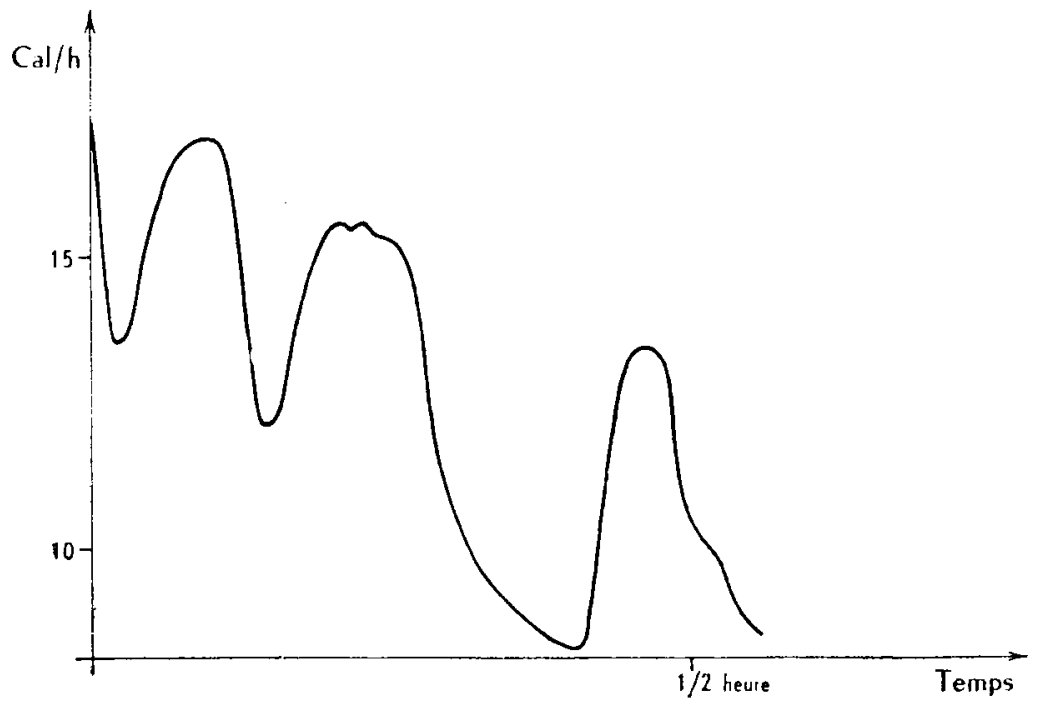

FIG. I. - Thermogramme d'une abeille immobile 
Ces différents aspects du comportement peuvent d'ailleurs être observés à l'aide du calorimètre électrique CALVET. Nous indiquons à la figure I3 quel peut être 1'aspect d'un thermogramme obtenu avec une abeille agitée et à la figure I4 l'aspect d'une courbe obtenue avec une abeille produisant de la chaleur sans mouvement apparent.

Il ressort de ces expériences que les abeilles sont capables de maintenir, dans une enceinte appropriée à leur nombre, une température convenable grâce à un processus de production de chaleur que nous avons qualifiée de chaleur statique.

C'est ce processus de chauffage qui est utilisé normalement par les abeilles. On peut observer, en effet, qu'un groupe d'abeilles, placé par exemple à $20^{\circ} \mathrm{C}$, s'agite peu ou pas du tout, bien que sa consommation d'oxygène et sa production thermique soient très importantes. Ce même groupe, à $30^{\circ} \mathrm{C}$, est souvent très agité alors
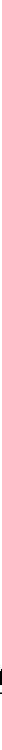

FIG. 15 et 16. - Combes de reiroidissement

que sa consommation d'oxygène et le dégagement de chaleur produit sont trois ot quatre fois plus faibles.

D'ailleurs, comme nous l'avons vu, les abeilles utilisent ce processus "statique" dès le début de nos expériences bien qu'à ce moment la vitesse de refroidissement soit maximum comme l'indique la formule de Durong et PeTrT : $\mathrm{V}=g \cdot \mathrm{H}^{c} \cdot \mathrm{T}^{b}$ où $b=\mathrm{I}, 233, c=0,45$ avec 1'air, $\mathrm{H}$ " l'élasticité " de l'air en mètres de mercure, $T$ l'excès de température en ${ }^{\circ} \mathrm{C}$ et $g$ un coefficient lié à l'air et à la nature du corps qui se refroidit.

T correspond d'ailleurs ici approximativement à la différence entre les indications des thermomètres $\mathrm{A}$ et $\mathrm{C}$ (voir fig. 7).

Esch confirme d'ailleurs ce point particulier lorsqu'il écrit : " la courbe de refroidissement du corps d'une abeille est conforme aux principes newtoniens du refroidissement ".

Nous indiquons ci-dessous deux aspects de courbes de refroidissement d'après Esch (fig. I.5) et d'après l'une de nos expérience (fig. I6). 
Remarquons enfin que ce processus thermique présente un aspect de chaleur pulsée, c'est-à-dire que le dégagement thermique n'est pas continu mais émis par "bouffées " successives.

La courbe représentée à la fig. I7 le montre clairement. Cette courbe est d'ail-

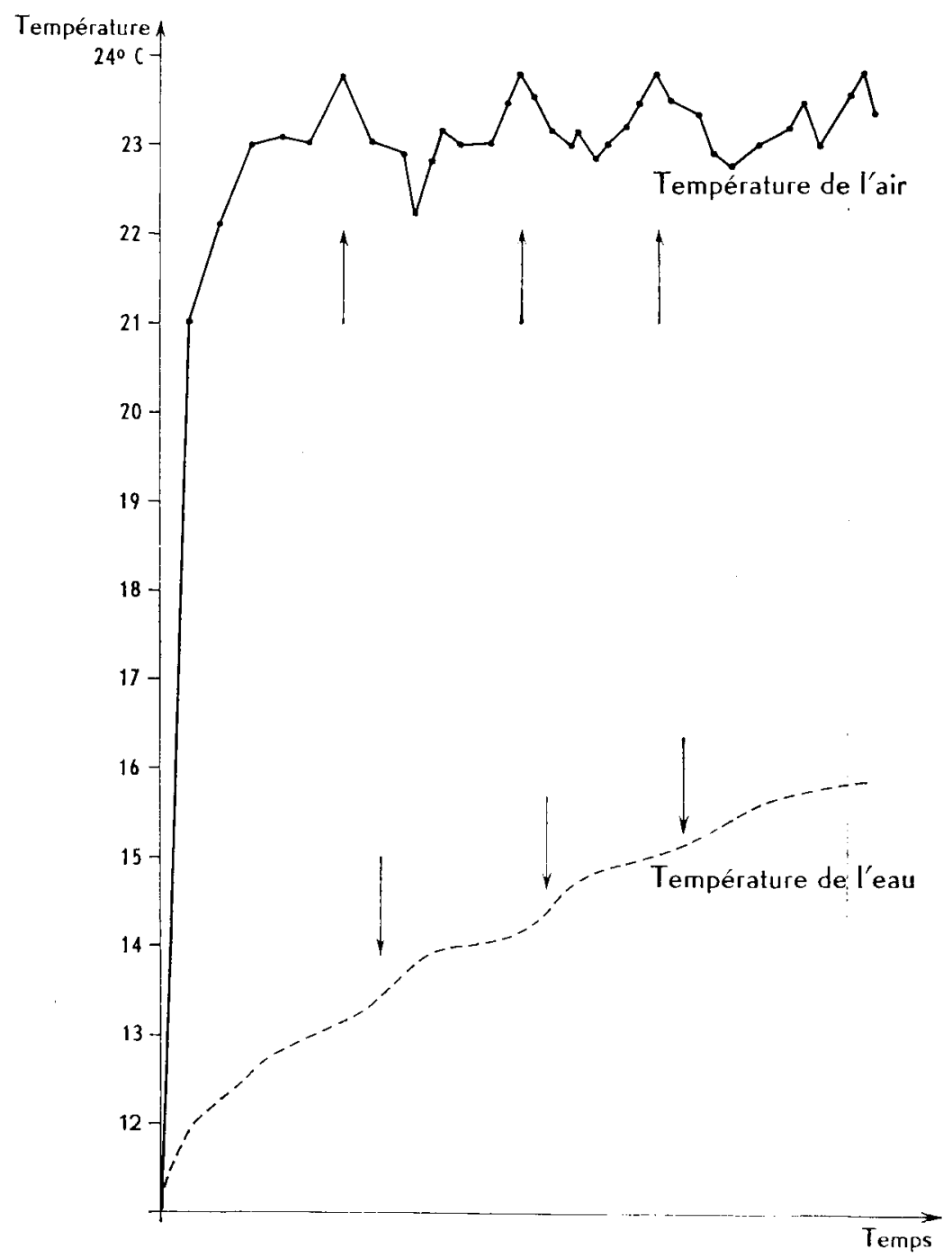

Fici. 17. - Courbes de températures obtenues avec un calorimètre Berthelot (aspect de "chaleur pulsée ")

leurs assez exceptionnelle parmi toutes celles recueillies, néanmoins cette notion de " chaleur pulsée " est constamment bien visible sinon aussi spectaculaire.

Nous en donnons d'autres exemples aux figures I 8 et I9 qui représentent des thermogrammes obtenus au calorimètre CALVET avec 2 abeilles et 4 abeilles.

Esch, dans son étude sur les températures du corps des abeilles, écrit d'ailleurs : 
" la température du thorax s'élève de quelques degrés au-dessus de celle des rayons à couvain par nombreux petits bonds, puis retombe ... ”.

Ceci n'en confirme pas pour autant la réalité du " cycle de LAMmERT " dont le rythme est d'ailleurs bien plus lent.

Rappelons donc succinctement, à ce propos, ce que sont le cycle de LAMMER'T et la théorie d'ARMiBruster.

Au cours de mesures faites dans des "grappes " d'hiver, Armbruster avait observé que, lorsque les abeilles sont placées à une température d'au moins $13^{\circ} \mathrm{C}$

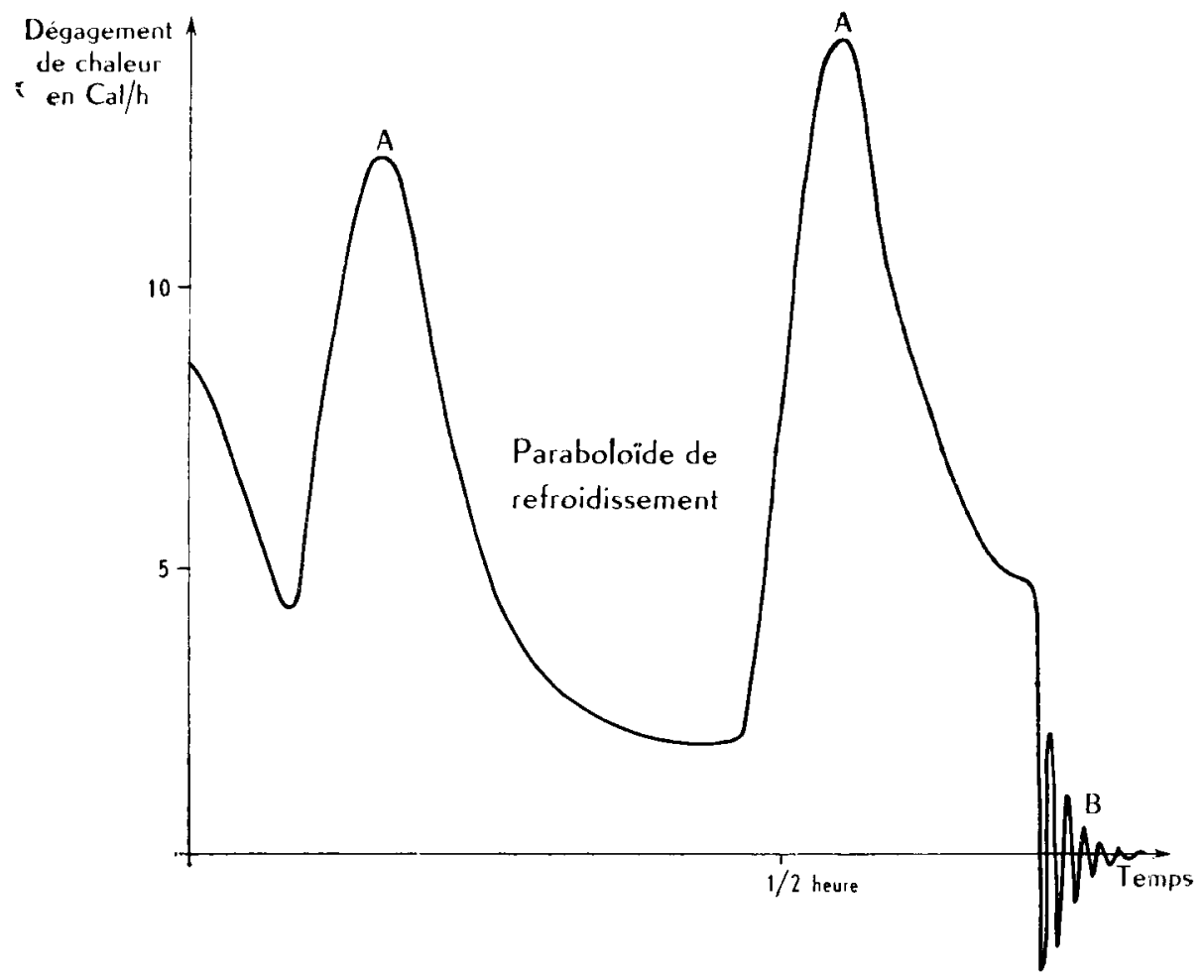

FIG. 18. - Thermogramme, 2 abeilles, $30^{\circ} \mathrm{C}$

(température de stimulation), elles élèvent la température de leur corps. I1 notait des élévations allant jusqu'à $20^{\circ}$ et même $30^{\circ} \mathrm{C}$, puis des abaissements jusqu'à I $3^{\circ}$, des remontées, etc.

Cet auteur avait cru observer ainsi une sorte de cycle thermique qui se déroulait sur 22 heures.

Ultérieurement, ces données n'ont pu être confirmées: HEss et Himmer, en particulier, n'ont pu que constater l'existence d'un nucleus chand au cœur de la grappe et dont la température variait mais de façon tout à fait acyclique.

Pour que le cycle de LAMMERT soit réel, il faudrait donc que toutes les abeilles produisent de la chaleur en même temps, cessent en même temps.

Or, si cela se trouve parfois réalisé, pour un lot d'abeilles, comme on peut le constater par exemple sur les figures I 7 et 18 , cela ne se produit pas en général et les courbes 
montrent le plus souvent une interférence des poussées thermiques, comme on peut le voir à la fig. 20. Il n'est pas douteux que le stimulus de la production thermique est le froid ambiant et ce facteur ne peut agir au même instant sur la totalité des abeilles de la ruche.

Signalons enfin une dernière particularité qualitative que nous avons pu mettre en évidence grâce aux enregistrements avec le calorimètre CALVET : les abeilles placées

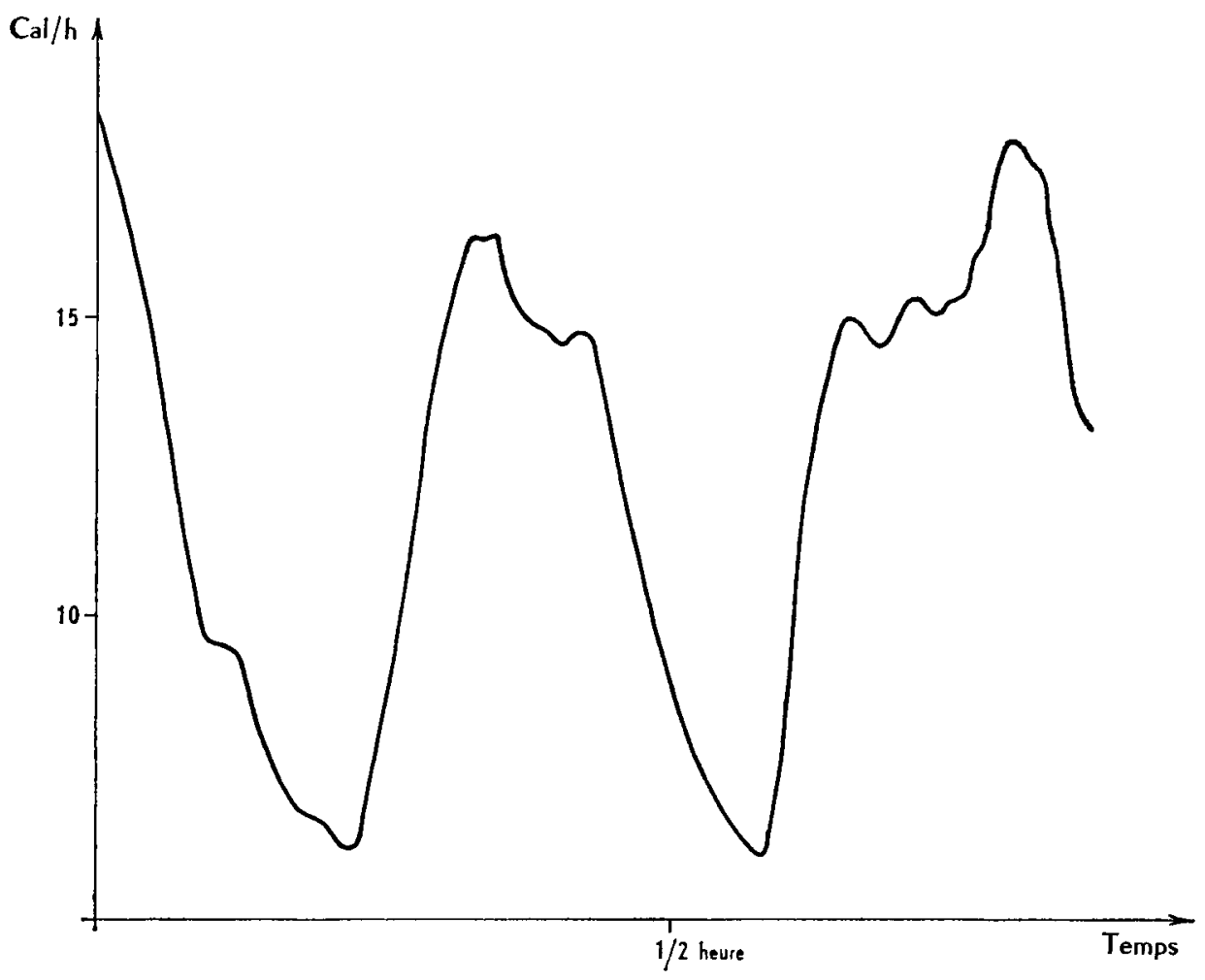

FIG. 19. -- Thermogramme, 4 abeilles, $30^{\circ} \mathrm{C}$

dans un milieu relativement froid $\left(20^{\circ} \mathrm{C}\right.$ par exemple) ont tendance à utiliser assez rapidement leurs réserves calorifiques et sont rapidement épuisées, ce qui ne se produit pas par exemple à $30^{\circ} \mathrm{C}$ (comparer les courbes, figures I 8 et 20 ). Cependant, cet aspect $\mathrm{d} u$ comportement est en partie inhibé par un effet de groupe dont nous parlerons au chapitre III.

\section{§ 2. Le mécanisme de la thermogenèse}

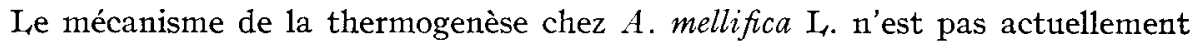
connu dans le détail, cependant parmi les hypothèses les plus récentes, il s'en trouve une qui donne entière satisfaction et attribue au travail des muscles thoraciques le dégagement de chaleur observé.

Certains auteurs, jugeant invraisemblable que des êtres aussi frêles puissent 
réchauffer une assez grande enceinte, ont attribué l'excès de température des ruches par rapport à l'ambiance à une réaction chimique du miel, appuyant même d'un calcul audacieux leurs assertions.

Certes, le miel fixe de l'oxygène, il n'est pas, comme on l'a cru longtemps, une substance inerte et nous avons pu le vérifier au respiromètre.

Mais ce phénomène est rle faible intensité et ne peut être comparé à l'extraordinaire capacité thermogène des abeilles.

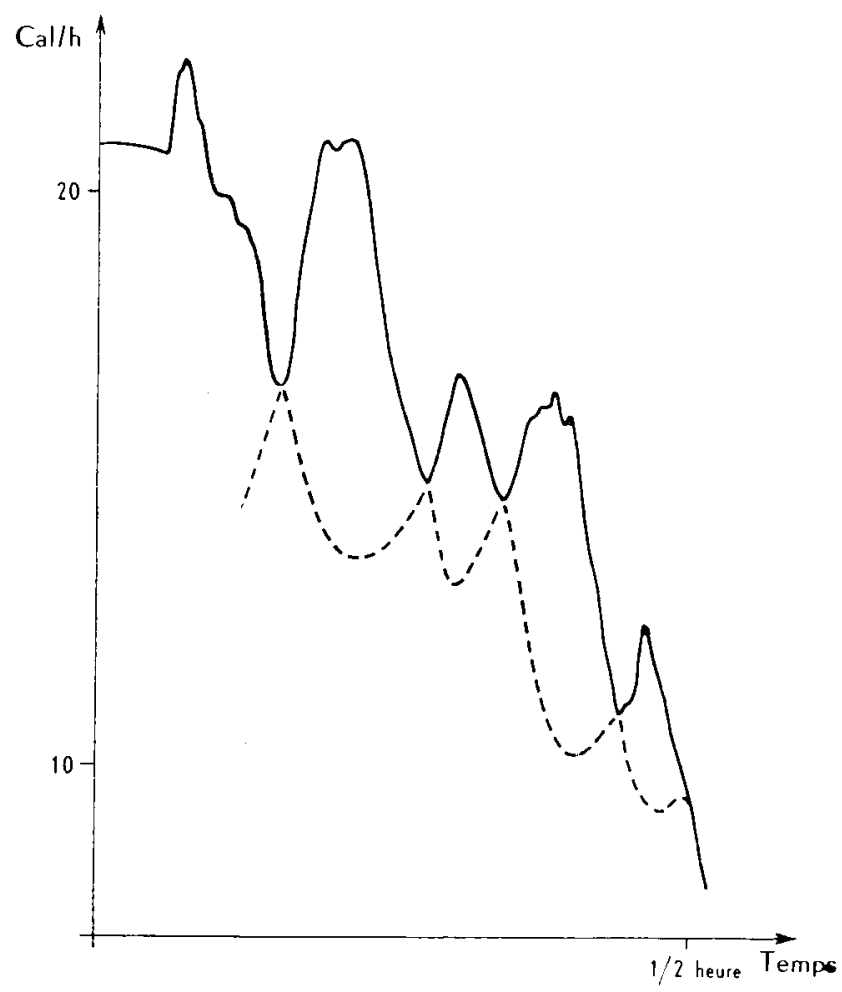

Fig. 20. - Asped d'un thermogramme obtenu avec 2 abeilles tont les periodes de thermogenèse sont décalées dans le temps $\left(20^{\circ} \mathrm{C}\right)$

Snipsox, dans le Traité de Biologie de l'A beille (à paraître) signale d'ailleurs que la consommation d'oxygène d'une abeille au repos correspond à celle d'un homme effectuant un rude travail manuel, et Esch $(1960)$ exprime l'idée que " vu la grande capacité de réchauffement de certaines abeilles, il est permis de penser que les températures des " nids " ne sont maintenues que par un nombre relativement faible d'abeilles $)$.

Il faut bien entendu considérer le terme "au repos " avec beaucoup de circonspection, nous avons vu en effet qu'une abeille parfaitement immobile peut dégager une forte chaleur et consommer une quantité correspondante d'oxygène lorsqu'elle ne se trouve pas dans une ambiance thermique satisfaisante.

Il importait en tout premier lieu, de chercher si une partie précise du corps de l'abeille est le siège du dégagement de chaleur. 
Plusieurs auteurs l'ont fait en approchant des diverses parties du corps de 1'insecte des thermomètres fins montrant alors que la chaleur est surtout issue du thorax.

İscr (I960) ayant effectué l'étude de la chaleur interne des abeilles à l'aide de microsondes thermoélectriques démontre ces phénomènes avec beaucoup de précision. I1 a mis en évidence que la température du thorax égale celle de l'abdomen pendant les périodes d'inactivité (il s'agit ici d'un repos vrai) et que dans tous les autres cas, elle lui est toujours très nettement supérieure (de Io à I $5^{\circ} \mathrm{C}$ par exemple).

Le thorax est donc bien le siège de la thermogenèse.

Comme il n'existe dans le thorax, pratiquement que des muscles, on peut estimer que, comme dans le cas général, l'activité musculaire est ici encore la source de chaleur.

Dès 1953, nous avions tenté de vérifier cette hypothèse en plantant dans le thorax d'abeilles placées dans une atmosphère assez froide ( $15^{\circ} \mathrm{C}$ par exemple) de longues et fines aiguilles, portant à leur extrémité un petit miroir réfléchissant un spot lumineux, mais il nous avait été impossible de déceler la moindre vibration.

Ce problème fut repris par la suite par BurkharnT (r954). Un thermoélément est planté dans le thorax, en mesure la température et sert en outre d'électrode.

Une deuxième électrode est également plantée dans le thorax, elle est faite d'un fil d'acier sur lequel on soude un mince fil de cuivre de o,or mm de diamètre. Le point de soudure et la plus grande partie de la pointe sont isolés avec du vernis.

L'activité musculaire crée un flux électrique qui est repris et amplifié pour être rendu audible.

On entend alors grésiller le haut-parleur pendant les périodes où le thermoélément indique une augmentation de la température du thorax.

Le dégagement de chaleur observé est donc bien le résultat de microvibrations des nuuscles thoraciques.

Les expériences de respirométrie que nous avons effectuées montrent d'ailleurs que la thermogenèse chez l'abeille suit, dans les cas d'oxygénation normale, les mêmes règles que celles observées chez d'autres espèces animales dont la production de chaleur est le résultat d'une activité musculaire, à savoir que, un litre d'oxygène est consonmé lorsqu'est produite une kilocalorie.

Cette hypothèse est également corroborée par des essais au calorimètre que nous avons fait avec des abeilles clécapitées. Les productions thermiques ont oscillé de 0,02 I à 0,024 calorie par abeille et par minute (en conditions normales : 0,26 en moyenne).

I1 n'y a donc guère eu de production de chaleur bien que les tissus aient continué de vivre (quand on ouvre le calorimètre, après une demi-heure d'expérimentation, les abeilles décapitées en sortent sans aide).

Cela semble bien prouver que si la thermogenèse est le fait d'organes qui sont sous la dépendance des neurones moteurs (ici les muscles), elle ne dépend pas uniquement des ganglions thoraciques comme beaucoup de réflexes et que le cerveau y participe d'une façon prépondérante.

On peut remarquer que les abeilles décapitées sont privées d'organes thermorécepteurs localisés dans les antennes et qui pourraient être à l'origine clu réflexe de vibration des muscles thoraciques. Nous ne savons cependant pas si les antennes sont les seuls organes portant des thermorécepteurs, en conséquence nous avons expérimenté avec des abeilles à antennes sectionnées (pendant quelque temps, une demi-heure au moins en tout cas, la blessure ne semble pas perturber l'insecte).

Annales de l'Abeille. - Ig6j. 
Dans ces conditions, nous avons observé des productions thermiques de l'ordre de 0, Io calorie par abeille et par minute, donc très supérieures à ce qu'elles sont avec des abeilles décapitées mais très inférieures d'autre part à la normale (près de trois fois plus faibles). Cela semble donc confirmer un rôle des antennes dans la thermogenèse, mais démontre que, dans le cas précédent de la décapitation, ce n'était pas la seule privation de ces organes qui annulait ou presque la production de chaleur.

Certaines expériences cependant paraissent aller à l'encontre de ces résultats qui démontrent l'origine musculaire thoracique de la production de chaleur. Èn effet, nous avons placé dans nos calorimètres des lots de 25 abdomens isolés d'abeilles. Les productions de chaleur observées (toujours en une demi-heure d'expérimentation) ont été de l'ordre de 0.045 calorie par abeille et par minute, ce qui est relativement important. Par contre, des abeilles privées d'abdomen (tête et thorax seuls) ont produit, dans les mêmes conditions, des dégagements thermiques qui peuvent être considérés comme parfaitement nuls lorsqu'on en retranche l'apport originel dî à la température propre de ces organes au moment de leur mise en calorimètre.

Ceci prouve qu'il ne faut pas négliger l'intervention de l'abdomen dans la thermogenèse comme cela a été fait jusqu'à présent.

Le manque d'efficacité thermique des ensembles tête-et-thorax peut s'expliquer par le fait que l'abdomen, avec ses nombreux stigmates et son aptitude à pomper l'air, intervient bien plus dans la réoxygénation des tissus que les stigmates thoraciques. Cependant, on sait que, chez l'abeille, les stigmates thoraciques sont inspirateurs et les abdominaux expirateurs ; on peut donc penser que l'abdomen intervient surtout dans la thermogenèse grâce aux abondantes réserves de glvcogène qui se trouvent dans le corps adipeux de ce tagme.

Pour en revenir au mécanisme propre à la production de chaleur, c'est-à-dire au travail des muscles, nous pouvons dire qu'il s'agit en quelque sorte d'un véritable phénomène de "frisson ", invisible à l'observation directe, suffisamment efficace cependant pour pallier d'importants déficits de température.

Cette origine musculaire de la production de chaleur est confirmée très simplement par le fait, plusieurs fois observé (BEutrer I936, Sotavalta I954, Esch I96o) que, pendant le vol et à l'envol surtout, une abeille consomme beaucoup plus d'oxygène et tout particulièrement "produit peut-être cent fois plus de chaleur qu'au repos " (SIMPSON, in litteris) (I).

HeUSNER (I963) a d'ailleurs tenté de comparer ces productions de chaleur à celles d'homéothermes, dans son étude respirométrique du métabolisme del'abeille isolée.

D'après cet auteur, l'abeille consomme $540 \mathrm{mll}$ d'oxygène par jour, à $35^{\circ} \mathrm{C}$, ce qui correspond à 64,8 calories en 24 heures.

A $37^{\circ}$, du fait que :

$$
\log \mathrm{q}_{37}=\log \mathrm{q}_{35}+\frac{37-35}{10} \log Q_{10}
$$

on obtient : $q_{37}=75,8$ calories en 24 heures, ce qui est très comparable à la chaleur dégagée par un embryon de poulet d'un poids sensiblement égal à celui d'une abeille $\left(77\right.$ cal. à $\left.37^{\circ}\right)$.

(1) Pendant la préparation de l'envol, la température du thorax peut croître de $20^{\circ}$ à $36^{\circ} \mathrm{C}$; elle baisse ensuite pendant le vol mais reste couramment supérieure de $10^{\circ}$ à la température ambiante (Esch, I960). 
Ce calcul est malheureusement erronné car HEuSNER considère donc que le métabolisme de l'abeille augmente avec la température ambiante. Ceci est vrai chez les poikilothermes mais comme nous le verrons plus loin et comme le relate d'ailleurs HeusNer quelques pages avant, c'est exactement le contraire qui se produit chez l'abeille, tout au moins pendant le jour.

Le métabolisme diurne étant dix fois supérieur au nocturne, si 1'on veut extrapoler ce qu'aurait été la production de chaleur à $37^{\circ}$, c'est moins de 64,8 calories que l'on doit trouver, car on ne peut compter ensemble les moyennes du jour et celles de la nuit.

Quoiqu'il en soit cette production de chaleur est tout à fait remarquable pour un insecte, il ne faut pas oublier de plus qu'elle a été obtenue dans la zone du thermopreferendum et qu'elle est de beaucoup supérieure si l'on abaisse la température d'expérimentation (voir chapitre III).

Ceci a d'ailleurs conduit HEUSNER à une autre erreur d'interprétation concernant l'origine de cette production de chaleur. Cet auteur a superposé des histogrammes respirométriques à des actogrammes et a observé qu'il n'y avait consommation d'oxygène importante que lorsqu'il y avait mouvement. Ces données sont tout à fait contraires à la réalité, mais les résultats obtenus par HEUSNER ne sont pas surprenants si l'on remarque qu'il a placé les abeilles à leur thermopréférendum, il n'y avait alors aucune raison pour que ces insectes utilisent le processus de production de chaleur si particulier qui consiste, comme nous l'avons vu, en une microvibration des muscles thoraciques.

HEUSNER a donc purement et simplement enregistré des consommations d'oxygène relatives à des déplacements quelconques des insectes et les véritables processus de " chauffage " intervenant dans la thermorégulation de la ruche lui ont totalement échappé.

Quant à apprécier la véritable importance de ces phénomènes, eu égard à leur variabilité, nous nous contenterons de citer un exemple choisi parmi nos résultats :

Prenons le cas de 25 abeilles soumises, en calorimètre, à une température de $20^{\circ} \mathrm{C}$; la production de chaleur observée est de 0,18 calories par abeille et par minute.

Si ces insectes pouvaient maintenir ce niveau de production thermique pendant une journée, on obtiendrait 259 calories en 24 heures. C'est une intensité énergétique qui, compte tenu du poids des animaux, surclasse de beaucoup les productions de chaleur habituellement trouvées chez les homéothermes.

De telles possibilités thermiques existent-elles chez d'autres insectes? A notre connaissance, cela n'a jamais été observé. Nous reproduisons ci-dessous, à titre d'exemple, quelques enregistrements au calorimètre CALVET, effectués par PRAT avecdivers insectes

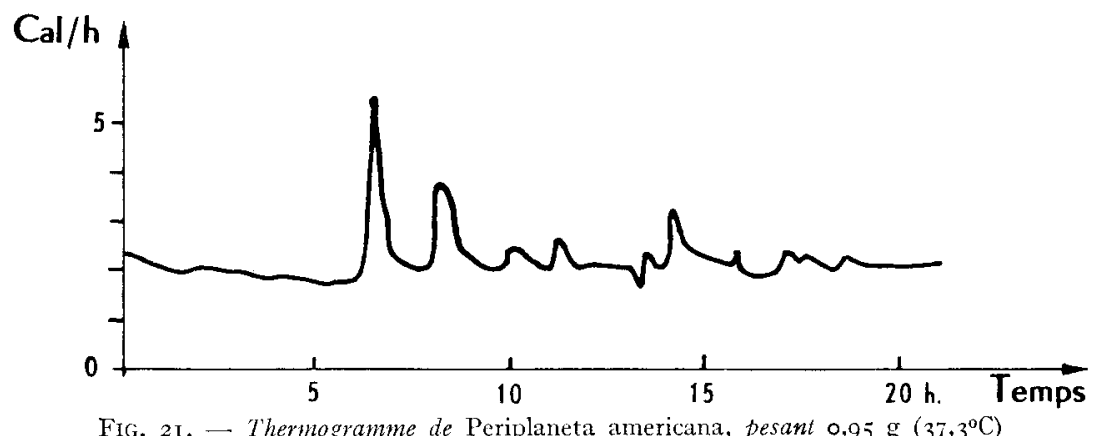

FIG. 2I. - Thermogramme de Periplaneta americana, pesant $0,95 \mathrm{~g}\left(37,3^{\circ} \mathrm{C}\right)$ 


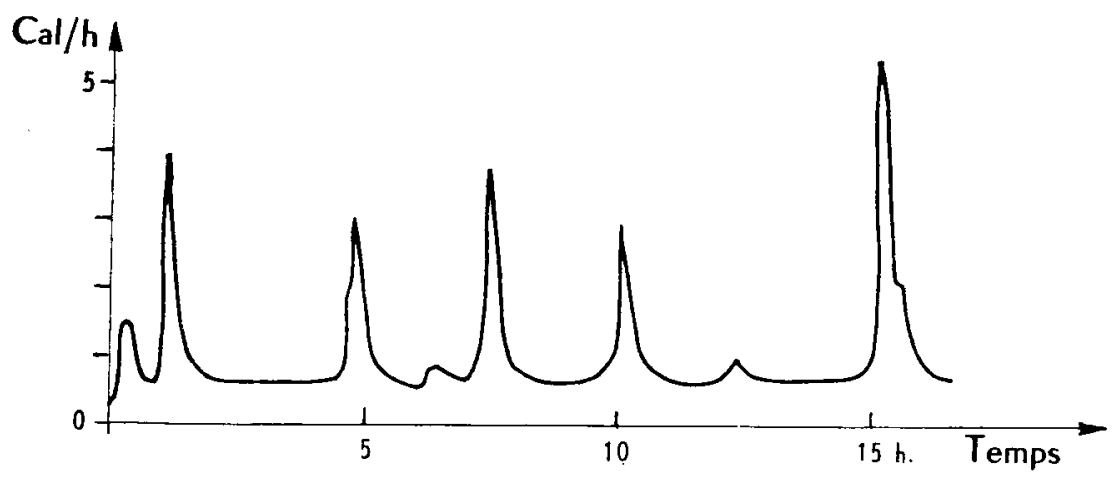

FIG. 22. - Thermogramme de P. americana, pesant $\mathrm{I}, 00+\mathrm{g}\left(26,5^{\circ} \mathrm{C}\right)$

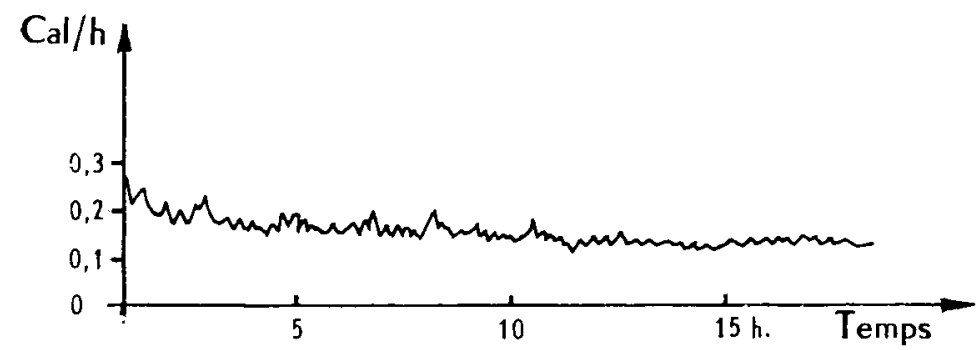

FIG. 23. - Thermogramme de Musca domestica, pesant o,0I4 $\mathrm{g}\left(3^{\mathrm{I}}, 4^{\circ} \mathrm{C}\right)$

Nous avons également effectué, au calorimètre CALVET, quelques enregistrements avec des Hyménoptères aussi comparables que possible, par la taille, aux abeilles domestiques, à savoir :

Polistes gallicus (Hyménoptères, Vespidae) 0,050g. Anthophora parietina (Hyménoptères Apidae) o,I2I g. Megachilesp. (Hyménoptères Megachilidae) 0,072 g.

Nous reproduisons ci-dessous quelques enregistrements étalonnés.

On voit que, en conditions de nourriture normales, l'insecte ayant été pris dans 1a nature et testé, la vespide n'a pas beaucoup produit de chaleur sinon vraisemblablement, la quantité obligatoirement liée à ses mouvements. On voit d'ailleurs, sur la partie détaillée, que l'enregistrement traduit une grande agitation.

Par contre, les courbes enregistrées avec les Apoïles montrent une production thermique appréciable, la courbe obtenue avec la Megachile ressemble même beaucoup à un enregistrement d'Apis mellifica, simplement ro fois plus faible.

Les productions thermiques que nous avons enregistrées sont, pour ces divers Hyménoptères, à $30^{\circ} \mathrm{C}$ :

$$
\begin{aligned}
& \text { Polistes } 0,003 \text { calorie/minute } \\
& \text { Anthophora } 0,017 \text { calorie/minute } \\
& \text { Megachile } \left.0,008 \text { calorie/minute ( }{ }^{1}\right) .
\end{aligned}
$$

Compte tenu du poids, d'ailleurs, la Megachile et l'Anthophora ont révélé des possibilités thermiques à peu près équivalentes. 


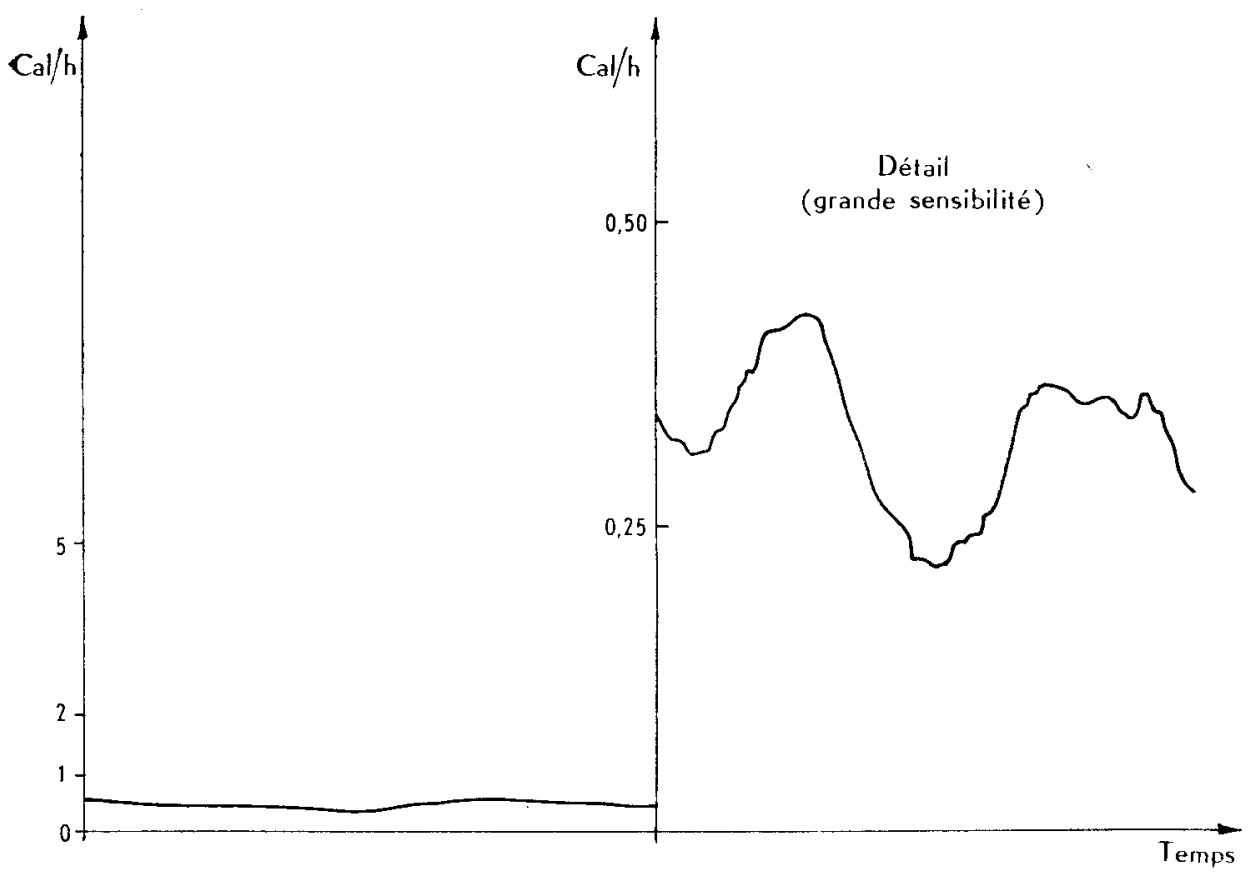

FIG. 24. - Thermogramme de Vespidae à $20^{\circ} \mathrm{C}$

Nous regrettons de n'avoir pu effectuer ces mesures à des températures plus basses car, s'il est certain qu'à $30^{\circ}$ une Apis n'est pas à son thermopréférendum et produit donc de la chaleur, nous ne savons pas si l'Anthophora et la Megachile ne se trouvent pas aux leurs. Dans un tel cas, les productions de chaleur enregistrées de ces insectes, correspondraient uniquement à une activité musculaire normale et ne seraient pas comparables à celles de l'abeille. Cependant, le tracé des courbes étant assez régulier, il semble bien que nous ayons là également affaire à un processus thermorégulateur. De semblables expériences sur les insectes sociaux ou subsociaux mériteraient d'être entreprises dans cette direction.

\section{Résumé du chapitre II}

L'examen des courbes obtenues soit par lecture continue des thermomètres des calorimètres Berthelot, soit par enregistrement direct dans le cas des calorimètres CALVET, permet les constatations suivantes :

- Le dégagement de chaleur produite par des abeilles placées à une température inférieure au thermopréférendum s'effectue sans mouvements apparents de ces insectes.

- Si, malgré ce dégagement de chaleur, le froid ambiant persiste, les abeilles s'agitent. L'apport de chaleur dû à ces mouvements est si faible par rapport au dégagement thermique sans mouvement extérieur, que les résultats obtenus ne sont pratiquement pas différents des précédents. L'agitation traduit donc simplement un trouble des abeilles.

(') Apis mellifica à $30^{\circ}: 0,090$ calorie/minute. 


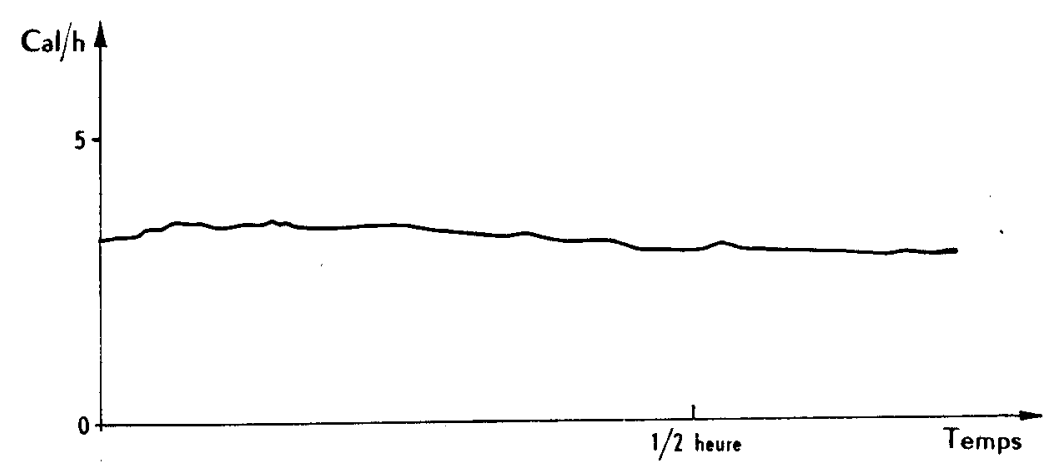

FIG. 25. - Thermogramme d'Anthophora $\left(30^{\circ} \mathrm{C}\right)$.

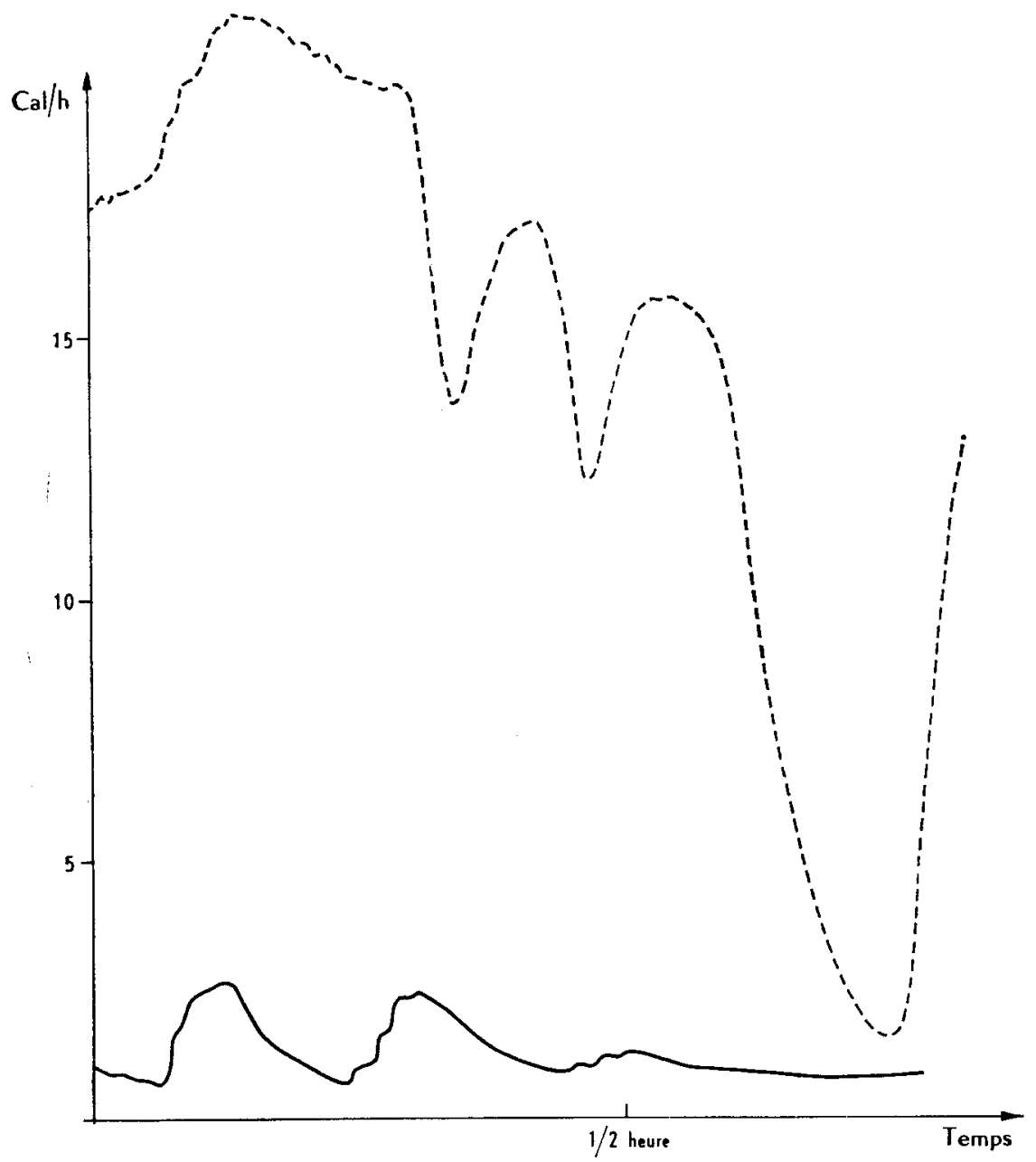

FIG. 26. - Thermogramme de Megachile $\left(30^{\circ} \mathrm{C}\right)$ (en pointillé un thermogramme d'Apis mellifica). 
- Le dégagement de chaleur n'est pas continu et se fait par périodes. Cet aspect de la production de chaleur est évidemment rarement perceptible lorsqu'on expérimente avec des groupes d'abeilles, car celles-ci n'effectuent pas toutes aux mêmes moments leurs périodes de production de chaleur ou de repos. Ce phénomène que nous avons qualifié de production de "chaleur pulsée " est bien visible dans le cas d'une ou deux abeilles.

- La production de chaleur a son origine dans une activité des muscles du thorax mais il n'y a pas de mouvements apparents pour un observateur. Des expériences effectuées avec un appareillage électronique ont montré que les abeilles réagissent au froid par des microvibrations des muscles thoraciques, analogues en quelque sorte au frisson des nammifères.

- Des abeilles privées d'abdomen ne peuvent pas produire de chaleur appréciable, sans nul doute parce que les réserves de glycogène nécessaire aux muscles se trouvent surtout dans le corps adipeux de ce tagme.

- Une production de chaleur aussi importante que celle que nous avons observée chez les abeilles domestiques, n'a jamais pu, à notre connaissance, être retrouvée chez d'autres espèces d'insectes. Seule, parmi toutes les mesures effectuées avec diverses espèces entomologiques, celle relative à la production de chaleur d'un Mégachile (Hyménoptère, Apoïdea) se rapproche des résultats obtenus avec Apis mellifica, quoique quantitativement beaucoup plus faible. 



\section{CHAPI'TRE III}

\section{VARIATIONS DE LA THERMOGENÈSE}

\section{$\S$ I. Abeilles en diverses conditions physiologiques}

\section{A. Possibilités thermiques des abeilles d'hiver}

Dans le but de vérifier si, pendant 1'hiver, la capacité de production de chaleur des abeilles est identique à celle mesurée à la belle saison, nous avons étudié la production thermique de ces insectes pendant le mois de janvier. Nous les avons prélevés de préférence à des périodes ensoleillées affn de pouvoir provoquer leur sortie par le trou du couvre-cadre plutôt que d'avoir à ouvrir la ruche pour en capturer.

Après le bref passage dans l'enceinte habituelle à $32^{\circ}$ et l'anesthésie, nous avons placé les insectes en calorimètre. Les $Q / t / a$ obtenus au cours de ces essais se sont (sauf très rares exceptions) toujours maintenus entre o, Io et $0, \mathrm{I} 2$ calorie par minute et par abeille. La capacité thermique est donc plus faible qu'en été ; cependant, nous pouvons considérer, qu'eu égard à la faible activité déployée et à la formation en " grappe " des insectes, ces médiocres possibilités suffisent à maintenir une température convenable dans la ruche. Fcr estime d'ailleurs qu'un petit nombre d'individus seulement doit contribuer à l'entretien de la chaleur du centre de la grappe (il est vrai que cet auteur n'avait pas connaissance de cette diminution des possibilités thermiques des abeilles hivernantes).

Il faut se rappeler également, qu'il n'y a plus, en hiver, de couvain et que c'est à l'intention de ce dernier que les abeilles déploient normalement leur activité thermique.

I1 suffit donc, 1'hiver, que ces insectes obtiennent une température qui leur évite la mort et ne les laisse pas aller au-delà d'un simple engourdissement.

Nous estimons que cette baisse de potentiel thermique des abeilles est imputable à un déficit alimentaire, tout au moins à un rationnement de la nourriture ; ces abeilles d'hiver consomment donc bien moins qu'en été. Si la consommation hivernale d'un essaim est bien connue, on ne peut préjuger de ce qu'elle est à la belle saison, car on ne peut mesurer que l'excès de la récolte. Nos résultats tendent à prouver que cette consommation estivale est plus importante qu'on ne pouvait le penser jusqu'alors, car rares sont dans nos régions les jours où les abeilles n'ont pas à réchauffer leur ruche.

Nous avons pensé que le déficit alimentaire pouvait être quantitatif et qualitatif.

Nous avons pu mettre très simplement en évidence l'existence d'un déficit quantitatif. Au point de vue qualitatif, s'il existe d'autres carences que la carence en miel, celles-ci n'interviennent pas dans la perte de possibilités caloriques. 
En effet, si l'on place des abeilles d'hiver, dans des cagettes mises en étuve à $32^{\circ}$ et bien pourvues en candi et en eau, on constate les faits suivants :

- au début de l'essai, on obtient des $Q / t / a$ variant de $0, \mathrm{IO}$ à $0, \mathrm{I} 2$ calorie par abeille et par minute.

- après 24 heures en cagette, les $Q / t / a$ se stabilisent entre $0, \mathrm{I}_{4}$ et $0, \mathrm{I} 8$ calorie par abeille et par minute.

- enfin après 48 heures, ils redeviennent normaux même forts, avec des valeurs oscillant autour de 0,34 petite calorie par abeille et par minute.

Nous voyons donc qu'il suffit, pendant quelque temps, d'assurer aux abeilles une alimentation satisfaisante et une température supérieure au seuil d'engourdissement $\left(3^{\circ} \mathrm{C}\right)$ pour que les insectes retrouvent leur potentialité thermogène printanière.

\section{B. Abeilles testées en période de sécheresse.}

En ce qui concerne les tests sur abeilles effectués pendant des périodes de sécheresse où la nourriture est rare (tout particulièrement le mois d'août par exemple), nous constatons une baisse sensible de la thermogenèse.

Plusieurs essais effectués vers cette époque nous ont donné une moyenne de production thermique de o, 6 calorie par abeille et par minute, avec une fréquence prépondérante pour des valeurs de $0, I_{5}$ à $0, I_{7}$.

Il faut sigıaler en tout cas, à ce propos, une hétérogénéité qui n'existe pas avec les abeilles d'hiver, les conditions écologiques étant ici beaucoup plus variées (pluies, floraison peut-être d'une espèce végétale, découverte d'un butin...). Ainsi, nos mesures ont varié de $0, \mathrm{I} 2$ à 0,26 calorie par abeille et par minute. Quoi qu'il en soit, il est presque toujours nécessaire, dans ces périodes, de nourrir les abeilles en cagette, $24 \mathrm{~h}$ avant de les tester, si l'on veut que les résultats soient comparables à ceux obtenus pendant les saisons favorables. Ceci corrobore donc les conclusions du précédent paragraphe, et nous retrouverons ce phénomène en ce qui concerne la production thermique des butineuses.

Fin tout cas, cette baisse de potentialité thermogène n'est pas liée à un cycle interne, car au cours du mois d'aô̂t I963, qui a été particulièrement pluvieux, elle ne s'est pas produite.

\section{Possibilités de perte de poids et de potentialité thermique en cagettes.}

La plupart du temps, pour faciliter les études sur les abeilles, on a coutume de conserver des lots d'ouvrières en cagettes, à l'étuve. Ces cagettes sont munies d'un abreuvoir et d'une petite auge contenant du candi (mélange de sucre à glacer et de miel).

Nous nous sommes aperçus que cette méthode n'était pas parfaite et que les qualités physiologiques des insectes peuvent être modifiées.

Ce problème est extrêmement important en ce qui concerne notre présente étude car il ne nous a pas toujours été possible de ne tester que des abeilles fraîchement tirées de la ruche ; il nous importait donc beaucoup de savoir quelles perturbations il pouvait résulter des élevages en cagettes, en particulier bien entendu en ce qui concernait la thermogenèse.

Nous avons donc placé, en cagettes, à l'étuve à $32^{\circ} \mathrm{C}$, des lots de $25^{\circ}$ à 300 
vrières, mesurant tous les jours leurs possibilités thermogène, leurs poids frais et leurs poids secs. Chaque jour, 25 abeilles sont extraites d'une cagette et pesées. Elles sont ensuite placées dans le calorimètre et, comme pour tous nos essais, nous enregistrons la quantité de calories produites en une demi-heure. Les abeilles sont ensuite déshydratées et pesées.

Il est évident que, dans ces conditions, le poids sec n'est pas tout à fait comparable au poids frais, en ce sens qu'un passage en enceinte froidesépare les deux mesures et que, pendant ces 30 minutes, il y a consommation de matières énergétiques. Ce procédé cependant, autorise des mesures qui ne visent qu'à être comparatives tout en réalisant une économie de matériel-insectes.

Notre but a été ici de comparer l'évolution du poids de l'insecte à ses facultés thermogènes. En effet, WiERsma et Jongriaso (I935) ont écrit que, pendant le vol, la perte de poids était égale à la quantité de sucre brûlé. Nous pouvions alors penser que le pouvoir de thermogenèse des abeilles était lié à l'abondance de leurs réserves. Pour le vérifier, il fallait éliminer le poids de l'eau ingérée ou incluse et faire la mesure du poids sec.

Nous avons utilisé deux méthodes pour déshydrater les abeilles :

- Dans la première méthode, nous avons placé les insectes dans de petits récipients à l'étuve, à $40^{\circ} \mathrm{C}$. Les insectes meurent, on enlève alors le couvercle et on les laisse se déshydrater. La déshydration peut durer plusieurs jours, et il est absolument indispensable de peser les lots d'abeilles après les avoir laissées à l'étuve exactement le même temps. Quarante-huit heures très précises suffisent pour atteindre la constance du poids.

Cette méthode n'assure pas une déshydration parfaite car on ne peut se permettre de chauffer trop sans risquer de transformer les matières organiques (les lipidespar exemple).

- La deuxième méthode permet une déshydration plus effective, elle consiste à passer les insectes à l'alcool absolu puis au xylène. Cette $2^{\mathrm{e}}$ façon de procéder a aussi ses inconvénients : elle enlève une partie des corps gras. Elle donne cependant, à notre avis, des résultats plus sûrs, si l'on prend soin de rajouter au poids de 1 'insecte déshydraté celui de l'extrait sec.

On constate alors que les abeilles d'un lot en bon état physiologique initial perdent du poids (sec ou frais) et une partie de leur potentialité thermique après quelque temps passé en cagettes.

Après 4 ou 5 jours, le poids remonte à un niveau normal, la potentialité thermique également, I jour après en général.

Les courbes obtenues (poids et $Q / t / a$ ) ne sont pas absolument superposables, mais il $\mathrm{y}$ a entre elles une très bonne corrélation surtout entre $Q / t / a$ et poids sec. Nous en donnons deux exemples aux figures 27 et 28 .

Remarquons d'ailleurs que l'on peut assister à de nouvelles chutes de ces valeurs, comme on le voit sur la figure 27 , il est donc important de faire très attention aux résultats obtenus avec ces méthodes d'élevage en cagettes.

Il serait préférable évidemment de ne tester que đes abeilles fraîchement tirées de la ruche. Cependant, nous avons déjà vu, dans les premiers paragraphes de ce ch apitre, que les abeilles prélevées en début d'hivernage ou pendant un été très sec n'offrant pas assez de nourriture, donnent des chiffres très bas. Si l'on veut donc 


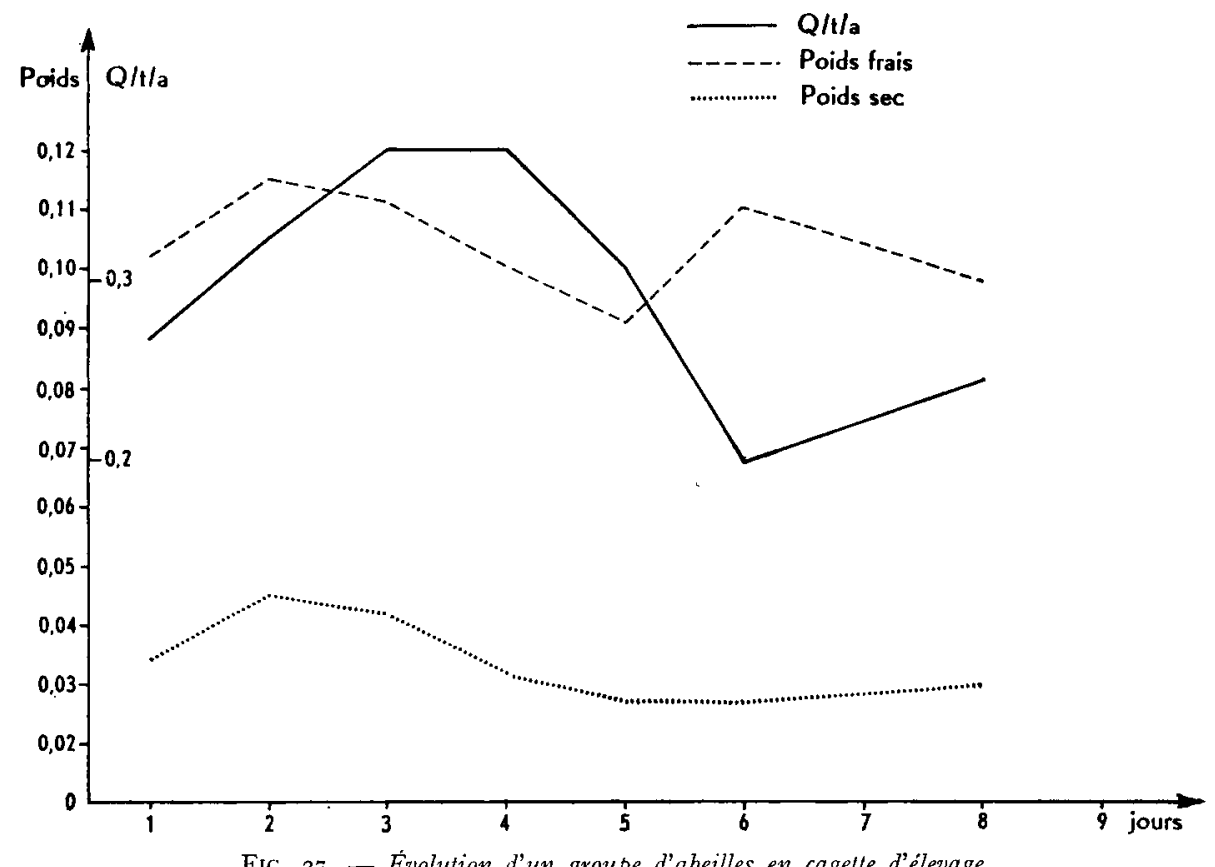

FIG. 27. - Evolution d'un groupe d'abeilles en cagelle d'élevage

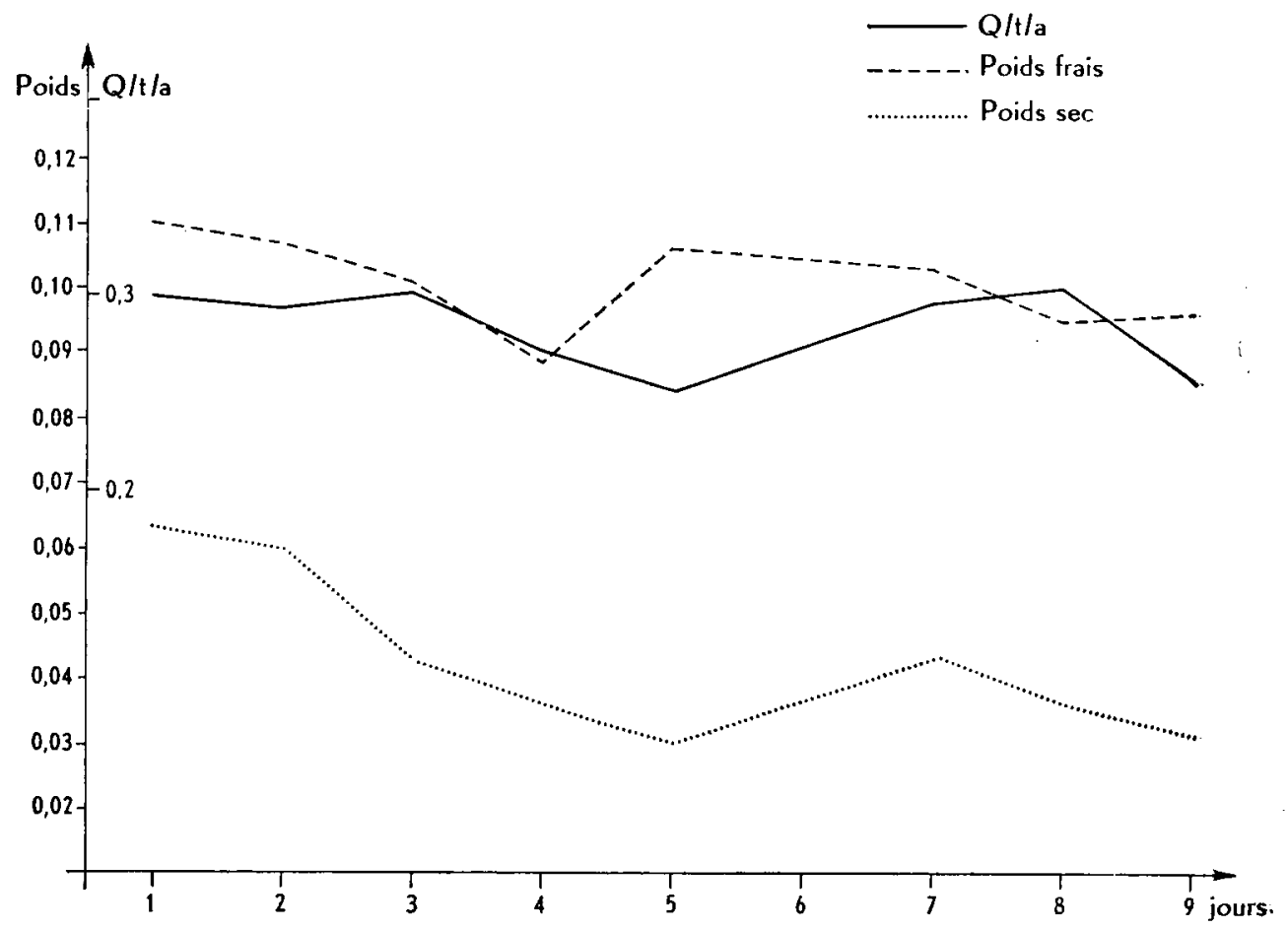

FIG. 28. - Évolution d'un groupe d'abeilles en cagette d'élevage 
continuer certaines expériences avec de tels insectes, il est nécessaire de les nourrir en cagettes avant essai.

Ces études nous ont permis de recouper des résultats de SPENCER, BOOTH et FREE qui ont étudié le rapport existant entre la consommation d'eau par les abeilles et la température ambiante.

Nous extrayons de leurs travaux le tableau suivant :

Consommation d'eau par jour et par abeille en $\mathrm{mm}^{3}$ pour

\begin{tabular}{c|c|c|c|c|c}
\hline $\begin{array}{c}\text { Température } \\
\left({ }^{\circ} \mathrm{C}\right)\end{array}$ & 10 abeilles & 25 abeilles & 50 abeilles & 100 abeilles & 200 abeilles \\
& & & & \\
\hline & & 0,3 & 0,0 & 0,0 & 0,0 \\
10 & 0,0 & 0,0 & 0,0 & 0,0 & 0,0 \\
15 & 0,0 & 0,0 & 0,0 & 0,0 & 0,3 \\
20 & 0,5 & 0,5 & 0,5 & 0,3 & 0,3 \\
25 & 0,0 & 0,0 & 0,5 & 0,5 & 0,8 \\
30 & 5,8 & 9,8 & 10,9 & 10,1 & 11,4 \\
35 & 10,1 & 20,4 & 20,7 & 16,7 & 21,7 \\
40 & & & & \\
\hline
\end{tabular}

Remarque: L'absorption d'eau suit d'ailleurs le processus inverse de la consommation en matières sucrées, cette dernière tendant vers des valeurs très faibles au-dessus de $30^{\circ} \mathrm{C}$ (voir au $\S 3$ de ce même chapitre).

Nous pouvons retrouver ces données, grâce à nos expériences, si nous comparons la capacité thermogène non plus au poids sec, mais à la valeur: poids frais moins poids sec. Nous voyons que, cette fois, les courbes de production de chaleur et de quantité d'eau libre et de constitution s'opposent nettement (voir fig. 29).

On peut se demander, à propos de cette variabilité très importante du poids et de la physiologie générale, si la cause n'en est pas la perturbation d'un phénomène social : la réduction du groupe, la privation de reine surtout, perturbent vraisemblablement l'appétit des abeilles.

\section{D) Production de chaleur suivant l'âge des abeilles.}

Nous avons pensé que la possibilité de production de chaleur chez les abeilles pouvait être liée au rôle qu'elles jouent dans la ruche et par conséquent se développer particulièrement chez les abeilles dites « nourrices » et " domestiques », c'est-à-dire âgées d'un à vingt jours environ.

Quelques mesures effectuées avec des butineuses, entrant ou sortant de la ruche, semblaient devoir confirmer cette opinion ; en effet, les résultats obtenus, très hétérogènes d'ailleurs, étaient toujours inférieurs aux quantités de calories produites par les abeilles jeunes demeurant en permanence sur les rayons.

Mais il ne s'agit là, en réalité, comme dans le cas des abeilles hivernantes, que d'un déficit de matières énergétiques. Placées en cagettes, à l'étuve, pourvues d'eau et de "candi ", ces mêmes butineuses peuvent, après quelque quinze à vingt minutes, 

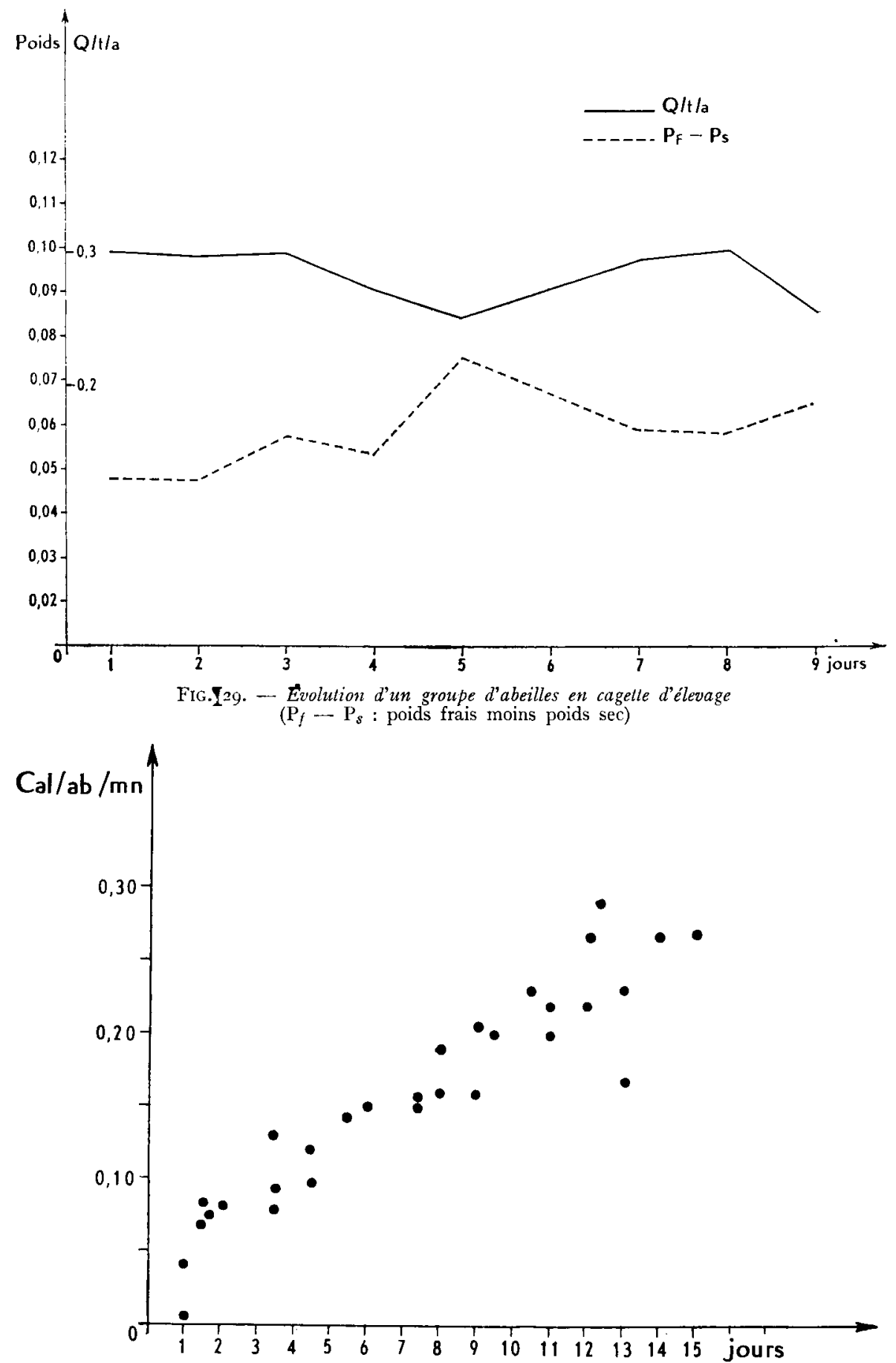

FIG. 3o. - Production de chaleur en fonction de l'âge en jours (en calories par abeille et par minute) 
produire autant et même plus de calories que les abeilles d'âge moyen. Nous avons ainsi obtenu, en moyenne, des $Q / t / a$ de 0,36 calorie par abeille et par minute $(0,26$ en moyenne avec les abeilles jeunes).

Nous avons alors étudié la capacité thermogène de lots d'abeilles nées au laboratoire, en effectuant chaque jour des mesures au calorimètre. Nous avons pu constater que, contrairement à notre hypothèse première, le maximum de possibilités thermiques des abeilles n'est pas l'apanage des ouvrières responsables du couvain. La quantité de calories que peuvent produire de jeunes abeilles est faible ; cette quantité augmente en même temps que 1'âge en suivant d'ailleurs une fonction apparemment linéaire, comme le montre fort bien la figure 30 , ci-avant.

Nous voyons donc qu'il faut, aux abeilles, vivre une quinzaine de jours, avant d'acquérir la capacité de production de chaleur habituellement mesurée lors de nos expériences sur des lots d'abeilles d'âge varié. Les butineuses, abeilles les plus âgées de l'essaim, après avoir été bien nourries, produisent une quantité de chaleur supérieure à ces moyennes; ce résultat n'est pas, en définitive, déconcertant si l'on se rappelle que la production de chaleur a son origine dans une activité des muscles thoraciques et que ces organes ne peuvent sans doute que se renforcer progressivement avec l'âge, jusqu'à acquérir leur maxinum de puissance chez les butineuses.

\section{$\S 2$ - Influence sur la thermogenèse et effet d'économie thermique du groupe.}

I1 est bien connu que l'activité des abeilles n'est normale qu'en groupe.

En ce qui concerne l'étude du phénomène de la production de chaleur, comme pour tous autres, il nous a paru indispensable de définir le nombre d'individus qu'il était nécessaire de rassembler pour obtenir un comportement cohérent.

Étant surtout intéressé par les possibilités de chauffage de la ruche par ses hôtes, la plupart de nos mesures ont été faites avec des abeilles d'âges divers, ce qui représente les conditions normales de population de la ruche.

Pour obtenir un échantillonnage aussi satisfaisant que possible, nous avons prélevé les abeilles par le trou du couvre-cadre, récoltant ainsi des insectes de tous âges, et même parfois des butineuses.

Au cours d'essais antérieurs, nous avions prélevé les insectes sur la planche de vol, c'est-à-dire surtout des butineuses ce qui, d'une part, n'était pas représentatif de la population totale, et d'autre part donnait des résultats assez peu homogènes.

Immédiatement après leur sortie de la ruche, les abeilles sont placées dans une enceinte à $32^{\circ} \mathrm{C}$ puis anesthésiées et glissées dans le calorimètre.

Les expériences ont été faites avec des lots d'abeilles variant de I à 50 individus avec des répétitions pour chaque nombre et les résultats ont été portés sur un graphique qui exprime le $Q / t / a$ en fonction du nombre d'abeilles testées (voir fig. 3I).

\section{a) L'effet de groupe.}

On distingue immédiatement une extraordinaire variabilité dans les valeurs du $Q / t / a$ pour des lots de faible importance numérique. La valeur enregistrée la plus forte est de 0,98 calorie pour I abeille seule, ce qui est considérable, la plus faible valeur est de $0, I$ environ. 
$4^{8}$

M. ROTH

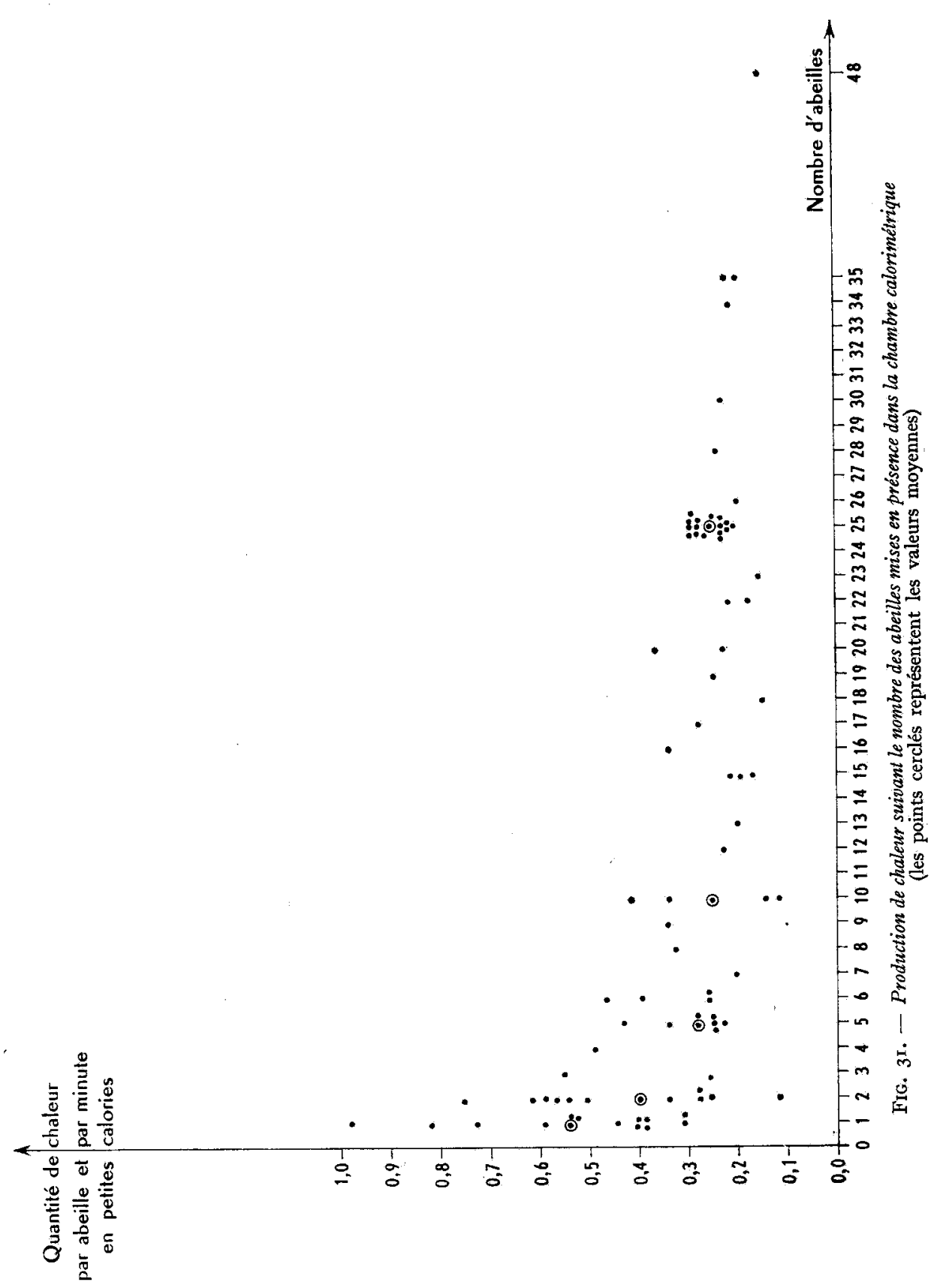


Cette variabilité se maintient pour des lots d'abeilles inférieurs à I 5 à 20 insectes, mais elle est déjà moins importante dès le nombre de $\Upsilon_{5}$ abeilles et devient ensuite très faible.

Les quantités de chaleur produites par abeille et par minute restent alors presque toujours comprises entre 0,20 et 0,28 calorie.

Remarque : Signalons d'ailleurs que malgré cette grande dispersion des valeurs du Q/t/a pour des nombres d'abeilles inférieurs à 20, la majorité d'entre elles se groupe néanmoins dans cette zone $0,20-0,28$ calorie.

Cette régulation que 1'on observe de la production thermique par abeille a vraisemblablement deux causes principales.

Io Il est bien évident que la production de chaleur de chaque abeille n'est pas rigoureusement déterminée et s'écarte plus ou moins des prođuctions moyennes calculées et indiquées sur le graphique $3 \mathrm{I}$. Plus les lots d'abeilles sont importants et plus il est normal que les productions thermiques "se tamponnent " et que les résultats moyens calculés deviennent moins dispersés.

En bref, l'effet de compensation arithmétique est d'autant plus efficace que le lot d'abeilles testées est plus important.

$2^{\circ}$ Cependant, le "phénomène arithmétique " n'est pas seul en cause. Enn effet, si nous observons à la figure 39 les productions thermiques obtenues pour une seule abeille à différentes températures, nous voyons que celles-ci sont également moins dispersées lorsque la température ambiante est plus forte.

Or, un des premiers effets du groupe est précisément d'augmenter cette température ambiante par formation d'une grappe tiède au sein de laquelle les abeilles sont à une température assez satisfaisante.

I1 est donc fort possible que ce phénomène de régulation de la production thermique joue également ici, lorsque les groupes sont suffisamment importants, ajoutant donc son effet à celui de compensation purement arithmétique signalé plus haut.

Mais le phénomène le plus important que traduit le graphique 3 I est la décroissance extrêmement nette que l'on observe dans les valeurs des $Q / t / a$, lorsque les groupes d'abeilles mis en expérience deviennent plus importants.

Nous verrons, au $\S 3$ de ce chapitre, que l'augmentation de la température ambiante jusqu'aux environs du thermopreferendum a pour effet de réduire les Q/t/a. Nous savons d'autre part que, lorsqu'un groupe d'abeilles est suffisamment important, celles-ci peuvent former une grappe au sein de laquelle la température devient assez proche de ce thermopreferendum. Mais cela ne peut se produire avec des petits groupes d'abeilles; la réduction des $Q / \mathbf{t} / \mathbf{a}$ observée pour des lots de $\mathrm{I}$ à Io abeilles ne peut donc dépendre que d'un effet dépresseur du métabolisme imputable au groupement.

Afin d'entériner mathématiquement ces résultats, nous avons tenté l'analyse globale des catégories I, 2, 5 et ro abeilles et les comparaisons classiques de moyennes deux à deux. Malheureusement, sauf pour le cas des abeilles isolées, les points indiquant les productions de chaleur par abeille et par minute représentent déjà des moyennes et les données étudiées à travers ces chiffres sont suffisamment hétérogènes pour que l'on puisse douter des comparaisons effectuées.

Ces comparaisons paramétriques classiques n'apportant donc rien, nous avons utilisé le coefficient de corrélation des rangs de Spearman.

Annales de l'Abeille. - 1965 . 
On s'aperçoit alors que, si l'on range les moyennes d'après le nombre d'abeilles utilisées, elles ne se classent pas d'une façon aléatoire :
4 catégories $(\mathrm{I}, 2,5$ et $\mathrm{IO}) \ldots \ldots \ldots$
$r_{s}=-$ I,000 (significatif);
5 catégories $(\mathrm{I}, 2,5$, Io et 25$) \ldots \ldots \quad r_{s}=-0,900$ (significatif); toutes
( 2 I catégories) $\ldots \ldots \ldots$
$r_{s}=-0,660$ (hautement significatif).

En conclusion, la production de chaleur par abeille est liée à l'importance du groupe mis en expérience.

Cet effet de groupe, dépresseur du métabolisme, apparaît également dans certaines expériences réalisées au calorimètre CALVET.

Nous avons réalisé deux séries d'expériences, d'abord à $30^{\circ} \mathrm{C}$, ensuite à $20^{\circ} \mathrm{C}$, avec des lots de $1,2,4$ et 8 abeilles.

Nous avons pu constater que, dans le premier cas $\left(30^{\circ} \mathrm{C}\right)$, les productions totales des I, 2, 4 ou 8 abeilles étaient sensiblement identiques et que, par conséquent, les Q/t/a étaient d'autant plus faibles que les groupes étaient plus importants.

Ceci pouvait être imputé au fait que, la température de $30^{\circ} \mathrm{C}$ n'étant guère éloignée du thermopreferendum, la production thermique des abeilles s'arrêtait dès que celui-ci était atteint pour reprendre seulement lorsque suffisamment de calories produites avaient pu diffuser à travers les couples thermoélectriques de l'appareil.

Mais nous avons repris ces expériences à la température ambiante de $20^{\circ} \mathrm{C}$ et, cette fois encore, les productions thermiques totales des différents groupes étaient assez semblables donc les $Q / t / a$ d'autant diminués.

Ceci confirmait bien l'existence d'un facteur social dépresseur du métabolisme.

Nous avons pu l'observer d'ailleurs dès la mise en présence de deux insectes seulement.

I $^{\circ}$ Si l'on place I puis 2 abeilles, dans le calorimètre CALVET, à $30^{\circ} \mathrm{C}$, on obtient des courbes assez semblables (voir fig. 32, I et II).

$2^{\circ}$ Si $1^{\prime}$ on place dans le calorimètre, I puis 2 abeilles, à $20^{\circ} \mathrm{C}$, on observe également des résultats très semblables (voir fig. 32, III et IV).

$\mathrm{Si}$, de même, on expérimente, à $20^{\circ} \mathrm{C}$, avec 2 abeilles séparées par un tampon de coton dans la cellule du calorimètre, la courbe obtenue est identique aux deux premières (voir fig. 32, V). Mais nous voyons, qu'à cette température, les courbes ne sont plus cycliques comme dans le cas précédent; elles présentent un pic important en début d'expérience et s'abaissent très rapidement, ce qui montre que les abeilles placées dans de mauvaises conditions de température utilisent assez rapidement leurs réserves énergétiques.

$3^{\circ}$ Nous avons donc utilisé des abeilles sous-alimentées.

Une seule a été placée, à $20^{\circ} \mathrm{C}$, dans le calorimètre CAIVET. Nous observons que la courbe enregistrée présente toujours un pic à son début, mais elle tend ensuite rapidement vers zéro et ne se maintient pas comme précédemment (voir fig. 32, VI).

Si nous plaçons dans le calorimètre 2 abeilles sous-alimentées, à $20^{\circ} \mathrm{C}$, on obtient une courbe très comparable à celles obtenues avec des abeilles normales, c'est-à-dire que le pic est suivi d'une courbe d'aspect cyclique et qui se maintient à des valeurs moyennes de la production thermique (fig. 32, VIII). 
Par contre, si, dans les mêmes conditions, nous plaçons 2 abeilles sous-alimentées, séparées par un tampon de coton, on enregistre une courbe typique d'abeille isolée. (voir fig. $32, \mathrm{VII}$ ).
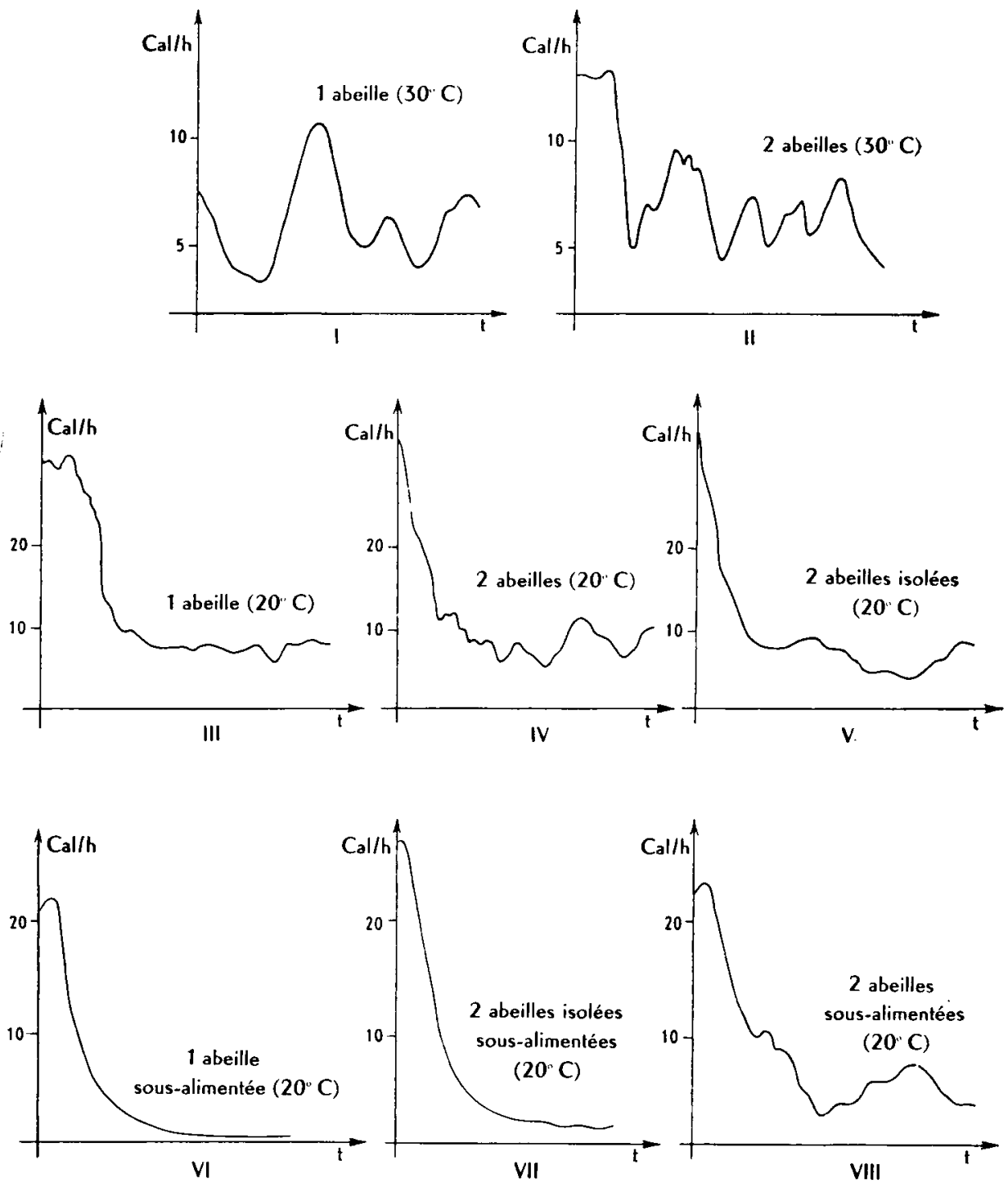

FIG. 32. - Courbes de production de chaleur enregistrées au calorimètre électrique CaLveT avec 1 el 2 abeilles dans différentes conditions expérimentales

L'effet de groupe joue donc dès que l'on place deux abeilles en présence.

Dans un travail récent sur le métabolisme de l'abeille, mesuré par respirométrie (I963), Heusner n'a pas vu cet effet de groupe.

La raison en est dans le fait que cet auteur a expérimenté en plaçant les abeilles à leur thermopreferendum. La consommation d'oxygène qu'il observe est alors due 
uniquement au métabolisme basal et aux quelconques mouvements des insectes. I1 est bien évident que dans de telles conditions, il y a peu de chances d'observer un effet de groupe.

Il fallait, pour trouver ce phénomène, obliger les insectes à utiliser le processus de chauffage très spécial qui leur est propre et pour cela, évidemment, éviter de se placer au thermopreferendum.

Remarque; Il faut reconnaître que nous n'avons pas systénatiquement obtenu ces résultats, plusieurs abeilles que nous aurions pu croire sous-alimentées ayant parfois gardé des ressources suffisantes pour que la courbe ne tende pas aussi rapi-
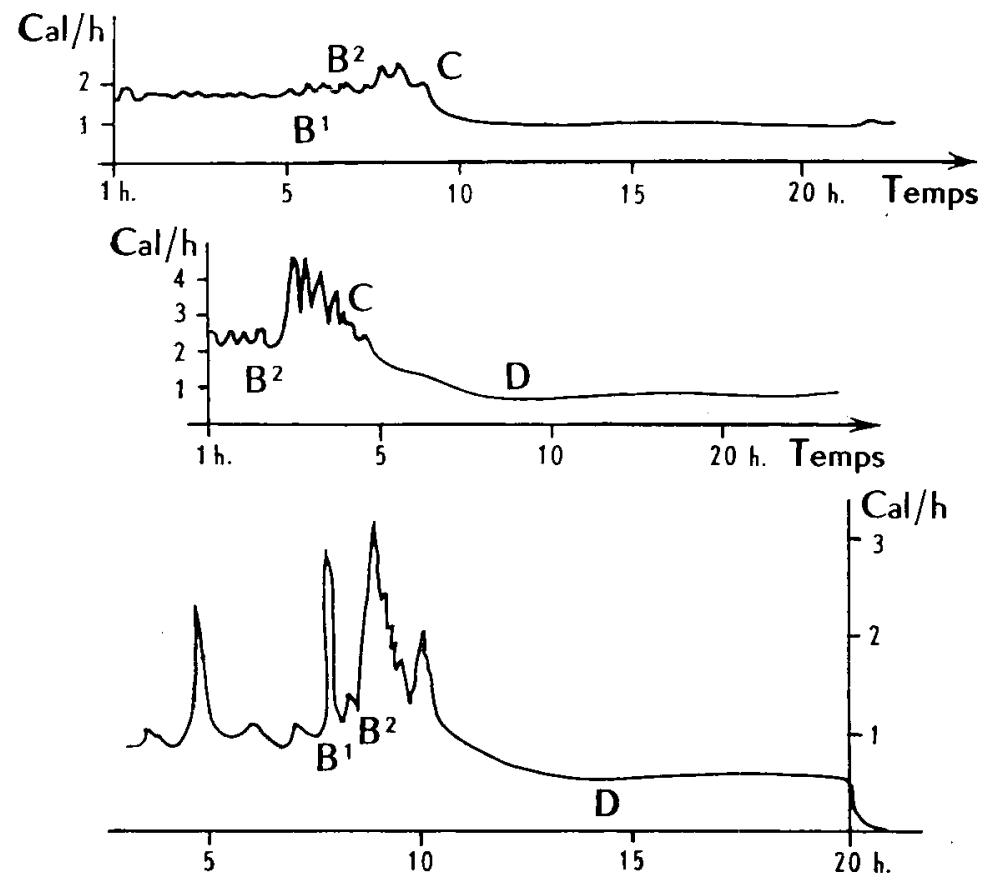

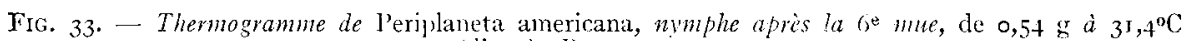
(d'après PRAT, I 954 ).

Fic. 34. - Thermogramme de Melanoplus bivittatus of de o,838 g a $24,9^{\circ} \mathrm{C}$ (d'après Prat, 1954)

FIs. $\quad 35 .-$ Thermogranme de Periplaneta americana, de $0,7^{6}$ an a $2.1,0^{\circ} \mathrm{C}$ (d'après PRAT, 1954)

dement vers zéro que dans les exemples présentés, mais nous retombions alors tout simplement dans le cas précédent oì l'effet de groupe se trouvait masqué.

Pour en terminer avec cette étude de l'effet de groupe, reprenons l'examen du graphique 3I. Nous voyons que, lorsque les lots d'abeilles mis en expériences dépassent le nombre de Io insectes, les $Q / t / a$ se maintiennent à un niveau sensiblement constant; nous avons d'ailleurs trouvé des valeurs moyennes identiques pour les lots de ro et 25 abeilles (o,26 calorie environ).

Cependant, d'après l'aspect général de la courbe, on peut distinguer une baisse moyenne assez lente mais nette au niveau des groupes les plus populeux. On ne peut 
cette fois conclure à un effet dépresseur proportionnel au nombre des abeilles mises en présence. Il ne faut pas oublier, en effet, que les abeilles en période de production thermique consomment beaucoup d'oxygène, et c'cst sans nul doute la raréfaction de l'air interne du calorimètre qui entraîne cette chute du Q/t/a pour des groupes importants d'abeilles.

Nous avons pu d'ailleuts étudier ce phénomène en insufflant de l'air dans nos calorimètres (par exemple 2 insuflations, l'une après io nın, l'autre après 20 mn au cours de nos expériences qui durent $30 \mathrm{mn}$ en conditions normales).

Les $Q /$ t/a à trouver sont alors légèrement plus forts, mais il est certain que ce procédé perturbe la mesure, pas tant d'ailleurs par l'apport d'air dont la capacité calorique est faible, que par l'excitation résultante des insectes. Il est donc difficile, dans ces conditions, d'avancer des chiffres valables, mais il semble bien que l'on peut conclure que, seul ici, dans le cas des groupes importants, le manque d'oxygène est responsable de la chute légère des valeurs du $Q / t / a$.

Ce qui est justement le plus surprenant, c'est que cette chute ne soit pas plus rapide, la capacité respiratoire des insectes testés dépassant, jour des groupes importants, la contenance de nos calorimetres.

Nous reviendrons sur ce problème au chapitre IV, disonss simplement ici que les abeilles sont capables de produire de la chaleur en anaérobiose, donc de réfuter le classique rapport : $\frac{\text { consommation en litres } \mathrm{O}_{2}}{\text { kilocalories }}=5$.

Nous reproduisons d'ailleurs ici quelques thermogrammes obtentus par PRAT au calorimètre CAIVET, avec des insectes en état d'asphyxie. Nous voyons que les possibilités de thermogenèse de ces insectes dépassent largement les ressources en oxygène offertes par 1'habitacle du calorimètre utilisé.

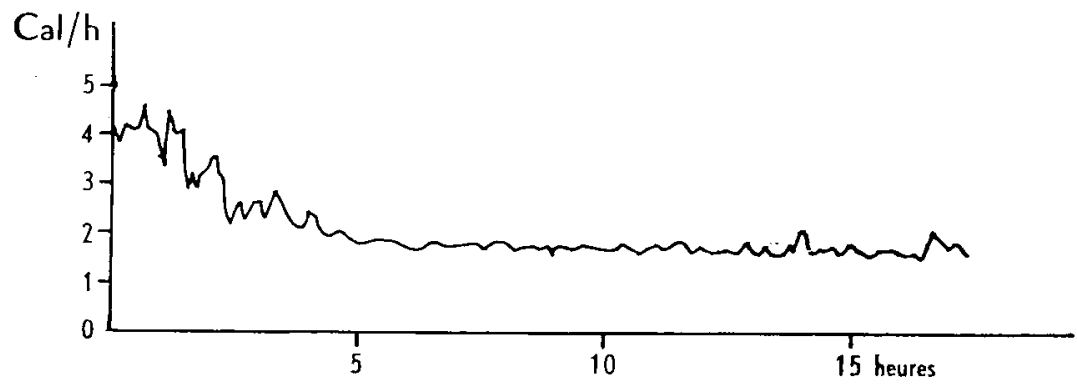

FIG. 36. -- Thermogramme de Melanoplus differentialis, de 0.098 g a $26,5^{\circ}{ }^{\circ}$, (d'après P'RAT, 1954)

b) Formation de la "grappe".

Ce comportement social jouant un rôle dans nos mesures calorimétriques, nous en dirons ici quelques mots.

On considère en général que 1'inter-attraction entre individus provoque la formation de la "grappe ", c'est-à-dire que les abeilles s'accolent assez étroitement en une masse confuse. Il faut bien noter que, pour des températures inférieures au thermopreferendum (et c'est le cas le plus fréquent), l'attraction thermique est certainement beaucoup plus importante que ce phénomène d'inter-attraction. 
Nous empruntons à SPEXCER-BOOTH et FREE des résultats qui le démontrent bien.

\begin{tabular}{ccc|c|c|c|c}
\hline \multicolumn{5}{c}{ Pourcentage des abeilles formant la grappe pour des lots de : } \\
\hline $\begin{array}{c}\text { Température } \\
\left({ }^{\circ}\right)\end{array}$ \\
\hline
\end{tabular}

N.B. - Nous estimons que les chiffres les plus faibles, inférieurs ici à II, sont sans signification.

Nous avons pu d'ailleurs mettre ce phénomène en évidence grâce à l'appareil représenté à la figure 37 .

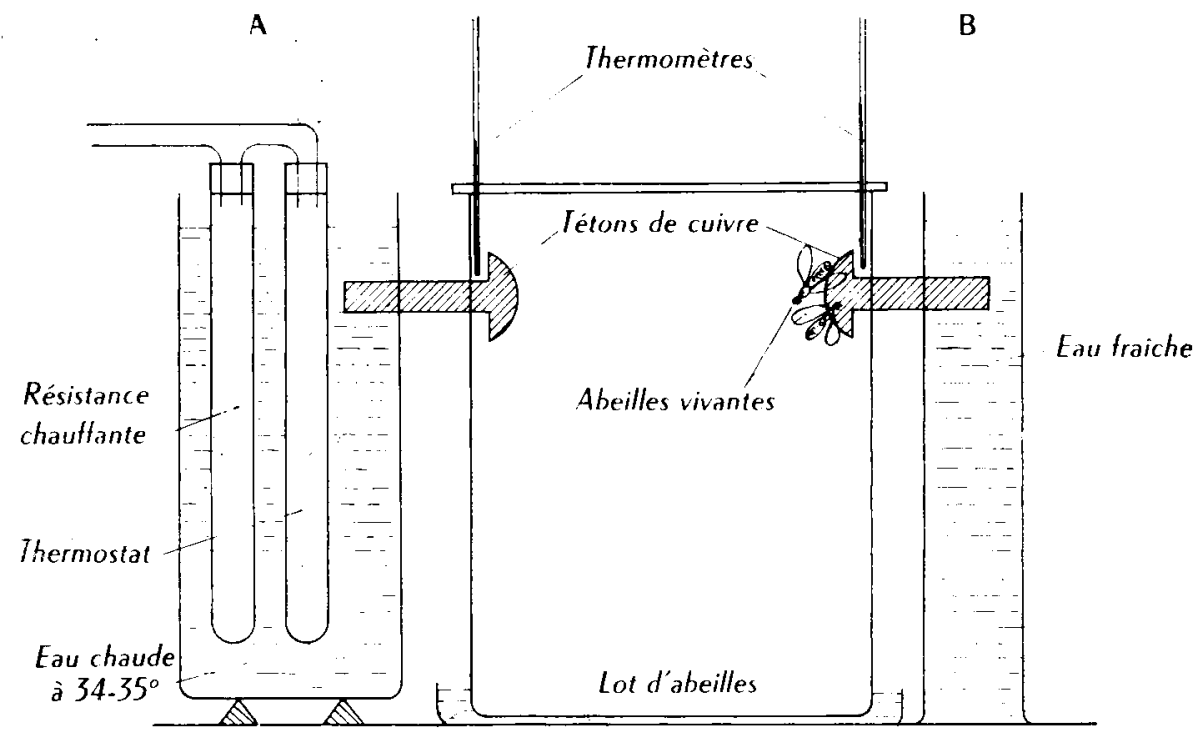

\section{Eau traiche}

FIG. 37. - Dispositif permettant de démontrer la prépondérance du stimulus thermique sur l'inter-altraction dans la formation de la "grappe " chez les abeilles domesliques

Il se compose d'un bac en matière plastique posé dans tune cuvette contenant de l'eau froide, de façon à ce que le fond de ce bac soit à une température non satisfaisante pour les abeilles.

Deux tétons de cuivre traversent le bac de façon à ce que leur tête dépasse à 
l'intérieur. Quant aux extrémités de ces pièces métalliques, elles sont plongées respectivement dans une cuve chaude (A) et une cuve froide (B).

On peut, grâce à des thermostats, régler les températures des têtes métalliques dépassant à l'intérieur du bac et les températures sont indiquées par les thermomètres $a$ et $b$; on peut choisir par exemple $35^{\circ} \mathrm{C}$ pour $a$ et $20^{\circ} \mathrm{C}$ pour $b$.

Si l'on place un lot d'abeilles dans le bac en matière plastique, à une température assez fraîche $\left(20^{\circ} \mathrm{C}\right.$ par exemple), une grappe ne tarde pas à se former, et elle se forme sur le téton chaud, ce qui est assez prévisible.

$\mathrm{Si}$, ensuite, on colle sur le téton froid, 3 ou 4 abeilles vivantes, la grappe se forme quand même sur le téton chaud. Dans de telles conditions de température, les abeilles ont donc été attirées davantage par la chaleur que par le petit groupe d'insectes déjà formé.

Ceci montre toute l'importance de la température dans la formation de la grappe. Nous voyons d'ailleurs, d'après les résultats de SPExCER-Boo'rH et FrEE, que, si cette formation est régulière pour des groupes de plus de roo abeilles, là encore la température joue pour déterminer l'importance du groupe.

Remarquons que la grappe se dissocie si l'on introduit un petit cristal de glace en son centre ou si l'on refroidit progressivement le téton chaud, la grappe se rompt alors au moment oì la température de ce téton rejoint la température ambiante.

La grappe se serre ou se desserre d'ailleurs suivant cette température ambiante, le resserrement diminue la surface de refroidissement et aussi, probablement, les courants internes de conduction (Corkixs, I930).

\section{c) Effet d'économie thermique du groupe.}

La formation du groupe diminuant le $Q / t a$, il est évident que ce comportement conduit à une remarquable économie de matières alimentaires. Nous avons tenté de la confirmer de la façon suivante.

Avant de tester des abeilles au calorimètre, nous avons pensé les placer au froid afin d'épuiser tout ou partie de leurs réserves. Nous avons ainsi voulu retrouver les résultats obtenus avec des abeilles sous-alimentées, voir pendant combien de temps une abeille privée de nourriture peut effectuer sa thermogenèse.

Nous avons donc placé au froid les abeilles en cagettes, groupées ou isolées. Nous avons également placé des abeilles isolées dans de petits tubes en verre. Ces petits tubes sont mis en groupes de 25 à roo dans une boîte de matière plastique, au frigidaire.

Boîtes ou cagettes sont laissées au frigidaire à $I I-I 2^{\circ} \mathrm{C}$ pendant $\mathrm{I} / 4$ d'heure, I/ 2 heure ou I heure, puis les insectes, rapidement, sont extraits et placés dans le calorimètre.

Les résultats sont assez inégaux au point que, dans certains cas, les productions thermiques ont été plus fortes après I heure passée au froid qu'après I/ 2 heure mais, si nous faisons les moyennes, nous observons une décroissance des $Q / t / a$, faible sans doute, néanmoins réelle.

Le plus important est de constater la très grande différence qui existe entre les abeilles groupées et les abeilles isolées.

Le tableau ci-dessous ainsi que la figure 38 , indiquent clairement l'importance de l'économie de substances énergétiques due à la formation de la grappe et qui a permis 
aux insectes placés en groupe au frigidaire, de conserver une assez bonne capacité de thermogenèse.

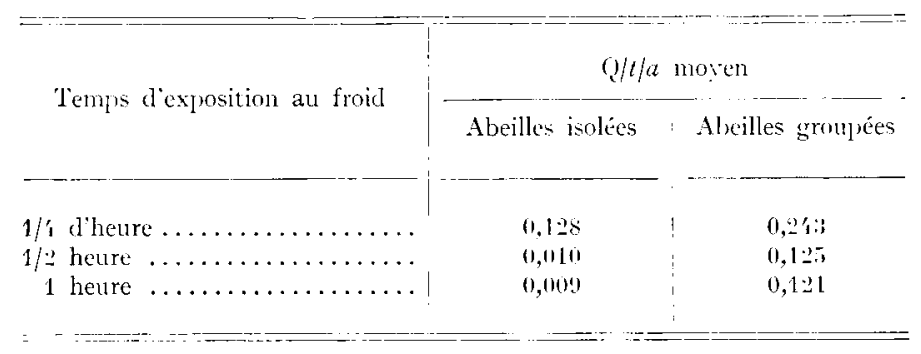

La grappe a sans doute eu un effet d'isolation thermique, mais il y a eu également intervention d'un stimulus sensoriel de groupe qui a déterminé les abeilles à produire moins de chaleur par unité de temps, ainsi que nous l'avons vu au début de ce chapitre. Les insectes groupés ont pu ainsi conserver plus de réserves caloriques que les isolés.

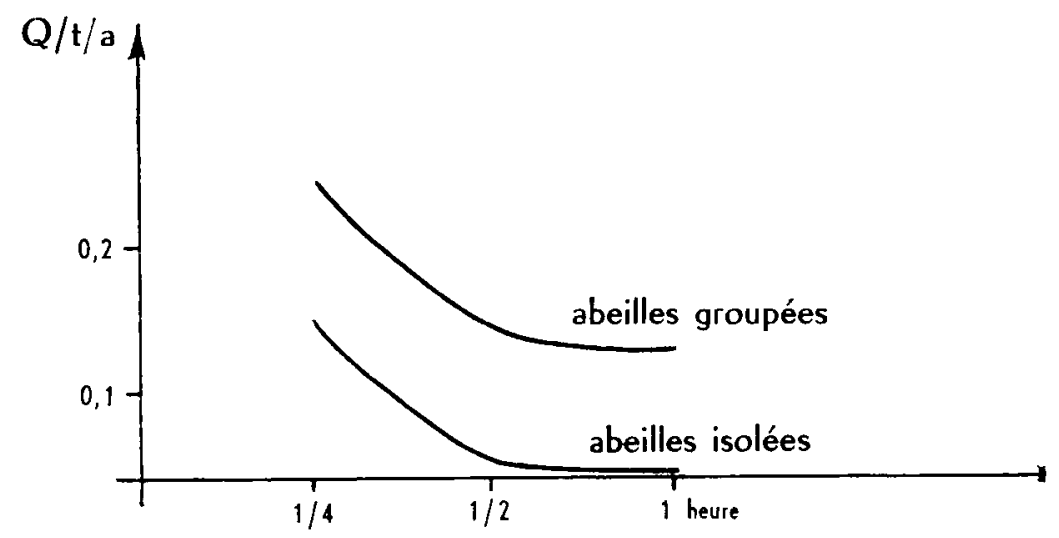

Fic. 38. - Coubes de proluctions thermiques compurées d'abilles exposées an froid $1 / 4$ d'heure, $\mathrm{I} / 2$ heure oul $\mathrm{I}$ hetwe, soit lisoleses, soil par grulpes de 25 à 100

$\$ 3$ Adaptation de la production de chaleur à la température ambiante.

Nous verrons au chapitre IV, concernant les résultats de nos études respirométriques, comment les abeilles adaptent leur consommation d'oxygène à la température ambiante.

Ces phénomènes avaient été observés par Parhox (Ig09), mais Esch (I950), n'admettait pas cette relation entre température et thermogenèse, estimant que les abeilles réagissent au maximum de leurs possibilités jusqu'à satisfaction de leur thermopreferendum.

Les expériences que nous avons faites ne peuvent trancher ce problème de façon absolue. En effet, lorsqu'un lot de 25 abeilles est placé dans l'enceinte calorimétrique, il y a thermogenèse immédiate, mais aussi formation de la "grappe ". Comme nous l'avons vu dans les paragraphes précédents, on peut considérer ce phénomène comme 
dépresseur du métabolisme; de plus, il est bien éviđent que les abeilles situées en profondeur dans la grappe sont rapidement dans une ambiance thermique plus élevée et réagissent moins. Ainsi, la moyenne de production de chaleur du groupe est-elle tout naturellement inférieure à celle des insectes isolés. De plus, les abeilles réchauffant très vite l'atmosphère dans laquelle elles sont placées, la température

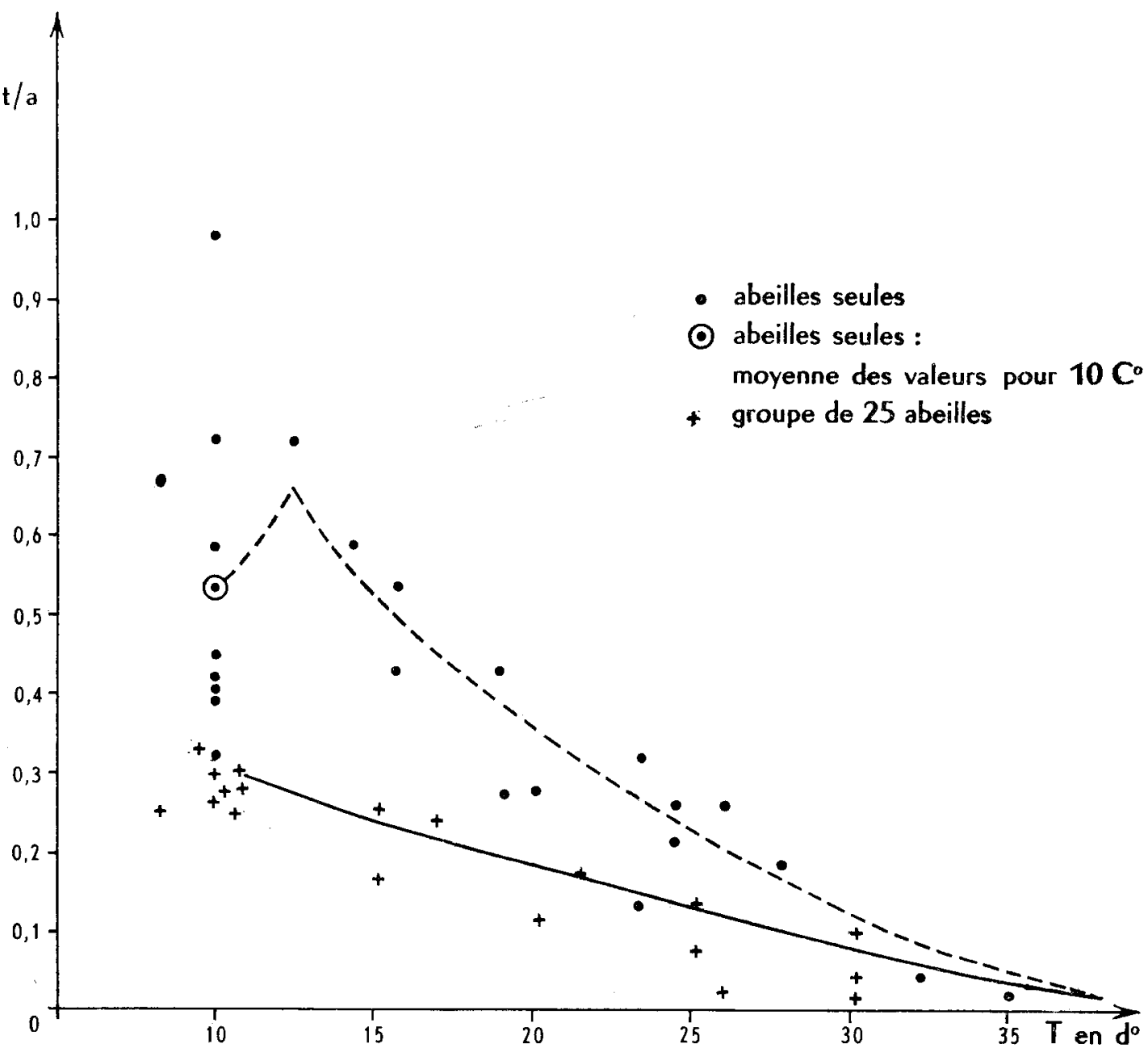

FIG. 39. -- Production de chaleur par insecte et par minute, pour des abeilles isolées ou des abeilles groupées, suivant la tempéralure ambiante

devient rapidement plus forte dans l'enceinte aérienne et les conditions ambiantes en quelque sorte moins stimulantes.

Néanmoins, la cuticule des abeilles étant peu thermo-isolante, la chaleur du groupe est très rapidement conduite, par le système métallique prévu à cet effet, vers l'eau froide du fond du calorimètre. Il y a donc une perpétuelle " demande " de calories et qui est d'autant plus grande que l'écart de température est plus important entre la température du groupe d'abeilles et celle de l'eau. 
Donc, si nos mesures sont gênées en valeur absolue par la formation de la "grappe " qui modifie l'ambiance et le fait que nos calorimètres Berthelot sont adiabatiques et non isothermiques (1), il existe cependant, suivant la température initiale offerte, un gradient du stimulus inducteur de la thermogenèse.

Nous avons pu le mettre en évidence en effectuant des mesures de production de chaleur à différentes températures initiales, avec des groupes de 25 abeilles et des abeilles seules.

Les résultats ont été reportés sur un graphique (fig. 39) qui indique ces productions de chaleur en calories par abeille et par minute.

On remarquera la chute de la moyenne des $Q / t / a$ pour les abeilles isolées, à moins de $13^{\circ} \mathrm{C}$; c'est que nous expérimentions alors à une température inférieure à la température de "stimulation ", les abeilles s'engourdissent et réagissent moins bien, quoique le stimulus soit théoriquement plus fort. Ce phénomène ne peut s'observer avec les groupes d'abeilles qui, réchauffant leur logette, ne se trouvent jamais à une température inférieure à ce seuil.

Nous verrons au chapitre IV que ces courbes s'apparentent très bien aux résultats acquis par respirométrie.

Cette adaptation de la thermogenèse à la température ambiante est assez surprenante, nous aurions plutôt pensé, avec EscH, que, surtout isolées ou en petits groupes, les abeilles feraient tout leur possible pour atteindre au plus vite leur thermopreferendum.

Nous sommes donc obligés de constater, après les expériences faites au respiromètre et au calorimètre, que les abeilles dosent leur effort thermique au prorata de l'intensité du stimulus, c'est-à-dire que leur production de chaleur est fonction de l'écart qui existe entre la température ambiante et le thermopreferendum. Il existe un autre moyen d'apprécier cette adaptation thermogène au froid, c'est de mesurer la quantité de matière sucrée consommée par des groupes d'abeilles suivant la température à laquelle ils sont placés. Ces valeurs devraient s'amoindrir quand la température augmente.

Ces expériences ont été faites par SPEXCER-BOOTH et FREE, en I957, aussi extrayons-nous de leur travail le tableau ci-après.

Consommation de sucre/abeilleljour en $\mathrm{mm}^{3}$ de sirop.

\begin{tabular}{|c|c|c|c|c|c|}
\hline T'empérature & 10 & 25 & 50 & 100 & 200 abeilles \\
\hline $10 \circ 0^{\circ}$ & 一 & 39,9 & בי, & jo,2 & 50,8 \\
\hline $15 \circ$ & 47,5 & $5,2,{ }^{\prime}$ & $58,{ }^{\prime}$ & 54,6 & 55,7 \\
\hline$=0 \circ$ & 39,9 & 45,9 & 38,2 & $: 37,7$ & 37,7 \\
\hline $25^{\circ} \mathrm{C} C$ & 30,0 & 30,15 & 27,8 & 21,3 & 22,4 \\
\hline $30^{\circ} \mathrm{C}$ & 32,8 & $2: 3,5$ & 13,6 & 11,5 & 17,5 \\
\hline $35^{\circ} \mathrm{C}$ & 22,9 & 15,8 & 18,0 & 18,6 & 14,2 \\
\hline $40^{\circ} \mathrm{C}$ & 3,3 & 1,6 & 6,0 & 5,5 & 11,5 \\
\hline
\end{tabular}

(1) Le calorimètre CALvet est isothermique mais ne permet pas, vu la petitesse de la cellule expérimentale de tester des groupes injortants d'abeilles. 
Nous constatons effectivement une chute de la consommation de matière sucrée lorsque la température ambiante augmente (voir fig 40).

Remarquons que toutes ces expériences ont été réalisées en périodes diurnes. Nous verrons, au chapitre IV, que nous avons pu effectuer, au respiromètre des expériences de longue durée couvrant au moins une période diurne et une nocturne.

On observe alors deux phénomènes inverses; si, pendant le jour, le métabolisme thermique des abeilles diminue quand la température augmente, il varie, par contre la nuit dans le même sens qu'elle. Les abeilles se comportent donc normalement comme des poïkilothermes en période nocturne, alors qu'elles réagissent à la façon des homéothermes le jour.

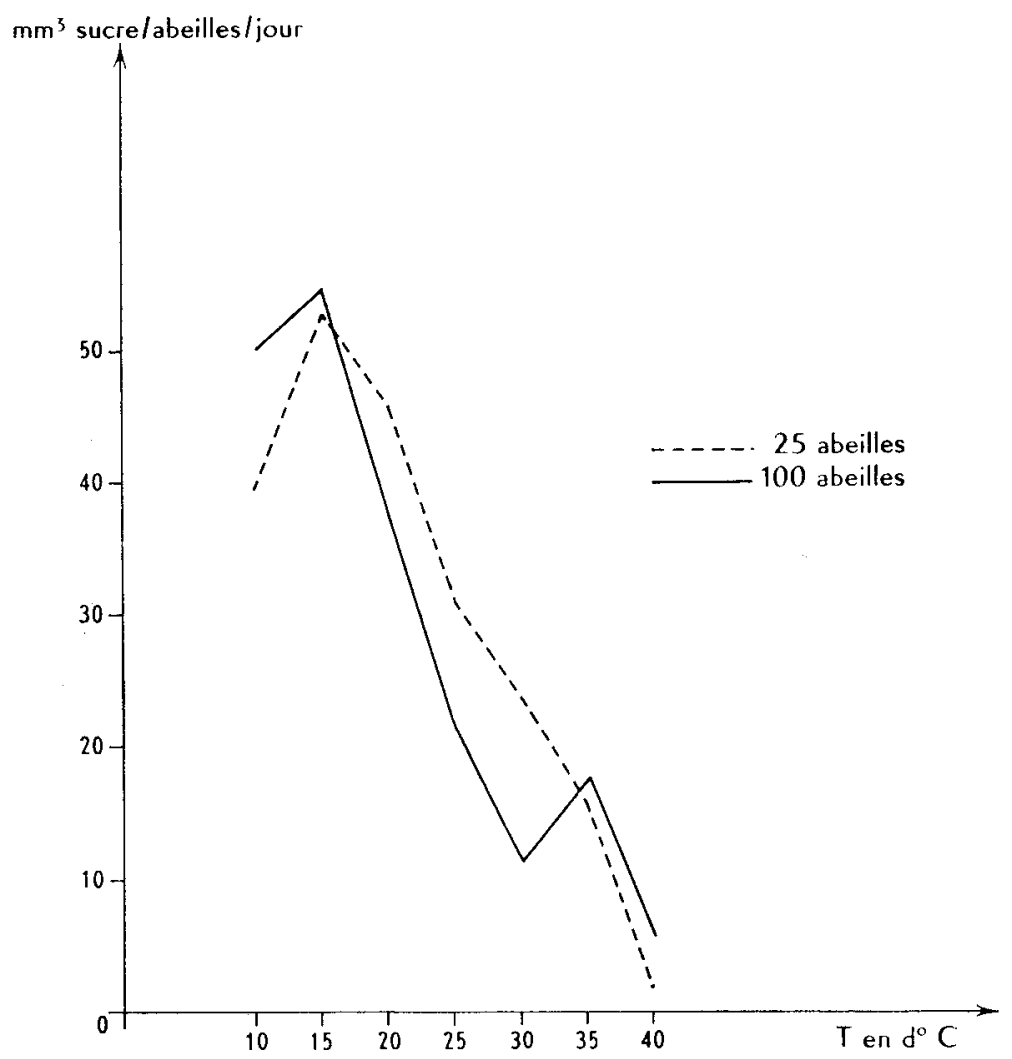

Fig. 40. - Consommation de jus sucré par des abeilles en fonction de la température ambiante (d'après des chiffres de Spencer-Booth et Free, I958).

On peut voir sur les graphiques ci-après (d'après HEUSNER, r963) toute l'importance de ce phénomène (fig. 4I et 42).

On notera d'ailleurs que le métabolisme diurne est dix fois supérieur au nocturne. 


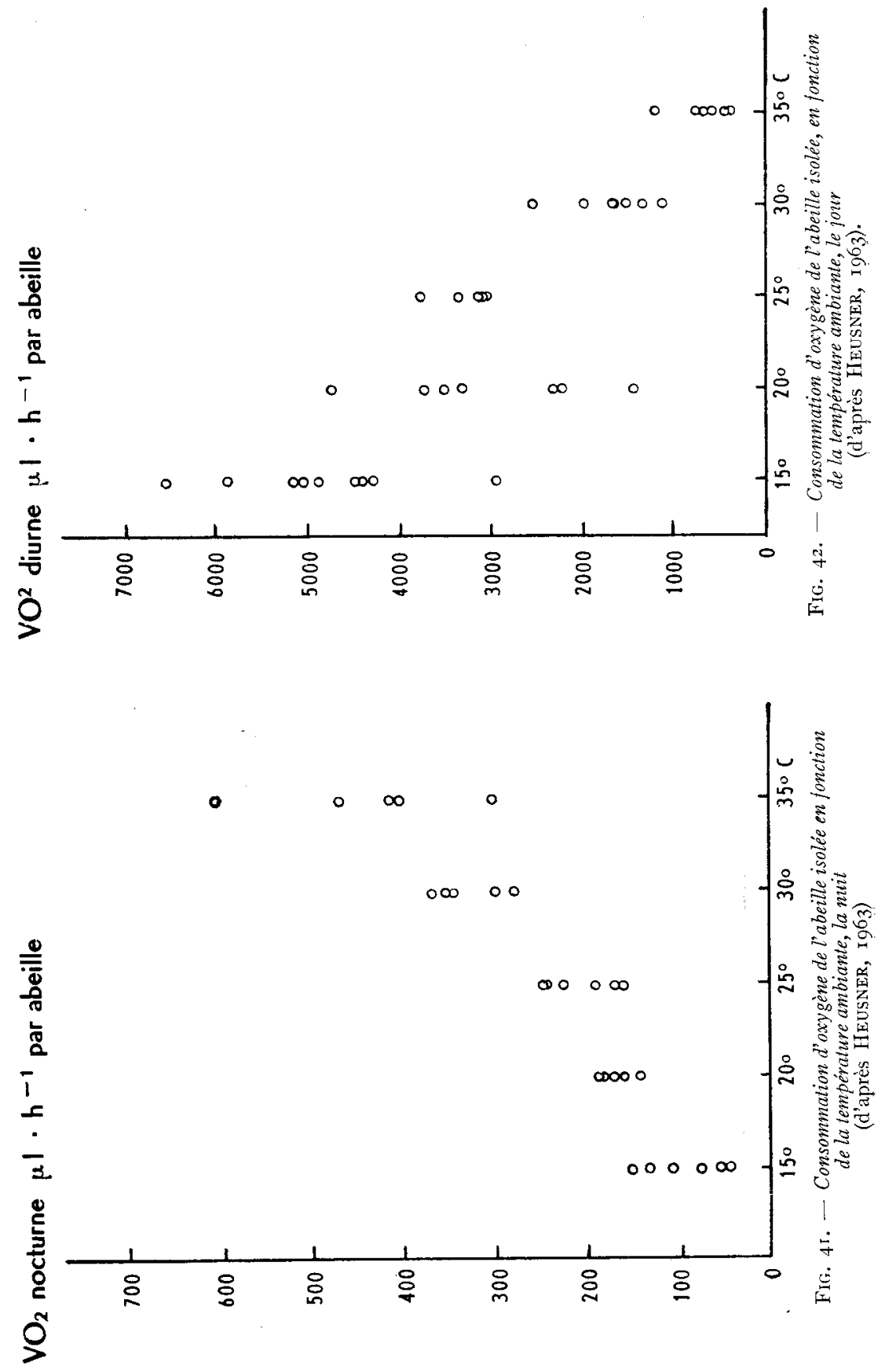




\section{$\$ 4$ Abeilles en conditions anormales}

a) Abeilles en atmosphère de gaz carbonique.

Pour réaliser ces conditions expérimentales, nous arons balayé l'atmosphère interne du calorimètre avec un jet de $\mathrm{CO}_{2}$. Les abeilles sont anesthésiées avec ce même gaz et glissées dans le calorimètre. La fermeture de ce dernier s'effectue toujours sous jet de $\mathrm{CO}_{2}$. Si l'opération est correctement réalisée, à l'ouverture du calorimètre, I/2 heure plus tard, les abeilles doivent être toujours inertes.

Dans ces conditions, nous avons obtenu des productions de chaleur appréciables de l'ordre de 0,07 à 0,09 calorie par abeille et par minute (en moyenne : 0,085 ).

L'anesthésie au $\mathrm{CO}_{2}$ n'a donc pas supprimé toute thermogenèse et la diminution des productions thermiques par rapport à la normale est sans nul doute imputable à une diminution de la consommation d'oxygène, soit à cause de sa raréfaction, soit par perturbation du rythme respiratoire.

Comme nous le verrons au chapitre IV, la privation totale d'oxygène n'entraîne d'ailleurs pas l'arrêt de la production de chaleur et, dans de telles conditions, les abeilles peuvent encore avoir une thermogenèse de cet ordre et qui ne peut s'expliquer par les faibles réserves des sacs aériens.

Ceci montre que l'accumulation de $\mathrm{CO}_{2}$ qui se produit dans la ruche ne gêne guère le métabolisme général des insectes, en particulier la régulation thermique de l'essaim.

\section{b) Abeilles anesthésiées au chloroforme.}

Nous avons expérimenté cette fois avec une atmosphère normalement oxygénée mais en plaçant une certaine quantité de chloroforme en surface de l'eau du calorimètre.

Avec deux ou trois gouttes de chloroforme seulement, qui anesthésient néanmoins les insectes, on obtient des productions de chaleur absolument normales : 0,25 à 0,30 calorie par abeille et par minute.

Si l'on introduit, dans le calorimètre, de plus fortes doses de produit $(\mathbf{r} / 2 \mathrm{cc}$ par ex.), on observe une baisse de la thermogenèse jusqu'à des valeurs oscillant entre 0,07 et $0, I_{3}$ calorie par abeille et par minute (en moyenne 0,09 ) mais en réalité on assiste ici à un début d'empoisonmement des insectes, car à ces fortes doses, un grand nombre d'abeilles meurt pendant ou après l'expérience.

\section{c) Abeilles en contention étroite.}

Il existe un procédé qui permet de priver les abeilles d'une oxygénation suffisante sans modifier les conditions normales de l'expérimentation et qui consiste à les serrer étroitement en grappe. Nous avons pris à cet effet, comme dans la plupart de nos essais, 25 abeilles. Nous les avons placées dans un petit morceau de tulle que 1'on replie et on ligote assez fermement le tout avec un fil à coudre enroulé en tous sens.

Il est bien connu que, chez l'abeille comme chez beaucoup d'autres insectes, l'abdomen joue un grand rôle dans la re-oxygénation en "pompant " littéralement l'air dans les trachées. Ces mouvements abdominaux sont particulièrement nets au moment de l'envol par exemple. 
Ainsi, très étroitement ligotées, les abeilles accomplissent sans doute plus difficilement ces mouvements. On enregistre alors des $Q / t / a$ variant de 0,06 à $0, \mathrm{I} 6$ calorie par abeille et par minute ( 0,09 en moyenne).

Nous retrouvons donc à peu près exactement les résultats obtenus en atmossphère de $\mathrm{CO}_{2}$ (en moyenne 0,085 calorie par abeille et par minute). Cela semble confirmer ce que nous avions déjà supposé : l'accumulation de $\mathrm{CO}_{2}$, anesthésiant les abeilles, n'a pas supprimé la thermogenèse, mais a probablement perturbé le rythme respiratoire et amoindri l'apport d'oxygène.

Ceci nous a conduit à effectuer des mesures en atmosphère d'azote pur.

d) Abeilles en atmosphère d'azote (voir chapitre IV.)

\section{Résumé du chapitre III}

La quantité de chaleur produite par les abeilles présente des variations très importantes suivant les conditions physiologiques ou écologiques expérimentales.

- Les abeilles en hivernage ont une production thermique plus faible, dans des conditions identiques (groupes de 25 insectes placés à $10^{\circ} \mathrm{C}$ ), que les abeilles testées à la belle saison, soit 0, I I calorie par abeille et par minute en moyenne au lieu de 0,26 .

Ramenés au laboratoire, ces insectes, correctement nourris et abreuvés, retrou1vent rapidement $(48 \mathrm{~h})$ une possibilite de production thermique normale.

- Les possibilités thermogènes des abeilles recueillies en périodes de grande sécheresse sont également faibles : 0,12 à 0,26 calorie par abeille et par minute.

- La capacité de production de chaleur d'une abeille varie suivant son âge. Elle est faible à la naissance ( 0,05 calorie par abeille et par minute environ) et croît régulièrement par la suite : 0,28 calorie par abeille et par minute pour des abeilles âgées d'environ 15 jours, 0,36 pour des butineuses nourries et abreuvées avant expérimentation.

- La production de chaleur est très forte et très hétérogène pout des abeilles isolées ( $0, \mathrm{I}$ à 0,98 calorie par abeille et par minute dans le cas de nos expériences). Lorsqu'on augmente le nombre des abeilles placées ensemble dans la chambre calorimétrique, l'hétérogénéité des résultats diminue par simple compensation arithmétique d'une part, mais aussi sous l'influence d'un effet de groupe régulateur. Cet effet de groupe est également dépresseur du métabolisme et les moyennes de production de chaleur s'abaissent progressivement pour se stabiliser aux environs de 0,26 calorie par abeille et par minute, à partir d'une importance numérique de 20 insectes environ par lot d'abeilles testé.

- Cet abaissement, d'origine sociale, du métabolisme, occasionne pour l'essaim une remarquable économie de matières énergétiques.

- L'intensité de la thermogenèse est fonction de la température ambiante ; le dégagement de chaleur par unité de temps est d'autant plus faible que la température ambiante se rapproche du thermopreferendum. Ce comportement à tendance homéotherme ne se réalise qu'en période diurne. La nuit, le phénomène est inversé ; comme tous les poïkilothermes, les abeilles présentent alors un métabolisme variant dans le même sens que la température ambiante. Cette énergie mise en jeu en période nocturne est dix fois plus faible qu'en période diurne.

- Anesthésiées, les abeilles conservent une possibilité de thermogenèse environ trois fois plus faible que la normale. 


\section{CHAPITRE IV}

\section{$\S$ I Résultats obtenus par respirométrie.}

On peut, à bien des points de vue, considérer l'abeille isolée comme un insecte à réactions aberrantes, par rapport aux insectes non sociaux du moins.

Nous avons cependant, avec HEUSNER, testé au respiromètre des abeilles isolées, afin d'observer quelles peuvent être les possibilités thermiques de " l'unitéabeille $)$.

Nous avons pu tracer le tableau suivant :

\begin{tabular}{|c|c|c|c|c|c|c|}
\hline \multirow{2}{*}{$\begin{array}{l}\text { Températ. } \\
\text { pendant l'ex- } \\
\text { périence (en } \\
{ }^{\circ} \mathrm{C} \text { ) }\end{array}$} & \multirow{2}{*}{$\begin{array}{l}\text { Nombre d'a- } \\
\text { beilles testees } \\
\text { (une par une) }\end{array}$} & \multirow{2}{*}{$\begin{array}{l}\text { Poids moyen } \\
\text { des insectes en } \\
\text { début d'expér. } \\
\text { (en mg) }\end{array}$} & \multicolumn{4}{|c|}{$\begin{array}{c}\text { Consommation moyenne d'oxygène } \\
\text { (en ml/abeille/heure) }\end{array}$} \\
\hline & & & $\begin{array}{c}\text { pendant toute } \\
\text { la durée de } \\
\text { l'exp. }\end{array}$ & $\begin{array}{l}\text { pendant la } 1^{\text {re }} \\
\text { phase cliurne }\end{array}$ & iphase nocturne: & $\begin{array}{l}\text { pendant la } 2 \text { e } \\
\text { phase dirune }\end{array}$ \\
\hline 20 & 7 & $125=23^{*}$ & $1,60 \pm 0,12^{* *}$ & $3,05=0,1$ & $0,216=0,05$ & $1,73 \doteqdot 0,50$ \\
\hline 30 & 7 & $135=15$ & $0,99=0,11$ & $1,69=0,17$ & $0,315=0,013$ & $0,96=0,09$ \\
\hline 35 & 7 & $119=16$ & $0,5^{\prime}=0,06$ & $0,68=0,10$ & $0,46 \quad \ldots 0,06$ & $0, \overline{3} 3=0 / 05$ \\
\hline
\end{tabular}

* Écart-type. ** Erreur-type.

Ces expériences ont été réalisées dans de petits récipients à température constante et dans lesquels l'abeille avait à sa disposition un petit tube de miel. Les essais ont donc pu être de longue durée et nous ont apporté ainsi deux faits nouveaux.

Ainsi que nous l'avons signalé au chapitre précédent, nous voyons tout d'abord qu'il existe une différence de la thermogenèse entre le jour et la nuit, l'abeille se comportant à la façon d'un homéotherme le jour, d'un poïkilotherme la nuit, avec, pendant cette dernière période, un métabolisme beaucoup plus faible.

La courbe que l'on peut en déduire présente donc un aspect cyclique avec des valeurs rapidement décroissantes d'ailleurs car, ainsi isolée, la physiologie de 1'abeille est assez perturbée après quelques 24 heures.

Remarquons également que, tout au moins pour des températures assez élevées, $30^{\circ} \mathrm{C}$ par exemple, les insectes sont susceptibles de conserver une thermogenèse importante pendant des temps très longs.

Nous indiquons ci-dessous les consommations enregistrées au cours d'une expérience effectuée à une température de $30^{\circ} \mathrm{C}$ pour un groupe de roo abeilles. Chaque 


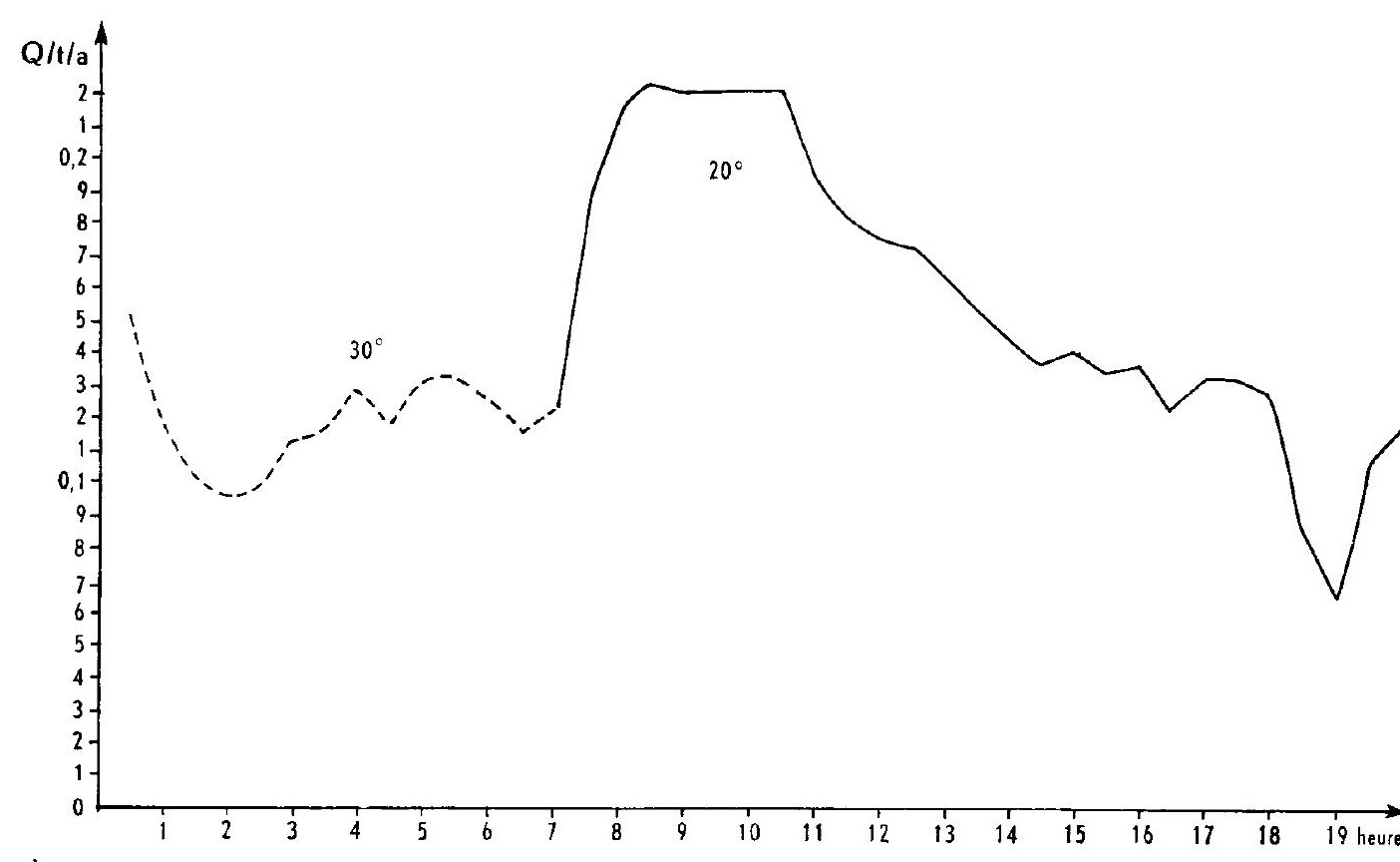

FIG. 43. - Courbe respirontétrique d'un groupe d'abeilles

subissant unelbaisse de température ambiante de 30 à $20^{\circ} \mathrm{C}$ (période diume)

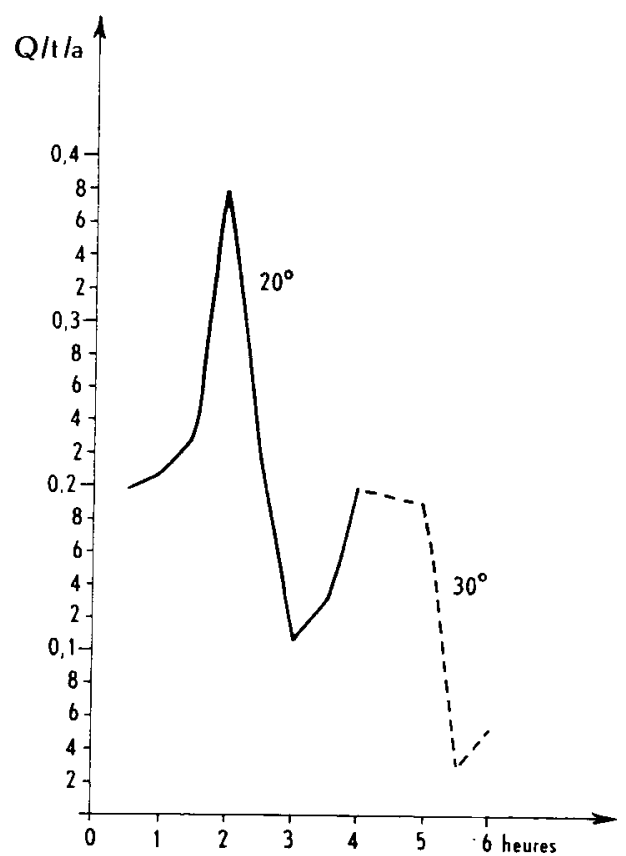

FIG. 44. - Courbe respironétrique d'un groupe d'abeilles subissant une augmentalion de température ambiante de 20 à $30^{\circ} \mathrm{C}$ (période diurne) 
chiffre représente le résultat obtenu au cours d'une mesure de 3 minutes et indique la consommation moyenne en millilitres de $\mathrm{O}_{2}$ par abeille et par heure, pendant cette période.

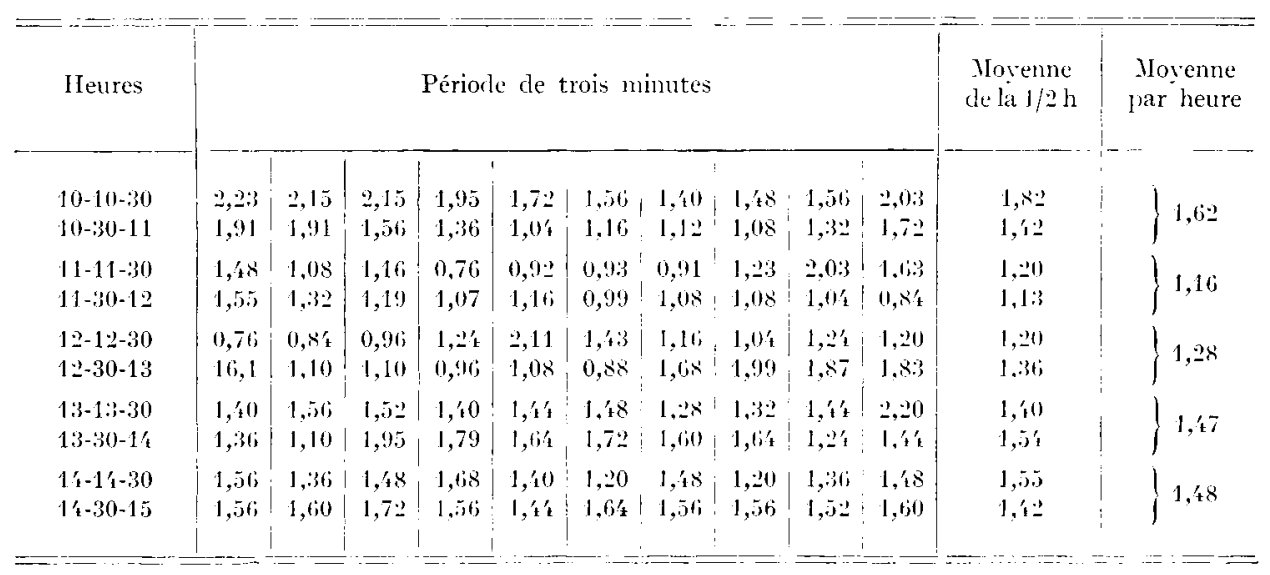

Nous avons pu maintenir ainsi des lots de roo abeilles en parfait état de productivité thermique pendant plus de 24 heures. MIais cela n'a pas été le cas général et, en particulier pour une ambiance de $20^{\circ} \mathrm{C}$, nous sommes parvenus à épuiser les insectes qui, ayant sans doute utilisé leurs réserves thermogènes, ne consommaient presque plus d'oxygène après 2 à 3 heures. tement.

Les courbes ci-dessus (fig. 43 et 44 ) traduisent bien ces différences de compor-

D'autre part, ces expériences de respirométrie nous ont permis de recouper les résultats qualitatifs et quantitatifs obtenus en calorimétrie directe.

a) Effet de groupe.

Nous retrouvons l'effet dépresseur du métabolisme occasionné par le groupement.

En effet, si nous comparons les essais effectués avec des groupes de roo abeilles et les expériences réalisées avec des abeilles seules, nous pouvons dresser le tableau suivant :

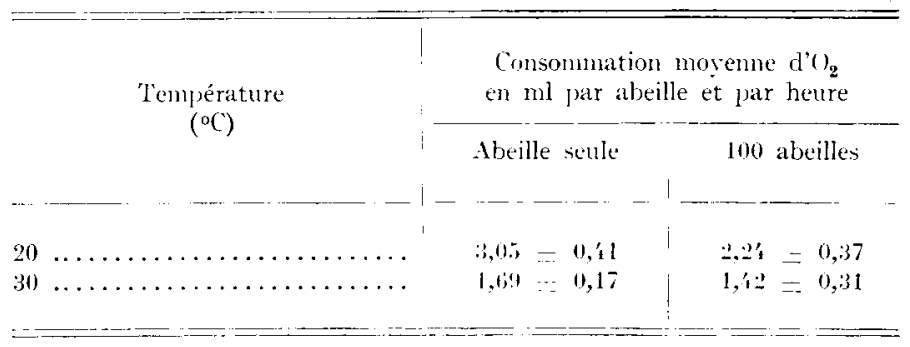

$N . B .-$ Nous sommes ici en $\mathrm{I}^{\mathrm{re}}$ phase diurne, les expériences arec des groupes de roo abeilles n'ayant été réalisées que dans ces conditions. 
b) Adaptation de la thermogenèse à la température ambiante.

Nous pourons comparer les productions de chaleur obtenues à ro, 20 et $30^{\circ} \mathrm{C}$ par les deux méthodes, soit pour des groupes d'abeilles, soit pour des abeilles seules.

Traduisons donc en calories par abeille et par minute, les résultats volumétriques obtenus par respirométrie.

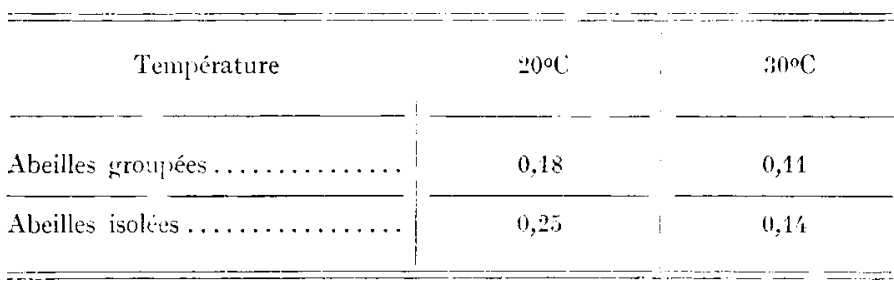

Nous comparons, dans le tableau ci-dessous, ces résultats avec ceux obtenus par les méthodes calorimétriques :

\begin{tabular}{|c|c|c|c|c|}
\hline \multirow{4}{*}{ a) Abeilles groupées } & & calorimétrie & Q///a moyen = & 0,09 \\
\hline & $\mathrm{A} 30^{\circ} \mathrm{C}$ & respirométrie & $(2 / t / a$ moven $=$ & 0,11 \\
\hline & \multirow{2}{*}{$A=0$} & calorimétrie & (9)/t/a moyen = & 0,18 \\
\hline & & respirométrie & Q/t/a moyen = & 0,18 \\
\hline \multirow{4}{*}{ b) Abeilles seules } & & calorimétrie & $Q / t / a$ moven $=$ & $0,1_{t}^{\prime}$ \\
\hline & $\mathrm{A}: 30^{\circ} \mathrm{C}$ & respirométrie & $\mathrm{Q} / \mathrm{t} / \mathrm{a}$ moyen $=$ & $0,1^{\prime}$ \\
\hline & \multirow{2}{*}{$A \geq 0$ C } & calorimétrie & Q///a moven $=$ & 0,36 \\
\hline & & respirométrie & Q $/ / / a$ moven $=$ & 0,25 \\
\hline
\end{tabular}

Il n'y a donc guère que pour les deux dernières valeurs que l'on observe une différence notable entre les mesures respirométriques et les mesures calorimétriques. Mais lors d'essais ultérieurs, Heusner a trouré, pour $25^{\circ} \mathrm{C}$, une consommation d'oxygène correspondant à un $Q / t / a$ de 0,27 . Donc en supposant que, dans les conditions les plus simples, l'augmentation du métabolisme soit simplement linéaire, c'est un $Q / t / a$ de $: 0,27+\left(0,27-0, I_{4}\right)=0,40$ qui aurait dû être trouvé. Il ne peut donc s'agir ici que d'une erreur dans les mesures respirométriques.

\section{c) Aspect qualitatif de la thermogenèse.}

$\mathrm{Si}$ nous observons les courbes (fig. 43 et 44), nous retrouvons les données fournies par le calorimètre électrique CALVÉT. Nous retrouvons par exemple pour une température de $30^{\circ} \mathrm{C}$, un aspect approximativement cyclique et des valeurs moyennes. Pour $20^{\circ} \mathrm{C}$, nous observons également un pic assez fort en début de mesure, suivi d'une courbe approximativement cyclique mais de valeurs plus faibles. 
L'épuisement des insectes est d'ailleurs tel que, replacés à $30^{\circ} \mathrm{C}$, ils ne peuvent alors fournir la production thermique habituelle à cette température.

En ce qui concerne la notion de " chaleur statique " et de " chaleur avec mouvements ", nous avons pu cette fois, observer directement le phénomène car les récipients dans lesquels les groupes étaient mis en expérience étaient en verre.

Ainsi, on peut constater qu'à $30^{\circ} \mathrm{C}$, les abeilles s'agitent beaucoup, vont et viennent, tentent de voler... et ceci se traduit par une consommation d'oxygène de l'ordre de I,I3-I,I5 $\mathrm{ml}$ par abeille et par heure. Par contre, à $20^{\circ} \mathrm{C}$, les abeilles se groupent et la plupart sont parfaitement immobiles ; la consommation d'oxygène est alors fréquemment de l'ordre de 2,25 à $2,40 \mathrm{ml}$ par abeille et par heure.

On voit ainsi toute l'importance du phénomène de régulation thermique spécial à ces insectes qui ainsi, sans mouvements apparents, sont susceptibles d'une telle production de chaleur.

\section{$\S 2$ Production de chaleur en anaérobiose}

Il est très important de savoir s'il est possible de considérer comme valable la transposition : volume d'oxygène consommé $=$ dégagement calorique.

Certaines écoles de physiologie énergétique considèrent qu'il y a liaison absolue entre volume d'oxygène consommé et dégagement de chaleur. De là, on passe très facilement à l'idée que la calorimétrie directe, si fastidieuse et délicate, se trouve périmée devant la respirométrie. Il suffit de mesurer le volume d'oxygène absorbé et de transposer grâce à la relation :

\section{I litre $\mathrm{O}_{2}=5$ kilocalories.}

Il n'en est cependant rien, et cette trop facile équation ne doit être utilisée qu'avec prudence. Il est normal d'admettre que toute la production calorique d'un animal trouve sa source dans une absorption originelle d'oxygène, mais les processus d'absorption de $\mathrm{O}_{2}$ et de production de chaleur peuvent ne pas être concomitants et être même très décalés dans le temps ( $\left.{ }^{1}\right)$,

Mises dans des respiromètres pourvus d'un appareil annexe producteur d'oxygène, les abeilles réagissent d'une façon telle que l'on peut, sans doute, transposer les résultats et établir des chiffres de production thermique calculée. La concordance des résultats que nous avons obtenus au calorimètre et au respiromètre, semblent le prouver, mais en est-il de même dans la ruche à l'atmosphère si confinée? Il semble en tout cas que ce n'est pas le cas de certaines de nos expériences dans lesquelles la quantité d'oxygène était très réduite ou nulle.

Comme l'ont montré des expériences en atmosphère d'azote, il semble exister chez l'abeille, une possibilité d'utilisation de réactions diastasiques en anaérobiose. Les processus de glycolyse sont d'ailleurs maintenant assez bien connus et nous rappelons ci-après, d'une façon très résumée, le schéma de EMBDEN-MEYERHOF, chez les insectes.

Chez les mammifères et in vitro, on arrive en fin de cycle à l'acide lactique. Chez

( ${ }^{1}$ De plus, cette équation ne vaut que pour les glucides et il ne faut pas oublier que le $Q_{r}$ varie suivant la température. 
les insectes, 1a réaction est souvent plus limitée et on aboutit plutôt à l'a-glycérophosphate comme le montre le tableau ci-après extrait du traité " The biochemistry of insects" de Darcy Grimour.

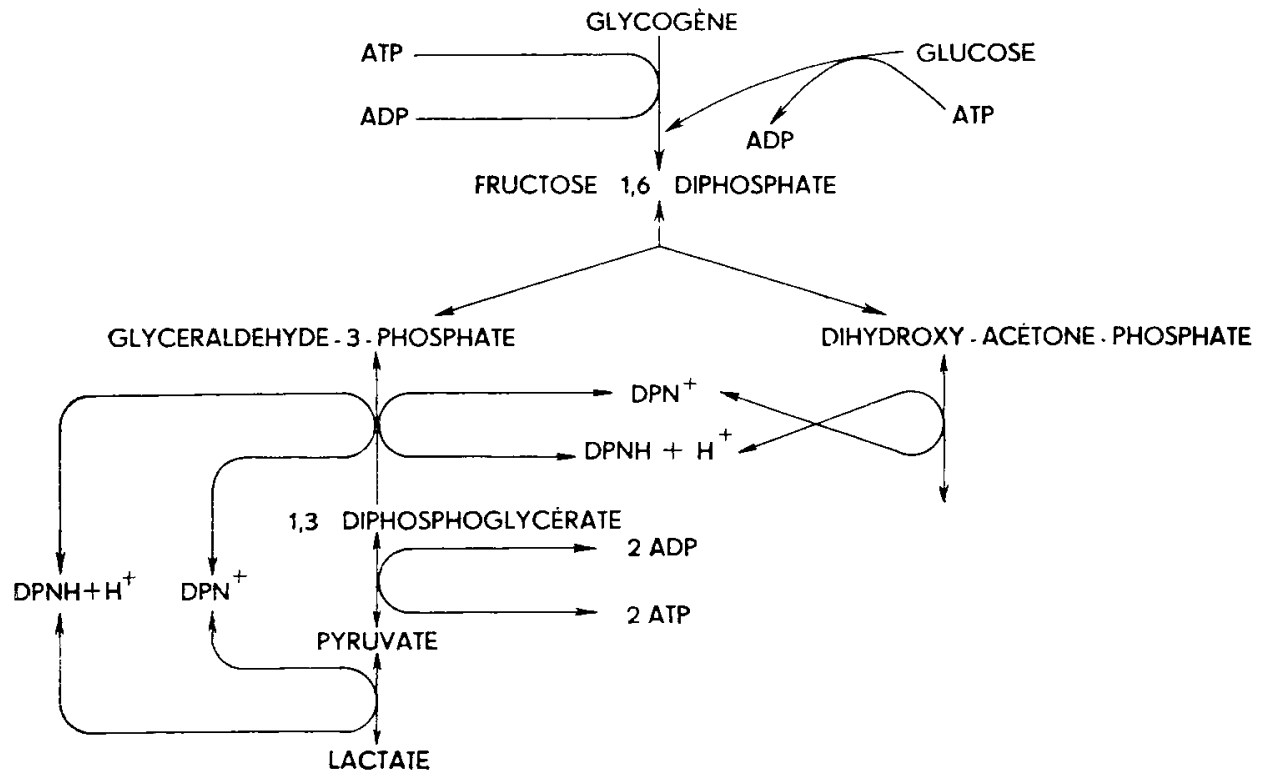

Fig. +5. - Schéma de EMbuex-MIESERIIOF

Tableau extrait du traité "The biochemistry of insects " de DARCY GILMOUR Activité dans les muscles thoraciques:

\begin{tabular}{|c|c|c|}
\hline Genres & $\begin{array}{l}\text { Activité de l' } \alpha \text {-gly- } \\
\text { cérophosphate dé- } \\
\text { hydrogénase en uni- } \\
\text { tés arbitraires }\end{array}$ & $\begin{array}{l}\text { Activité de la lacti- } \\
\text { que déhydrogénase }\end{array}$ \\
\hline Phormic $\ldots \ldots \ldots \ldots \ldots \ldots$ & 613 & 4 \\
\hline 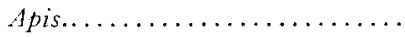 & 800 & 3 \\
\hline 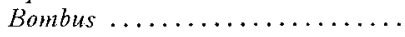 & T光 & 3 \\
\hline 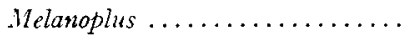 & 313 & 40 \\
\hline
\end{tabular}

Ceci est également démontré par le fait que la quantité d'acide lactique trouvée n'équilibre jamais celle du glycogène disparu ; mais d'autres inconnues jouent certainement encore dans ce domaine.

Il faut donc, à propos de ces processus, parler "d'oxygénation " mais dans un sens très large : oxygénation vraie ou déhydrogénation ou même simplement peutêtre transfert de charges électroniques. De ce fait, il peut se produire des réactions métaboliques en anaérobiose totale. 
C'est ce que nous avons pu montrer en plaçant du pyrogallol dans la chambre aérienne et dans l'eau de nos calorimètres.

Dans ces conditions, nous avons observé que la production de chaleur persistait, plus faible, un peu supérieure à la moitié de ce qu'elle est normalement, c'està-dire $0, I_{5}$ à $0, I 9$ calorie par abeille et par minute au lieu cle 0,26 en movenne (pour des groupes de 25 abeilles placés dans une chambre à $10^{\circ} \mathrm{C}$ ).

On peut penser (ue ce procédé de déoxygénation n'est pas suffisamment efficace : d'ailleurs, en absence totale d'oxygène, les abeilles sont inertes, ce qui n'était pas le cas au cours de ces expériences.

Aussi avons-nous repris ces essais en atmosphère d'azote pur, le critère d'une parfaite étanchéité de nos calorimètres étant précisément la parfaite immobilité des insectes durant tout le temps de l'expérience.

Nous avons alors trouvé des $Q / t / a$ variant de 0,020 à 0,035 avec une moyenne de 0,029 calorie par abeille et par ninute $(1)$, toujours dans les conditions expérimentales définies ci-dlessus.

Rappelons qu'un $\mathrm{g} / \mathrm{t} / \mathrm{a}$ normal moyen est de 0,26 .

Mais dans les conditions normales, les abeilles sont éveillées.

Il serait donc plus logique de comparer ces $Q / t / a$ obtenus en azote à des $Q / t / a$ obtenus en atmosphère normale avec des insectes anesthésiés.

Si nous considérons donc la production thermique moyenne obtenue avec anesthésie au chloroforme, soit 0.00 et la production en atmosphère d'azote, on peut calculer que la production therniquue en absence d'oxygène est de $\frac{0,029}{0,000}$ soit 32 p. roo environ de ce qu'elle est en présence d'oxygène.

Or, si nous considérons le cycle d' EMBDEX-MEYERHOF, nous voyons que l'énergie est issue du substrat à 2 échelons, d'abord lors de la déhydrogénation du glycéraldehyde-3-phosphate et dans la déshydratation de l'acide-2-phosphoglycérique.

On peut calculer alors que 30 p. 100 environ de l'énergie mise en jeu dans la glycolyse est conservée sous une forme capable de produire du travail dans l'organisme (d'après I). Girmour).

Ces calculs recoupent donc d'une façon assez satisfaisante nos résultats expérimentaux (qui montrent les extraordinaires possibilités de production d'énergie que peuvent utiliser les insectes en cas de manque ou de ra réfaction de l'oxygène.

Ajoutons que l'on a proposé également un cycle des pentoses (HORECKER) mais il reste hypothétique, on pense également qu'il existe chez les insectes des "lipidolyses" car les corps gras sont une des plus inportantes réserves de leur organisme.

L'abeille et la drosophile ont un quotient respiratoire $Q_{k}=$ I et consomment du glycogène, elles peuvent maintenir leur vol tant que le taux des réserves de ce carbohydrate n'atteint pas un seuil inférieur critique. Les graisses ne semblent pas intervenir ici, mais s’il en est de même chez $C$ mlex celui-ci peut, pendant des périodes de repos, reconstituer un "carburant " efficace et cela aux dépens des graisses.

Infin criquets et papillons, pendant leur vol, "brûlent " leurs graisses et consomment peu d'oxygène $\left(Q_{\mathrm{R}}\right.$ Schistocerca $=0,75$ à 0,$82 ; Q_{\mathrm{R}}$ Lépidoptères $\left.=0,73\right)$, même s'ils sont gorgés de glucose.

(1) On peut admettre que les abeilles étaient pourves d'une certaine réserve d'air. emmasasince dans les sacs aériens fort importants chez ces insectes, malgré cela une sommaire estimation du volume d'air ainsi utilisable permet de constater que l'on ne peut expliquer de cette ficon une aussi forte attivité thermique (25 abeilles totalisent un volume corporel frobal de $3\left(\mathrm{~cm}^{3}\right)$. 
Il y a donc de multiples possibilités pour les insectes de produire de l'énergie et toutes ces réactions sont susceptibles de se réaliser en anaérobiose.

L'intervention de l'oxygène aurait surtout pour effet de limiter ces réactions, d'arrêter par exemple la glycolyse au niveau des diphospho- ou glycérophosphates, sans aller jusqu'à l'acide lactique. L'action de l'oxygène peut donc être, chez les insectes, sporadique et nos expériences ont montré que cela est très naturel chez les abeilles. Il serait donc vain de relier impérativement production de chaleur et consommation d'oxygène si l'on ne prend pas soin de bien préciser les conditions expérimentales.

\section{Résumé du chapitre IV}

Les expériences de respirométrie que nous avons effectuées avec des abeilles placées dans de bonnes conditions d'oxygénation, nous ont permis cle confirmer tous les résultats, tant qualitatifs que quantitatifs, obtenus avec les calorimètres Berthelot et le calorimètre électrique CALVET.

Les expériences faites en anaérobiose, en l'occurrence en atmosphère d'azote pur, ont montré que les abeilles conservent, clans ces conditions, de remarquables possibilités de thermogenèse. Si l'on compare ces productions de chaleur à celles d'abeilles en parfaite condition d'oxygénation (et également anesthésiées), on constate qu'elles représentent en moyenne environ 32 p. roo de ces dernières. Ceci correspond très bien à la théorie sur les réactions de glycolyse enzymatiques, pour lesquelles on peut calculer que $30 \mathrm{p}$. roo de l'énergie totale mise en jeu peuvent être utilisés à des fins effectivement énergétiques.

\section{CONCLUSION GÉNÉRALE}

Nous ne reviendrons pas, dans cette conclusion, sur les variations du pouvoir thermogène des abeilles en rapport avec les diverses contingences physiologiques étudiées, nous insisterons seulement sur l'aspect social du phénomène et sur son type homéotherme.

Ce processus thermogène si particulier est avant tout un phénomène social. Une abeille isolée produit de la chaleur, elle n'en produit pas d'une façon désordonnée, l'intensité de cette production est liée à la température ambiante, mais le dégagement de chaleur est très intense : très rapidement, 1'insecte épuise ses réserves énergétiques et finit par mourir si on le laisse exposé au froid.

Dans le cas de l'essaim, le phénomène se présente d'une façon tout à fait différente et qui assure la survie de la colonie d'abeilles.

En effet, il existe $u n$ effet de groupe dépresseur d $u$ métabolisme qui fait que chaque insecte produit moins de calories qu'à l'état isolé dans le même temps et dans les mêmes conditions ambiantes. Ce phénomène dépresseur est compensé par le fait que les abeilles exposées au froid forment ce que l'on appelle en termes d'apiculture "la grappe ". L'ensemble des abeilles constitue alors une masse thermiquement isolée de l'air ambiant par la couche externe des insectes et une faible production thermique suffit alors à entretenir, au sein de ce groupe, une température vitale. 
On sait d'ailleurs que, l'hiver, un lent mouvement de brassage amène les insectes situés à la périphérie vers l'intérieur et réciproquement.

Ces phénomènes sociaux concourent donc à réaliser une remarquable économie de matière alimentaire et à entretenir dans la masse d'insectes, une température suffisante pour que l'essaim survive à l'hivernage.

Mais le phénomène le plus inattendu que nous ayons pu mettre en évidence est que les abeilles se comportent à la façon d'homéothermes (tout au moins pendant les périodes diurnes, comme nous l'avons vu au chapitre III).

On peut cependant observer que, comme tous les insectes, les abeilles s'agitent beaucoup quand la température augmente et tendent à devenir immobiles quand elle diminue. Le métabolisme lié aux mouvements musculaires suit les règles générales des poïkilothermes.

C'est donc uniquement le processus thermogène spécial à ces insectes et qui consiste en une microvibration des muscles thoraciques qui les situe dans le type homéotherme.

Cette considération n'est d'ailleurs pas absolument rigoureuse. Si l'on place une abeille suffisamment longtemps dans une atmosphère de température suffisamment froide, après quelque temps l'insecte est incapable de surmonter cette épreuve, sa température interne s'abaisse rapidement et la mort peut survenir.

Il faut considérer qu'à l'inverse de la fourrure des mammifères ou du plumage des oiseaux, la cuticule de l'abeille n'est guère thermo-isolante; aussi les réserves énergétiques de l'insecte sont-elles vite épuisées.

Aussi proposerons-nous, avec Himner, de classer les abeilles dans les hétérothermes, suivant la définition de WEIXLAxD : "les hétérothermes sont des animaux dont la température interne est soumise à d'importantes variations, mais qui sont en mesure d'engendrer de la chaleur au point que leur propre température peut s'élever, suivant les circonstances et les besoins, à différents degrés ».

\section{RÉSUMÉ}

La température qui règne dans une ruche d'abeilles domestiques, toujours plus élevée que celle de l'air ambiant, est le résultat d'une production thermique de ces insectes.

Cette production thermique a son origine dans une activité musculaire des abeilles, mais cette activité est extrêmement particulière : elle consiste en une microvibration des muscles thoraciques, indécelable par des moyens mécaniques ordinaires et qui serait, en quelque sorte, l'homologue du frisson des nnammifères. Une abeille parfaitement immobile peut ainsi produire un fort dégagement de chaleur.

Nous avons mesuré cette production thermique dans différentes conditions expérimentales tant écologiques que physiologiques.

Nous avons utilisé, pour ce faire, des méthodes calorinétriques (calorimètre adiabatique de BERTHELOT, calorimètre isothermique électrique de CALVET) et des méthodes respirométriques.

Une abeille isolée, en conditions normales de satiété et d'oxygénation, placée à une température légèrement supérieure à la température de stimulation $\left(\mathrm{i} 3^{\circ} \mathrm{C}\right)$, peut produire, en moyenne, pendant un laps de temps de quelque vingt minutes, une quantité de calories égale à 0,65 calorie par minute.

Des abeilles groupées ont une production thermique individuelle moins importante, car ces insectes, placés à basse température, se groupent étroitement, créant au sein de la "grappe "ainsi formée une température plus élevée, moins stimulante. La production thermique est alors en moyenne de 0,26 calorie par abeille et par minute. 
Il est en effet remarquable de constater que ce dégagement de chaleur est lié à la température ambiante et d'autant plus faible que celle-ci est plus proche du thermopreferendum $\left(35-36^{\circ} \mathrm{C}\right)$.

Comme l'ont montré certaines expériences récentes de respirométrie, cette réaction de type homéotherne se produit le jour, le phénomène est inversé la nuit, le métabolisme décroissant alors avec la température ambiante comme chez tous les poïkilothermes.

Il intervient d'ailleurs, dans ces phénomènes, en effet de groupe. dépresseur du métabolisme perceptible dès que l'on place deux abeilles en présence. Te dégagement thermique individuel d'abeilles groupées est donc plus faible que celui d'abeilles isolées du fait à la fois de cet effet de groupe et de la température plus clémente qui existe au sein d'une grappe comme nous l'avons vu précédemment. Il nous a été impossible d'expérimenter avec des groupes d'abeilles à une températures inférieure à la température de stimulation en raison précisément de la chaleur produite. Cela nous a cependant été possible avec des insectes isolés : nous avons constaté alors que la production thermique est, cette fois, très faible ; l'abeille est engourdie et ne réagit guère au stimulus thermique.

Cette production thermique peut également être modifié par des conditions physiologiques. Jes résultats que nous allons indiquer ci-dessous sont tous relatifs à des groupes d'abeilles placés à une température ambiante à peine supéricure à la température de stimulation.

Les abeilles en hivernage produisent moins de chaleur que les abeilles mises en expérience à la belle saison (0,10 à 0,12 calorie par abeille et par minute). Ceci est lié uniquement à un déficit de réserves énergétiques dans l'organisme ; ramenées au laboratoire et bien approvisionnées en " candi ", ces abeilles retrouvent rapidement ( 48 heures) une production normale $(0,26$ calorie par abeille et par minute).

De la même façon, des abeilles mises en expérience en période de forte chaleur et sécheresse ont produit beaucoup moins de calories ( 0,12 à 0,26 calorie par abeille et par minute), mais retrouvent également leur pouvoir thermogène normal après avoir été nourries et abreuvées.

Cette capacité thermogène n'est pas l'apanage des "nourrices " comme on pourrait le penser. Elle est très faible à la naissance et croît lentement, pour prendre sa valcur habituelle $(0,26$ calorie par abeille et par minute) après le $\mathrm{I}_{5}^{\mathrm{e}}$ jour.

On peut constater cependant que les butineuses mises en expérience produisent moins de chaleur, toujours dans les conditions définies ci-dessus, que les jeunes abeilles prélevées au coeur de la ruche. Il s'agit cette fois encore d'un déficit de réserves énergétiques, placées en cagettes, bien nourries ne serait-ce que I 5 à 20 minutes, ces butineuses remises en expérience ont montré un pouvoir thermogène normal, même un peu supérieur à la moyenne, soit : 0.36 calorie par abeille et par minute.

Des abeilles décapitées ont une production thermique extrềmement faible : 0,02 I à 0,024 calorie par abeille et par minute, le réflexe thermogène n'est donc pas sous la dépendance unique des ganglions thoraciques, le cerveau y participe d'une façon prépondérante (dans les mêmes conditions, les réflexes locomoteurs persistent).

Des abeilles anesthésiées conservent une production thermique appréciable : $0,07 a$ à 0,09 calorie par abeille et par minute avec du gaz carbonique, 0,07 à $0, \mathbf{I} 3$ avec du chloroforme.

Enfin, en anaérobiose (atmosphère d'azote) et toujours dans les mêmes conditions expérimentales définies ci-dessus, les abeilles sont parfaitement capables de produire de la chaleur. Cette production représente habituellement 32 p. roo de ce qu'elle est en conditions normales d'oxygénation. Ce chiffre correspond à ce que l'on peut attendre d'une réaction de glycolyse diastasique ; d'après le cycle d'Embuen-MeYerohfF, on peut en effet calculer qu'une telle réaction pcimet de conserver à des fins effectivement énergétiques, $30 \mathrm{p}$. Ioo de l'énergie totale mise en jeu, ct qui serait presque intégralement utilisable en présence d'oxygène.

\section{SUMMARY}

\section{THe production of heat BY Apis mellifica $\mathrm{L}$.}

The temperature prevailing in a bee-hive is always higher than that of the ambient air as a result of heat production by the insects. This heat is due to an extremely specific muscular activity of the bees. It consists of microvibration of the thoracic muscles, which cannot be detected by ordinary mechanical means and which is to some extent analogous to the shivering of mammals. A completely immobile bee can in this way liberate a great deal of heat.

We have measured the heat produced under different experimental conditions. In order to do this, we used calorimetric methods (Berthelot's adiabatic calorimeter, CALVET's electric isothermal calorimeter) and respirometric methods. 
In isolated bee in normal conditions of satiets and oxyen supply, placed in a temperature slightly higher than the stimulation temperature $\left(13^{\circ} \mathrm{C}\right)$, can produce on average 0.65 calorie per minute over a period of some twenty minutes. The heat produced by one of a group of bees is however smaller, for these insects cluster logether when placed in a low temperature, creating in the middle of the cluster a higher, less stimulating temperature. In this case the heat produced is on average 0.26 calorie per bee per minute. It is remarkable that this heat liberation is related to the ambient temperature, declining when the thermal optimum $\left(35-360^{\circ} \mathrm{C}\right)$ is approached.

Certain recent respironetric experiments have shown that this homeothermic reaction occurs during the day, while at night the metabolic rate decreases with the ambient temperature, as with all poikilothermic animals.

Added to these phenomena, there is a group elfect. which is a metabolic depressant, perceptible as soon as one places two bees together. The heat liberated by individuals in a cluster is thus smaller than that liberated by isolated becs. owing buth to the group effect and to the more clement temperature that exists in the middle of the cluster. It has been impossible for us to experiment with groups of bees at a temperature lower than the st imulat ion tomperature. because of the heat produced. This was however possible with isolated insects, when the heat production was found to be very weak ; the bees were torpid and hardly reacted to the thermal stimulus.

This heat production can also be modified by physiological factors. (The results given below all relate to groups of bees placed in an ambient iemperature only slightly greater than the stimulation temperature.) For example, wintering bees pruduce less heat than the bees experimented with in fine weather (0.10 to 0.12 calorie per bee per minute). This is linked solely to the deficit of energy reserves in the organism; re-established in the laboratory and well provisioned with " candy ", these bees in 48 hours recovered their nomal heat production of 0.26 calories per bee per minute. In the same way, at high temperatures and low humidity, bees produced far fewer calories (0.I 2 to 0.26 calories per bee per minute), but recovered their nomal themogenet ic power when provided with food and water.

This thermogenetic power is not, as might be thought, the natural accompaniment of nourishment. It is very weak at emergence, and increases showly, reaching its usual value (o.26 calorie per bee per minute) after the I 5 th day. It can however be stated that foraging bees produced less heat (always under the conditions defined above) than the young brought up in the heart of the hive. This is again explained by a deficit of the energy reserves. When placed in small cages, well nourished if only for 5 to 20 minutes, these foraging bees again showed a normal thermogenetic capacity, cven a little greater than average, i. e. 0.36 calorie per bee per minute.

l)ecapitated bees have an extremely weak heat procluction -- 0.02 I to 0.024 calorie per bee per minute. The thermogenetic reflex does not therefore depend solely on the thortcic granglions, the participation of the brain being predominant (under the sane conditions, the motor refleves persist.)

Anæesthetised bees retain appreciable heat production $: 0.07$ to 0.09 calorie per bee per minute in carbon dioxide, 0.07 to 0.13 in chloroform.

Finally, under anaerobiosis (in an atmosphere of nitrogen) and always under the experimental conditions defined above, the bees were perfectly capable of producing heat. 'This production usually represented $32 \%$ of its value under nomal oxygen supply. This figure corresponds to what one would expect from a diastasic glycolysis reaction; from the Embden-Meyerhoff cycle, it is possible to calculate that such a reaction allows the conservation, for eflectively energetic ends, of $30 \mathrm{p} .100$ of the total energy involved, which would be almost entirely utilisable in the presence of oxygen.

\section{RÉFÉRENCES IBIBLIOGRAPHIQUES}

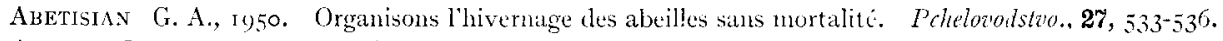

AGRELL I., 19+7. Some experiments concurning themal adjustment and respiratory metabolism in inserts. Arch. Zool., 39, 1-48.

ALles W. R., 1959. Respiration rates of worker honey bees of different arges and at different temperatures. J. Exper. Biology, 36 (1), 92-10I.

Allex W. R. et Richiards A. (i., I954. O, uptalie by insects muscles. Cianal. J. Zool, 32, i-8.

Armbruster 1., 1922. I'ber den Wïmehaushalt im Bienenstaat. Arch. Bienenk., 4. 268 -26g.

Arusbruster L., I923. Der Wärmehaushalt im Bienenvoll. (Pfenningstorff-Jerlin).

BAChantjeW P., I 899 . Uber die Temperatur der Insekten nach Beobachtungen in Bulgarien. Z. witsensch. Zool., 66. 
BaILEy L., 1945. The respiratory movements in the tracheal system of the arlult honeybee. J. Exper. Biol., 71

Barron E. S. G. et Tammisian 'T. N. J., 1948. Metabolism of cockroach muscle. J. Cell. Comp. Physiol., 32, 57-70.

Benment J. W. L., i945. The cuticular lipoids of insects. J.exper. Biol., 21.

Bell K., I940. Oxygen consumption, bee moth pupac. J. Physiol. Zool., 13, 73-8I.

Bettler R., 1936. Über den Blutzucker der Bienen. \%. Vergleich. Physiol., 24.

Bосн R., 1956. Die 'Tänze der Bienen bei nahen und fernen Trachtyuellen. Z. vergleich. Physiol., 38.

Bonenuemer F. S., I934. T(mperature relations, grasshoplers, bees and ants. Zool. Jahrb. Abt. Syst., 66, I I $3^{-1} 5$ I.

Boprne J. H., i928. The anaerobic metabolism of an insect (Orthoptera). Biol. Bull., 55, 395.

Brandt von 'T'., I946. Anaerobiosis in invertebrates. Normandy, Mo., Biodynamica, pp. I37-278.

BRAUN F. et (GEIGER J. E.., 1955. Comparison on methods for wintering honeybees (Apis mellifera) in the Prairies Provinces. Canad. Dept. Agric. Plubl., 689.

Brúnich K., I922. Von den Innenwärmedes Bienenleibes. freh. Bienenk., 4.

Buck J. 13. et KeIsTer M. L.., 1953-56. (yclic $\mathrm{CO}_{2}$ release by saturnid noth pupae cutaneous and tracheal respiration; tracheal filling, fly larvate. Biol. Bull., 105. to2-t1 I, 1953; 109, 144-163, 1955; J. Exper. Biol., 32, 681-691, 1955; Physiol. \%ool., 29, 1 37-146, 1956.

Bundenrrock Von et Rolrr (i., I923. Respiration of Dixippus. \%. Allg. Physiol., 20, in I-I60.

Büdel A., 1948. Der Wasserdampfhaushalt im Bienenstock. \%. vergleich. Physiol., 31, $249-273$.

Büdel A., 1953. Der Wärmetransport in dem von den Bienen wïhrend des Winters nicht besetzten Innenraum der Beute. Z. Bienenforsch., 2, 67-84.

Budel A., ig6o. Bienenphysik. In Biene und Bienenzucht. ed. Bïlel \& llerold. (Ehrenwirth, Munich).

Bullock T. H., 1955. Temperature adaptation in poikilothemic animals. Binl. Rev., 30, 31 I-342.

Burkhardt D., I954. Rhythmische Erregungen in den optischen Zentren von Calliphora erythrocephala. Z. Vergleich. Physiol., 36.

Calvet E. et Pra' H., I956. Microcalorimétrie. Applicalions pllysicochimiques et biologiques. 395 p. Masson et Cle, Éditeurs.

Chauvin R., 1948. Physiologie de linsecte. I.N.R.A. Feliteur.

Chauvin R., iq49. Sur le preferendum thermique des insectes. Physiol. Comp. acol., Vol. I, no2, 76-82.

ChadwiCK L. I.., I947. R. Q.,Drosophila in fight. Biol. Bull., 93, 229-239.

Cubrurka W. Carbohydrate metabolism, Musca muscles. Biochim. Biophy's. Acia, 17, $294-296$.

Curreir N. S., rg6o. Heat loss and body temperatures of flying insects. J. Exper. Biol., 37, I $71-185$.

Ciesielsik Th. Zit. nach Brüninch 1922.

Chark A. M. et Herr li. 13., r954-1960. Oxygen toxicity, IIabrobracon and Prodenia. Biol. Bull., 107, 320-334,1954; Ann. J. Phys., 198, 441-444, 1960.

Cokkiss C.I., 1930. Metabolism of the honeybee colony in winter. Bull. Wyo. Agric. Exp. Sta., 175, r-54.

Corkins C. l.., et Gilber'T C. S., I932. The metabolism of honeybees in the winter cluster. Bull. Wyo. lgric, Exp. Sta., 187, I-3o.

Crescitelli I', 1935. Respiratory netabolism, bee moth. J. Cell. Comp. Jhysiol, 6, 351-368.

DAN1s J. G. et SLATER W. K., 1023. The anacrobic metabolism of the cockroach (Periplaneta orientalis). Biochint. J., $\mathrm{n}^{\mathrm{0}} 20$.

Dobzmaxiky T. et Pottsex D. F., 1935. O. consumption by Jrosophila pupae. Z. Vergleich. Physiol., 22, $473-478$.

Dotterweich H., I928. Warming-up of butterflics for flight. Zool. Jahrb. Abl. Allg., 44, 399-425.

Eder R., 1940. Die kutikuläre Transpiration der Insekten. Zool. Jahrb. Abt. Allg. Zool. u. Physiol., 50

EDNey 1:. B., I954. Tenperature relations of arthropods. Biol. Rer., 29, 185-219.

Escu H., I960. Über die Körpertemperaturen und den Wïmehtushalt von 1pis mellifica Z. vergleich. physiol., 43, 305-335.

Farrar C. I.., 1943. In interpretation of the problems of wintering the honey bee colony. Glean. Bee Cull.,

71, 5I3-5 $\mathrm{I} 8$.

Faulkner P., i 956. Malic dehydrogenase, insects. Biochem. J., 64, $430-+35$.

Fox H. M., Wingfiet. C. A. et Smanonds 13. G., 1937. O 2 consumption by aquatic insects from different enviromments. J. Exper. Biol., 14, $210-218$.

Fraenkel G. Respiration during flight, insects. Z. vergleich. Physiol., 16, 394-417.

FrAENkEL G. et HOPF II. S., i940. 'Temperature adaptation and saturation of phosphatides, blowfly larvae. Biochem. J., 34, Pp. 1085-1002.

Free J. B. et Butler C. G., 1955. An analysis of the factors involved in the formation of a cluster of honeybees. Behaviour, 7, 30+-316.

Free J. B. et Simpson J., I96.3. The respiratory metabolism of honeybee colonies at low temperatures. Entontol. exper. appl., $6(3), 234-238$. 
FreE J. B. et SPENCER-BOOTH, I958. Observations on the temperature reirulation and food consumption of honeybee. J. Exper. Biol., 35.

Friscil Von K., I9to. Jie Tänze der Bienen. Österr. Zool. Z., 1.

Gates V., rgit. The temperature of the bet-colony. Bull. U.S. Dep. Agric., 96.

Gilmotr J), I940. The anaerobic gascous metabolism of the thermite Zootermopsis nevadensis. J. Cell. Comp. Physiol., 15, 331-342.

Gicmour D., roft. Metabolism in the Larvale of Tenebrio nolitor ; gaseous metabolism and changes in glycosen, fat and lactic acid. J. Cell. Comp. Physiol., 18, 93-roo.

Gilnour D., 196r. The biochemistry of inse's. Academic Press, N. V. London.

Grzıva J., I956. Fine neue Methode der Feuchtigkeitanessung im Bienenvolk. Z. Bienenforsch., 3 (8), 199-204.

Hallijin V., I956. Om stadeluftens kulzyreindhold om vinteren. Nord. Bilidskr., 8, (3), 78-82.

IIARker J. li., 1958. Metabolic rhythms. Biol. Eiev., 33, I-52.

IIARNiscil $0 ., 19+3$. Aerobe und anaerobe Glycolyse bei einisen wirbellosen Tieren. Z. zergleich. Physiol.. 30, $145-166$.

Hausman J., 1803. De animalium exanguinum respiratione commentationis. Goettingae I803. Zitnac BACHMTJEW (1899).

IAZElinofl E. II, 1938. Oxysen utilization, invertebrates. \%.vergleich. Physiol., 26, 306-327.

Hazerifory li. H., 1954. 'Temperature control in bee-hives. Physiol. Conp. (ecol.. 3, 343-364.

Herax 11., 1956. Fin Beitrag zur Frage nach der Wahmehmungsgrundlise der Entfernungsweisung inn Tanz der Bienen. Z. vergleich. Physiol., 38, 168-2 I8.

Herax II., 1952. Temprature sense of honey bees. Z. vergleich. Physiol., 34, 1,9-206.

Herour) Ji., Ig6o. Ginndsigge der Bienenhallang. In Biene und Bienenzucht, ed. Büdel \& Herold (Ehrenwirth, Munich).

Heusnier A. et MaRx Ch. II., i 962. 'Techniques pour enregist rer, pendant de longrues périodes, les volumes d'oxygene consommés, en trois minutes, par le rat. Arch. Sci. Fhysiol, vol. 16, no I, 3 I-38'.

IIfusicr A., 1963. Hétabolisme éneresétique de l'abeille isolée : son role dams la thermorégulition de le ruche ( ton publié).

Hess W. R.,1926. Die temperaturregelung im Bienenvolk. \%. a'ergleidh. Physiol., 4.

Himmik A., 1926. Der soziale Wärmehaushalt der Honisrbienc, I. Die Wäme in nichtbritenden Wintervoll: Lilinger Jahrb. Bienenk., 4, [-49.

Himmer $\Lambda .$, i93r. Uber die Wärme im IIornissennest. Z. vergleich. Physiol., 13.

Hrmek A., 1932. Die temperaturverhiltnisse bei den sozialen Hymenopteren. Biol. Rez., 7, $224-253$.

Himuer A., 1953. Die nestwärme bei Bombus agronum F. Jiol. Jbl., 53.

Hsuen T. Y. et TANG I'. S., 1944. Respiration and growth, bee. Physiol. \%ool., 17, 7J-73.

Huble Ti., Is1\%. Touvelles observations sur les abeilles, 11. Paschoud, Geneve.

JeFFreli E. P. et ALLEN M. D. The influence of colony size and of Nosema discase on the rate of population loss in honeybee colonies in winter. f. con. Entomol., 49, (6), 831-8,34.

Jongbran I. et Wiersin C. A. G., I934. Oxygen consumbtion of bees. Z. Vergleich. Physiol., 21, $5 \mathrm{I}(9)-533$.

Joxgri,kin I. et Wiersm C. A. G., I935. Stoffwechsel der Ilonigbiene wibrend des Fluges. Z. Vergleich. Physiol., 21.

Keister M. I., I953. Pupal respiration in I'hormia. J. Worphol, 93, pp. הis-ss;.

Kiтret, A., 1945. Körperarüse, Körperzuten und Eneroidilanz Sauerstoff. Verbrauch der lnsekten in Abhängrigkeit von der Körpergrösse. Z. zergleich. Physiol., 28.

Krogi A., 1948. Deternination of temperature and heat production in insects, Z. aergleich. Physiol, 31.

Krogir A. et Weis-Fogn T., 1951-52. Respiratory exchanges in desert lnuts. J. Exper. Biol., 28, 34+-357, 195 г; Trans. t. enlonol. Soc. London, B, 237, 1-36, 1952.

Kurlani) C. G. et Scheldirman II. A., 1959. Respiratory enzymes of silkworm pupae. Biol. Bull., 116, $136-16$ г.

Lavif, P. et Roti H., 1953. Sur le thermopreferendun et lit production de chaleur chez l'abeille. Physiol. Comp. Uecol., 3, (1), $57^{-62}$.

Le BIgor L., I953. Les particularités de l'atmosphère interne des ruches. Apiculteur (Section Scient.). $97,39-46$.

Leconte J., I950. Sur le déteminisme de la formation de la writpe chez les alucilles. Z. iergleich. Physiol., 32, 499-506.

Levenbook I., et Wili.mans C. M., I956. Mitochondria of ilight muscles of instets. J. Gen. Physiol., $39,495-512$.

Levy R. et Schnemermay II. A., I958. Analysis of cliscontineous respiration, insects. Nature, 182, 49r493-

Lindaukr II., I951. Die T'emperaturregulierung der Biene bei tocküberheitzuns. Ratumissenschajten, 38, 
Lindauer M., 1952. Ein Beitrag zur Frage der Arbeitsteilung im Bienenstaat. Z. vergleich. Physiol., 34 Lindauer M., 1.954. Temperaturregelung und Wärmehaushalt im Bienenstaat. Z. rergleich. Physiol., 46. Ludwig D. et Birst I. C., I957. Intermediary metabolism of Tenebrio. Ann. Entomol. Soc. America., 40, I $28-13^{2}$.

Lvov O. S., I954. I a formation de la grappe hivernale et l'utilisation des rayons à couvain par les abeilles. Pchelovodstvo, 31, 37-44.

Mathis F., I952. Mise en évidence, dans une colonie d'abeilles, d'un centre thermique autorégulateur. Résistance de ce centre aux chocs thermiques. Ann. Sci. Nat., Zool., 14, 434-437.

Meyerirof C., 1953. Untersuchungen über die Thermotaxis der IIonigbiene, Apis mellifica. Arch. Geflugels. Kleintierk., 2, (I), 36-38.

Milner R. D. et Dexuth G.S., ig21. Heat production of honey bees in winter. Bull. U.S.Dep., Agric. 988.

Nigon V. et Fotrche J., 1958. Ta précision des mesures microrespirométriques réalisées à l'aide du ludion. Bull. Biol. Fr. Belg., 92, (1), 36-54.

PARK O. W., 1925. The storing and ripening of nectar by honeybees. J.econ. Intom., 18, 405-410.

Pardion M., I909. Stoffwechsel der Honigbiene in Beziehung zur Temperatur. Ann. Sci. Nalur., Zool. $\mathbf{9},(9)$.

Phillies E. F, et DFurril G. S., Igr4. The temperature of the honeybee cluster in winter. Bull. U. S. Dep. Agric., 93.

Prat H., I954. Analyse microcalorimétrique de la variation de la thermogenèse chez divers insectes. Canad. J. Zool., 32, I $72-197$.

Prat II., i956. Régines de la thermogenèse chez la blatte américaine. Rez. Canad. Biol., 14, $360-398$.

Precit H., Christophersen J. et Hensed II., i955. Precht II., Cirristophersen J. et Hensei, 11., 1955. Temperalur und Leben. Berlin-Göttingen-Ileidelberg: Springrer.

Prosser C. I. et Browy F. A., 1962. Comparaive animal physiology. W. B. Saunders \& Cie Éditeurs (2th edition).

PUNT A. et coll., 1950-57. Respiration and cyclic $\mathrm{CO}_{2}$ production in insects. Physiol. Comp. Oecol., 2, 59-74, 1950; 4, 121-135, 1956;4, I32-I41, 1956; Biol. Bull., 112, 108-1 19, 1957.

RAFFy M. et Portier P'., i932. L'intensité des échanges respiratoires pendant le vol chez les Lépidoptères C. R. Soc. Biol., 108, 1062-4.

REES K. R., I953-54. Oxidative enzymes of hepatopancreas of Ilelix and muscles of Locusta. Biochem. J., 55, 470-481, $1953 ; 58$, I $26-202$, 1954.

RibBands A. R., I953. The behaviour and social life of honeybees (Bee Res. Ass., London).

Rockstein M., 1957. Intermediary metabolism, insects. Ann. Rev. Enton., 2, 19-36.

Roeder K. D., I053. Insect Physiology. N. Y. : John Wiley \& Sons, Inc.

Rona P., Parfentjey J. A. et Lippyan H., 1930. Die Oxydation. Skatalysatoren bei Insekten. Biochem. Zool., 233, 205-212.

Schnemerman M. A., 1956. Discontinuous respiration in silkworm. Nature, 17\%, Ir69-117 I and C. M. Williams, I954. Biol. Bull., 109, $123-143$.

Schreuder J. E. et DE WILde J., I952. Respiratory stimulation by $\mathrm{CO}_{2}$, coackroach. Physiol. Comp. Oecol., 2, 355-36I,

Simpson J., I950. Humidity in the winter cluster of a colony of honeybees. Bee World, 31, (6), 4I-44.

Simpson J., I954. Effects of some anaesthetics on honeybees : nitrous oxide, carbondioxide, ammonium nitrate smoker fumes. Bee World, 35, 35, (8), I 49- 55 .

Simpson J., i958. Observations on Apis indica. Rep. Rothamst. exp. Sta., p. I50.

Simpson J. In Traité de Biologie de l'abeille (A paraittre).

SLADEN F. W. L., I901. A scent producing organ in the abdomen of the bee. Glean. Bee Cult., 29, (I5), $639-640)$.

Slater W. K., 1928. Anaerobiosis. Biol. Rev., 3, 308-328.

SNodgras L., 1956. The anatomy of the honeybee. Ithaca, N. Y. Comstok Publishing Axsociates, Cornell University Press.

Sotavalta O., 1954. On the sugar comnsumption of honeybees in flight experiment. Ann. Soc. Zool* Bot., 16, I-27.

Sotavalta 0., 1954. On the thoracic temperature of insects in flight. Ann. Soc. Zool. Vqnamo, 16, (1).

Sutherland A. E., I944-45. Acoustic observations in winter. Bee World, 25, (I.2), 90-91 ; 26 (6), 44.

Taranov G. F. et Vichatiov K. I., ig5o. (La concentration de $\mathrm{CO}_{2}$ dans la grappe hivernale des abeilles). Pchelovodstvo, 37, (10), 5-10.

Tokuds Y., 1924. Studies on the honeybee with special reference to the Japanese honeybee. Trans. Sapporo. Nat. Hist. Soc., 9, I-27.

VAnsell G. H., I930. Bee hive temperatures. J. Econ. Entom., 23, 4r8-42r.

Verron H., 1955. Les réactions des abeilles à l'humidité. Insectes Sociaux, 2, (1), $57-62$. 
ViLLumsted E., ig6o. Forforbruk, bitap og rimdannelse : kuber med ulik isolasjon. Birokteren, 76, 57-60. Watanabe M. E. et Williams $\quad$ C. M., I95I. Lnzymes of insects sarcosomes. J. Geiz. Physiol, 34, 675-689. WEDMORE E. B., I953. Some problems of the winter cluster : report based on experimental work by H. A. DELLow. Bee Res. Ass., London, Publication B. R. A., ro4.

Wigglesworth V. B., 1939. Principles of insect physiology. Ed. Methuen \& Co., London. Wigglesworth V.B., I946. Water relations of insects. Experientia (Basel), 2, (6).

WoHLGEMUTII R., I957-58. Die Temperature regulierung des Bienenvolkes unter regeltheoretischen Gesichspunkten. Z. vergleich. Physiol., 40, IIg-159. 